\title{
A critical review on VOCs adsorption by different porous materials: Species, mechanisms and modification methods
}

\author{
Lingli Zhu ${ }^{\mathrm{a}}$, Dekui Shen ${ }^{\mathrm{a}, *}$, Kai Hong Luo ${ }^{\mathrm{b}}$

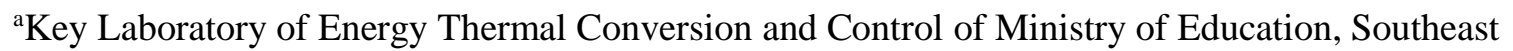 \\ University, Nanjing 210096, PR China. \\ ${ }^{\mathrm{b}}$ Department of Mechanical Engineering, University College London, London WC1E7JE, UK \\ *Corresponding author: Dekui Shen, email: 101011398@seu.edu.cn, telephone: +86025 \\ 83794735, fax number: +8602583794744
}

\begin{abstract}
Volatile organic compounds (VOCs) have attracted world-wide attention regarding their serious hazards on ecological environment and human health. Industrial processes such as fossil fuel combustion, petrochemicals, painting, coatings, pesticides, plastics, contributed to the large proportion of anthropogenic VOCs emission. Destructive methods (catalysis oxidation and biofiltration) and recovery methods (absorption, adsorption, condensation and membrane separation) have been developed for VOCs removal. Adsorption is established as one of the most promising strategies for VOCs abatement thanks to its characteristics of cost-effectiveness, simplicity and low energy consumption. The prominent progress in VOCs adsorption by different kinds of porous materials (such as carbon-based materials, oxygen-contained materials, organic polymers and composites is carefully summarized in this work, concerning the mechanism of adsorbate-adsorbent interactions, modification methods for the mentioned porous materials, and enhancement of VOCs adsorption capacity. This overview is to provide a comprehensive understanding of VOCs adsorption mechanisms and up-to-date progress of modification technologies for different porous materials.
\end{abstract}

Keywords: VOCs treatment; Porous materials; Adsorption mechanism; Modification

\section{Contents}

1. Introduction. 2

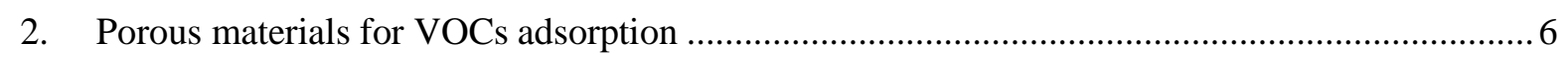

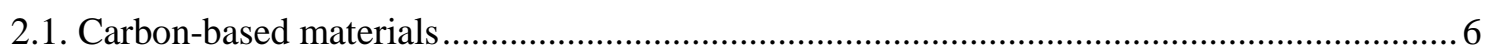

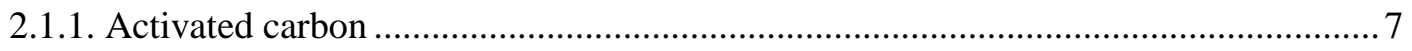

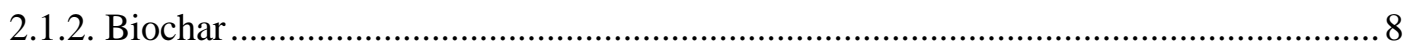

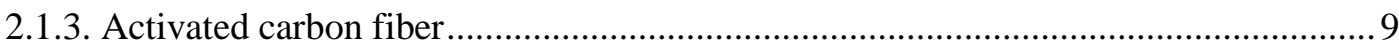




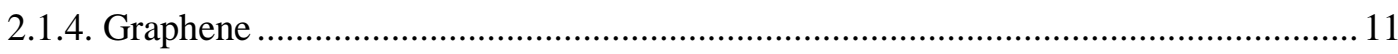

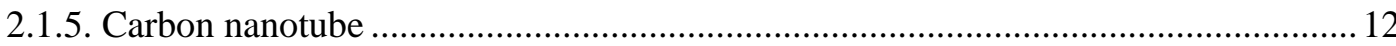

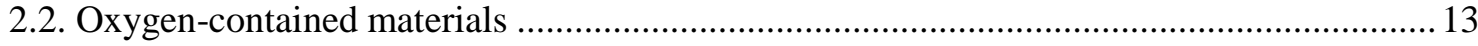

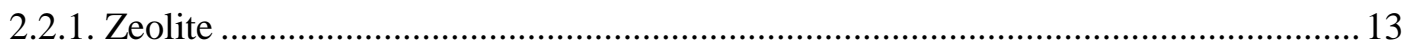

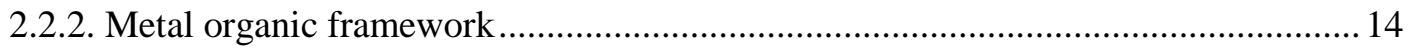

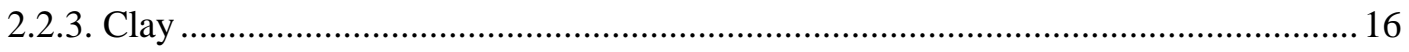

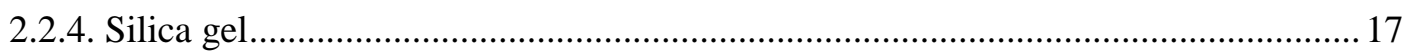

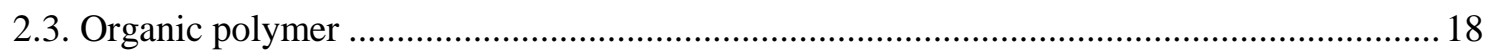

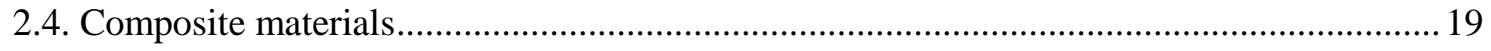

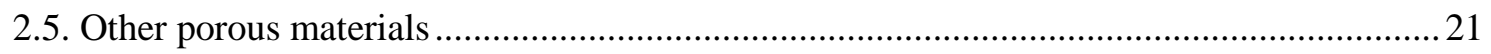

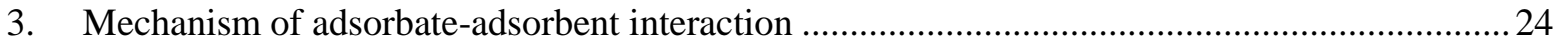

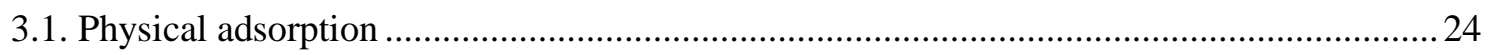

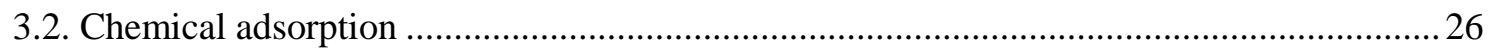

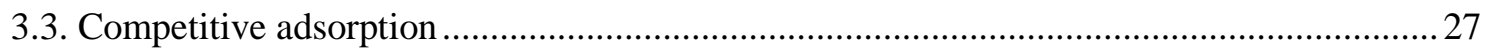

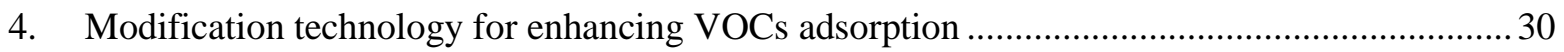

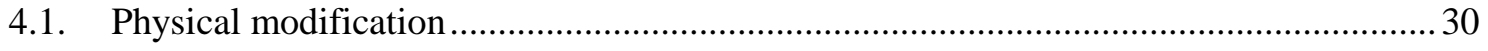

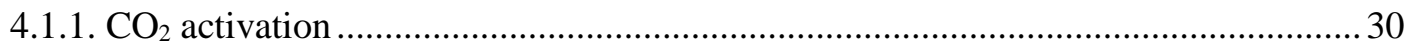

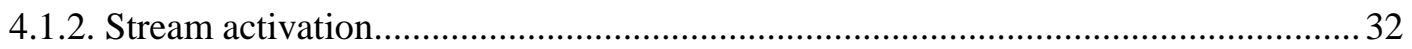

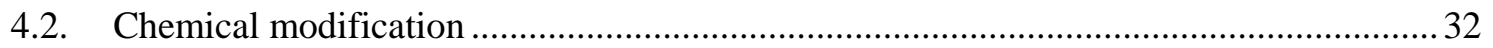

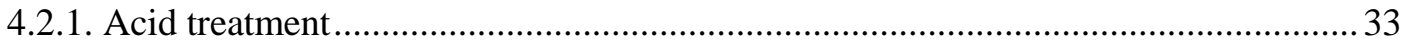

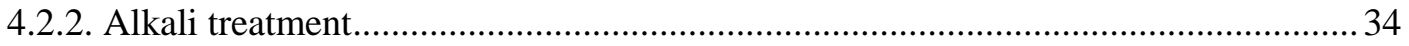

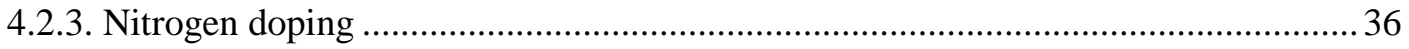

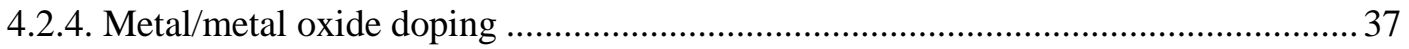

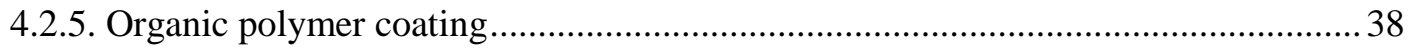

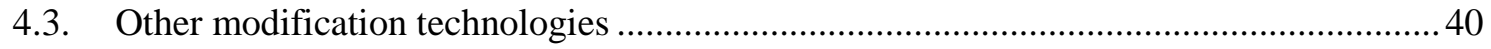

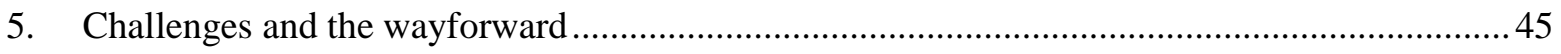

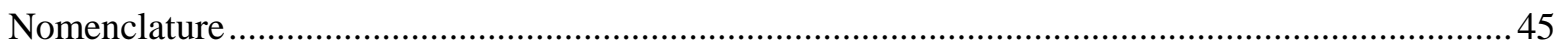

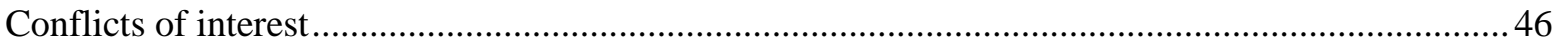

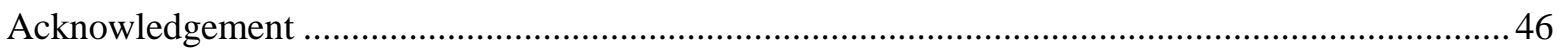

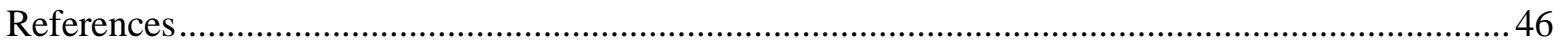

\section{1. Introduction}

64 VOCs refer to a group of organic substances characterized by their low boiling point (Wang et al., 65 2007). The various definitions of VOCs are conducted by main international organizations. It can be defined 66 as any compound of carbon, excluding carbon monoxide, carbon dioxide, carbonic acid, metallic carbides 67 or carbonates, and ammonium carbonate, which participates in atmospheric photochemical reactions, 
proposed by US Environmental Protection Agency (US EPA) (Hunter et al., 2000). The World Health Organization (WHO) regards VOCs as organic compounds with saturated vapor pressure over $133.322 \mathrm{~Pa}$ and boiling point ranging from 50 to $260^{\circ} \mathrm{C}$ at atmospheric pressure (Zavyalova et al., 2008). The common VOCs can be classified into several groups on the basis of their different properties. Based on the boiling point, the VOCs can be divided into very volatile organic compounds (VVOCs), VOCs, semivolatile organic compounds (SVOCs) and particulate organic matters (POMs) by WHO. For the molecular structure, the VOCs include alkanes, alkenes, aromatic hydrocarbons, alcohols, aldehydes, ketones etc. Moreover, the polar and nonpolar VOCs are distinguished according to the degree of molecular polarity (Li et al., 2012; Wang et al., 2018; Meng et al., 2019). The detailed classification about the common VOCs is shown in Fig. 1.

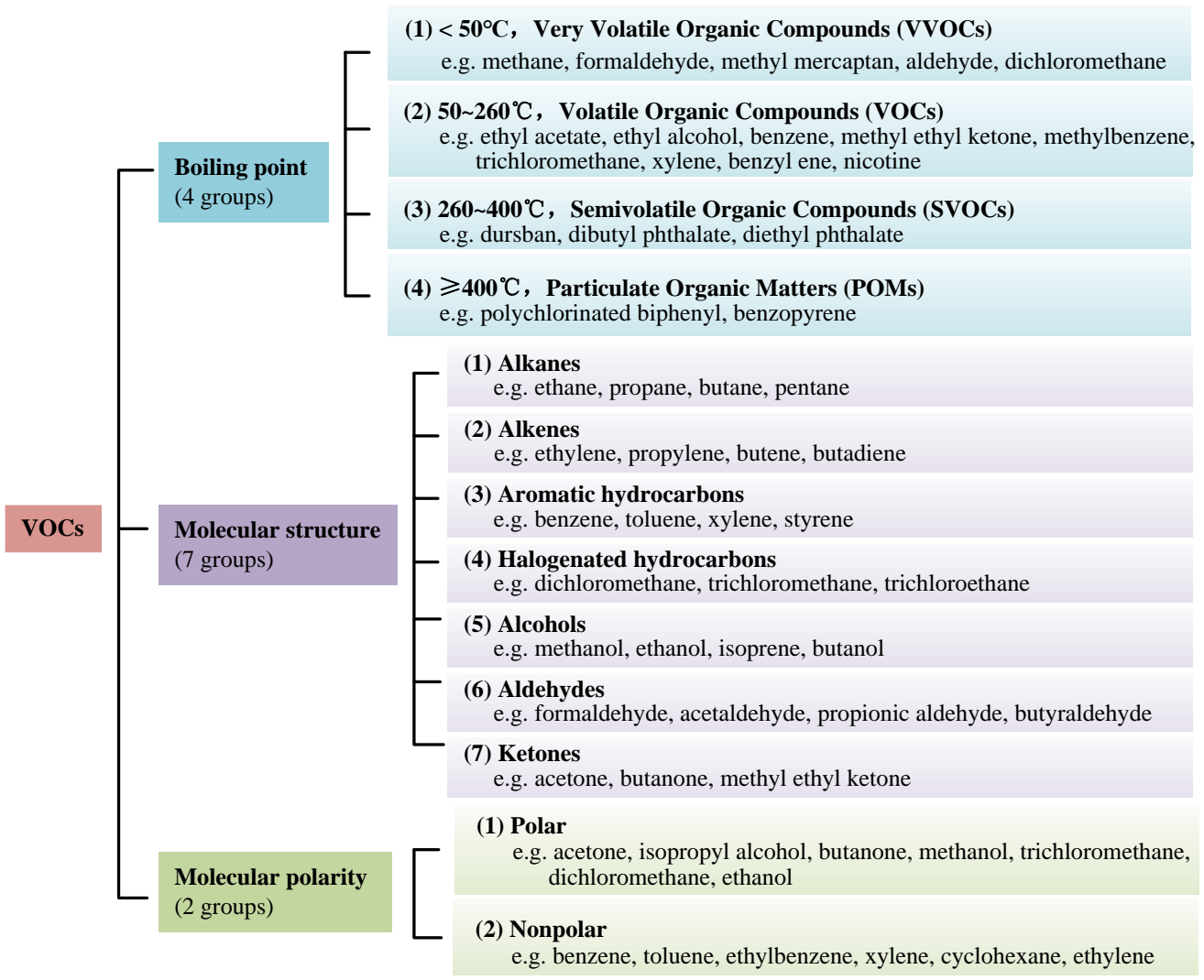

Fig. 1. The classification of different VOCs

The emission of biogenic VOCs consisting of isoprene and monoterpenes accounts for almost $90 \%$ of total global emissions (Guenther et al., 1995). With the accelerated urbanization and industrialization, the emission amount of VOCs from anthropogenic sources in China are predicted to be persistently increased above $5.9 \%$ annually (from $19.4 \mathrm{Tg}$ in 2005 to $25.9 \mathrm{Tg}$ in 2020) (Wei et al., 2011). As shown in Fig. 2, the anthropogenic emission sources of VOCs are primarily derived from industrial process (43\%), vehicle 
exhausts (28\%), daily life (15\%) and agriculture (14\%). Industrial VOCs emissions are extensively involved in petroleum refinement, solvent production, use of fossil fuels, coal combustion, etc. (He et al., 2019; Yang et al., 2019; Baltrenas et al., 2011). Among them, the VOCs emission amount from coal combustion accounts for a large proportion of $37 \%$ in the industrial sources (Yan et al., 2017). Benzene, toluene, ethylbenzene, and xylene (BTEX) are known as major VOCs species emitted from coal combustion, which have been all identified as hazardous air pollutants (HAPs) by the US EPA (Panagiotis et al., 1997). VOCs as the important precursors of ozone, photochemical pollutants and secondary organic aerosols (SOAs) pose serious harms to both the ecological environment and human health. The condensation and nucleation of $\mathrm{OVOC}_{\mathrm{S}}$ (oxygenated volatile organic compounds), SOAs and SNAs (secondary nitric aerosols) can contribute to PM2.5 formation (Weber et al., 2007). VOCs are also responsible for the greenhouse effect, especially methane, which is more than 20 times more potent than $\mathrm{CO}_{2}$. Most VOCs in particular aromatic compounds and polycyclic aromatic hydrocarbons are malodorous, toxic and carcinogenic to human health even at low concentration (above $0.2 \mathrm{mg} \mathrm{m}^{-3}$ ), leading to respiratory inhalation and skin mucosa and damage of nervous and blood systems. In addition, some VOCs such as ethylene and propylene are widely used in the petrochemical industry. Although these compounds are less toxic and less harmful to the human body, they are flammable and explosive as the solubility reaches a certain amount (Castro-Hurtado et al., 2013; Main et al., 1983).

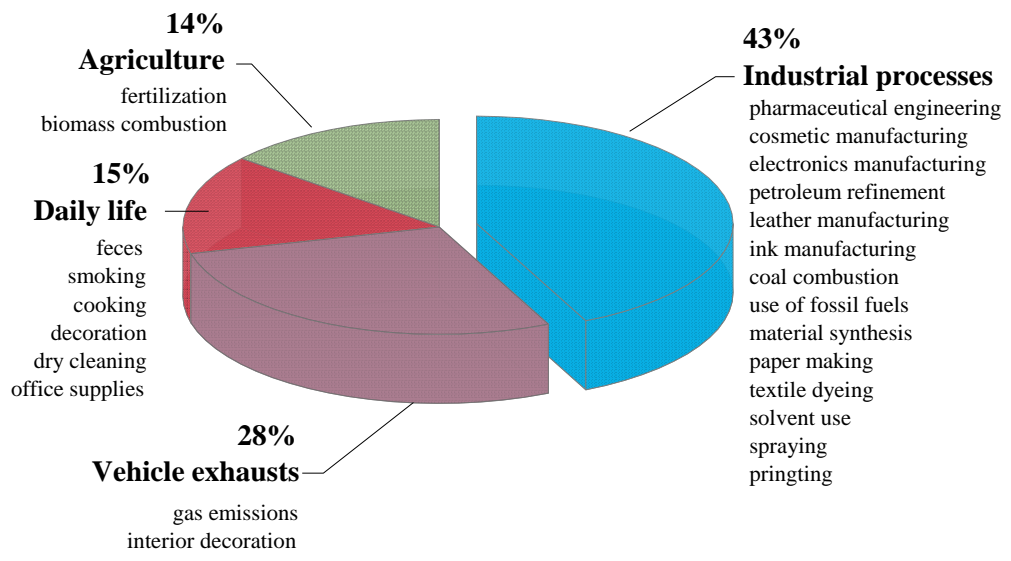


Table 1

Comparison of different VOCs treatment technologies.

\begin{tabular}{|c|c|c|c|c|c|c|c|c|c|}
\hline $\begin{array}{l}\text { Treatment } \\
\text { technologies }\end{array}$ & Principles & $\begin{array}{l}\text { Temperature } \\
{ }^{\circ} \mathrm{C}\end{array}$ & $\begin{array}{l}\text { Concentration } \\
\text { ppm }\end{array}$ & $\begin{array}{l}\text { Efficiency } \\
\%\end{array}$ & Costs & Contaminant products & Advantages & Disadvantages & References \\
\hline \multicolumn{10}{|c|}{ Destruction technologies } \\
\hline $\begin{array}{l}\text { Thermal/catalytic } \\
\text { oxidation }\end{array}$ & $\begin{array}{l}\text { Catalysts are used to reduce the } \\
\text { temperature of complete oxidation } \\
\text { of VOCs }\end{array}$ & $300-820$ & $20-1000$ & $90-98$ & High & $\mathrm{CO}, \mathrm{NOx}$ & $\begin{array}{l}\text { Simple and easy, } \\
\text { complete } \\
\text { treatment, } \\
\text { high efficiency }\end{array}$ & $\begin{array}{l}\text { Catalyst poisoning, } \\
\text { non-recyclable }\end{array}$ & $\begin{array}{l}\text { (Yang et al., 2019; } \\
\text { Alejandro-Martín et } \\
\text { al., 2018) }\end{array}$ \\
\hline $\begin{array}{l}\text { Photocatalytic } \\
\text { oxidation }\end{array}$ & $\begin{array}{l}\text { Catalysts produce free radicals } \\
\text { with strong oxidizing ability under } \\
\text { the radiation of light }\end{array}$ & $<90$ & $<500$ & 100 & High & $\begin{array}{l}\text { Strong oxidant } \mathrm{OH} . \\
\text { radicals }\end{array}$ & $\begin{array}{l}\text { Fast and efficient, } \\
\text { low energy } \\
\text { consumption }\end{array}$ & $\begin{array}{l}\text { Low concentration, } \\
\text { secondary pollution }\end{array}$ & $\begin{array}{l}\text { (Kim et al., 2018; Jo } \\
\text { et al., 2009) }\end{array}$ \\
\hline Biofiltration & $\begin{array}{l}\text { Oxidation occurs under the action } \\
\text { of microorganisms }\end{array}$ & $<50$ & $<5000$ & $60-95$ & Low & $\begin{array}{l}\text { Acetaldehyde, Propanol, } \\
\text { Acetone }\end{array}$ & $\begin{array}{l}\text { Simple, low cost } \\
\text { Security }\end{array}$ & $\begin{array}{l}\text { Slow reaction rate, big } \\
\text { equipment, high } \\
\text { pressure drop }\end{array}$ & $\begin{array}{l}\text { (Mohamed et al., } \\
\text { 2016; Lu et al., } \\
\text { 2010) }\end{array}$ \\
\hline Plasma catalysis & $\begin{array}{l}\text { Plasma is produced under strong } \\
\text { electric field, which bombards } \\
\text { organic compounds and destroys } \\
\text { their chemical structure, thus } \\
\text { degrading }\end{array}$ & $<80$ & $<500$ & $74-81$ & High & $\begin{array}{l}\text { Formic acid, Carboxylic } \\
\text { acids, } \mathrm{NOx}, \mathrm{O}_{3}\end{array}$ & $\begin{array}{l}\text { Simple operation } \\
\text { Low energy } \\
\text { consumption, } \\
\text { wide scope of } \\
\text { application }\end{array}$ & $\begin{array}{l}\text { Low concentration, } \\
\text { incomplete treatment }\end{array}$ & $\begin{array}{l}\text { (Sultana et al., 2015; } \\
\text { Luengas et al., } \\
\text { 2015) }\end{array}$ \\
\hline \multicolumn{10}{|c|}{ Recovery technologies } \\
\hline Absorption & $\begin{array}{l}\text { Dissolve VOCs in water or } \\
\text { chemical solvents }\end{array}$ & Low & $500-15000$ & $90-98$ & $\begin{array}{l}\text { Low/Mo } \\
\text { derate }\end{array}$ & Spent solvent & $\begin{array}{l}\text { Simple process } \\
\text { recycled }\end{array}$ & $\begin{array}{l}\text { Limited absorption } \\
\text { capacity }\end{array}$ & $\begin{array}{l}\text { (Luengas et al., } \\
\text { 2015; Heymes et al., } \\
\text { 2006) }\end{array}$ \\
\hline Adsorption & $\begin{array}{l}\text { Use porous materials as } \\
\text { adsorbents }\end{array}$ & $0-60$ & $700-10000$ & $80-97$ & Moderate & Spent adsorbent & $\begin{array}{l}\text { Cost- } \\
\text { effectiveness, } \\
\text { flexible operation, } \\
\text { low energy } \\
\text { consumption }\end{array}$ & $\begin{array}{l}\text { Poor thermal stability, } \\
\text { pore blockage, limited } \\
\text { adsorption capacity }\end{array}$ & $\begin{array}{l}\text { (Luengas et al., } \\
\text { 2015; Shih et al., } \\
\text { 2008) }\end{array}$ \\
\hline Condensation & $\begin{array}{l}\text { VOC is cooled to liquid at low } \\
\text { temperature }\end{array}$ & $<700$ & $>5000$ & $70-85$ & High & - & $\begin{array}{l}\text { High } \\
\text { concentrations } \\
\text { recycle }\end{array}$ & $\begin{array}{l}\text { High investment cost, } \\
\text { high operating cost }\end{array}$ & $\begin{array}{l}\text { (Luengas et al., } \\
\text { 2015; Belaissaoui et } \\
\text { al., 2016) }\end{array}$ \\
\hline $\begin{array}{l}\text { Membrane } \\
\text { separation }\end{array}$ & $\begin{array}{l}\text { The separation, purification and } \\
\text { concentration of different VOCs } \\
\text { are realized by selective } \\
\text { separation of membrane }\end{array}$ & $0-45$ & $2000-50000$ & $90-95$ & $\begin{array}{l}\text { Moderate } \\
\text { /High }\end{array}$ & Clogged membrane & $\begin{array}{l}\text { High efficiency, } \\
\text { high recovery } \\
\text { efficiency }\end{array}$ & High investment cost & $\begin{array}{l}\text { (Luengas et al., } \\
\text { 2015; Zhen et al., } \\
\text { 2006) }\end{array}$ \\
\hline
\end{tabular}


Stringent regulations have been proposed to control VOCs by developed countries (US legislation calls for a $90 \%$ reduction in emissions of 189 pollutants over the next few years where VOCs occupies about $70 \%$ of those pollutants) (Kolade et al., 2009). A large number of post-processing technologies have been developed for VOCs abatement, which can be categorized into destruction technology and recovery technology. The destruction technology can decompose VOCs into $\mathrm{CO}_{2}, \mathrm{H}_{2} \mathrm{O}$ and non-toxic or less toxic compounds through different chemical or biological methods, such as thermal/catalytic oxidation, photocatalytic oxidation, biofiltration and plasma catalysis. The recovery technology, termed as absorption, adsorption, condensation and membrane separation, can separate VOCs via changing the conditions of temperature and pressure in the process. The advantages and disadvantages of those VOCs treatment technologies are summarized in Table 1.

Adsorption is regarded as one of the most promising VOCs treatment technologies owing to its characteristics of cost-effectiveness, flexible operation, and low energy consumption. A number of porous materials (such as carbon-based materials, oxygen-containing materials, organic polymers, composites etc.) were investigated for improving the adsorption of VOCs in terms of capacity, hydrophobic property, thermal stability and regenerability. It is needs to be noted that activated carbon, zeolite and organic polymer are considered as three of the most popular adsorbents for VOCs treatment estimated by the US EPA (SernaGuerrero et al., 2007; Zhu et al., 2017; Long et al., 2011; Zaitan et al., 2008).

Modification technologies are employed to adjust specific surface areas, chemical functional groups and pore structure of VOCs adsorbent, in order to improve their adsorption performance. The previous reviews are mainly focused on carbonaceous materials and their modifications, while VOCs adsorption performance of some other absorbents is inadequately reported in the literature (González-García 2018; LeMinh et al.; 2018, Le Cloirec 2012; Zhang et al., 2017). In this work, VOCs absorption performance of different porous materials would be comprehensively reviewed, including activated carbon, biochar, activated carbon fiber, graphene, carbon nanotube, zeolite, metal organic framework, clays, silica gel, organic polymer and composites. The interactions between adsorbate and adsorbent would be intensively discussed for obtaining different modification methods to enhancing the adsorption capacity of the adsorbent. The work is trying to provide a comprehensive understanding of VOCs adsorption and guidance for future research directions in this area.

\section{Porous materials for VOCs adsorption}

\subsection{Carbon-based materials}




\subsubsection{Activated carbon}

Activated carbon (AC) is considered as a versatile adsorbent owing to its large specific surface area $\left(600 \sim 1400 \mathrm{~m}^{2} \mathrm{~g}^{-1}\right)$, well-developed pore structure $\left(0.5 \sim 1.4 \mathrm{~cm}^{3} \mathrm{~g}^{-1}\right)$ and high VOCs adsorption capability (10 600 $\mathrm{mg} \mathrm{g}^{-1}$ ). Industrial AC commonly uses carbonaceous material as the precursor such as coal, wood, coconut shell, peat and lignite, cost of which production is ranging from $\$ 1000$ to $1500 \mathrm{t}^{-1}$ (Zhao et al., 2018). It can be manufactured in form of pellet, granule, powder or sphere after the process of carbonization and activation (Romero-Anaya et al., 2015). Environmental applications of AC have been widely studied such as wastewater treatment, soil remediation and air purification, especially for VOCs disposal.

Yang et al. (2018) investigated adsorption behaviors of ACs on toluene at $25{ }^{\circ} \mathrm{C}, 200 \mathrm{ppm}$ and $\mathrm{N}_{2}$ atmosphere, which derived from different raw materials including wood, coal and coconut shell. The specific surface area and total pore volume ranged from 570 to $1284 \mathrm{~m}^{2} \mathrm{~g}^{-1}, 0.25$ to $0.83 \mathrm{~cm}^{3} \mathrm{~g}^{-1}$, respectively. The adsorption capacity of these ACs ranged from 62.5 to $184.0 \mathrm{mg} \mathrm{g}^{-1}$. The wood-based AC with the largest surface area and total pore volume had the maximal adsorption capacity of $184 \mathrm{mg} \mathrm{g}^{-1}$. Under the similar adsorption conditions except inlet toluene concentration of $2000 \mathrm{ppm}$, Li et al. (2012) found that the adsorption capacity of commercial AC were over $260 \mathrm{mg} \mathrm{g}^{-1}$, the surface area and total pore volume of which were $932 \mathrm{~m}^{2} \mathrm{~g}^{-1}$ and $0.432 \mathrm{~cm}^{3} \mathrm{~g}^{-1}$. Yu et al. (2018) explored the impact of functional groups on adsorption of coconut shell based $\mathrm{ACs}$ at $27^{\circ} \mathrm{C}, 500 \mathrm{ppm}$ and $\mathrm{N}_{2}$ atmosphere. The nitric acid modified AC exhibited high adsorption capacity of $433.9 \mathrm{mg} \mathrm{g}^{-1}$ on acetone, which might be attributed to the interaction between carboxylic groups and acetone. Similarly, Zhou et al. (2018) observed magnesium oxide modified $\mathrm{AC}$ also presented high equilibrium amount of acetone $\left(432.7 \mathrm{mg} \mathrm{g}^{-1}\right)$ at $25^{\circ} \mathrm{C}, 85.21 \mathrm{~g} \mathrm{~m}^{-3}$. It indicated that introduced oxygen functional groups offered active sites, which had strong adsorption affinity on polar acetone.

In summary, the adsorption performance of $\mathrm{AC}$ on VOCs is influenced by adsorption conditions, physicochemical properties of adsorbent. It seems that $\mathrm{AC}$ is suitable to be used to adsorb VOCs at room temperature, low/medium concentration and $\mathrm{N}_{2}$ atmosphere (Amitay-Rosen et al., 2015). The large surface area and pore volume of $\mathrm{AC}$ have positive effects on the adsorption capacity for VOCs. Specially, the chemical functional groups on the AC surface are also the key factor for certain VOCs adsorption. However, challenges of further large-scale applications of AC to industrial level are still existing. Firstly, Jahandar Lashaki et al. (2016) implied that heel formation during the incomplete desorption process, affect the lifetime and regeneration cost of AC. This could be attributed to the irreversible adsorption including chemisorption, adsorbate coupling or decomposition. Secondly, Jafari et al. (2018), Wang et al. (2016) and Wang et al. (2014) pointed that the flammability of AC may cause fire risk especially in the exothermic adsorption process. Moreover, high transmission resistance, pore blocking and hygroscopicity of AC also restrict its widespread application in VOCs abatement (Wang et al., 2014). 


\subsubsection{Biochar}

Biochar is a representative member of the carbon family, which is regarded as a potential alternative of commercial AC due to its abundant feedstocks, and efficient-low cost (Aguayo-Villarreal et al., 2017). Compared to $\mathrm{AC}$, biochar is produced in the milder pyrolysis condition under an inert atmosphere (slow pyrolysis and relatively low temperature of $<700{ }^{\circ} \mathrm{C}$ ) (Fig. 3) (Abdul Manap et al., 2018; Shen et al., 2019a; 2019b). Abundant carbon-rich materials, such as wood materials, agricultural and forestry residues, fruit byproducts, etc., can be used for biochar production (Zhao et al., 2018). Its production cost of $\$ 20 \mathrm{t}^{-1}$ is much cheaper than that of AC ( $\$ 1000$ to $1500 \mathrm{t}^{-1}$ ) (Suzuki et al., 2007). The features of biochar highly depend on raw materials and production conditions. Generally, the raw materials with high lignin and mineral content tend to produce high yield of biochar, and the mineral content may decrease as the increasing pyrolysis temperature and time (Suliman et al., 2016). The biochar produced from carbonization is a disordered elementary graphitic crystallite with a rudimentary pore structure (Hsi et al., 2011).

Zhang et al. (2017) evaluated 15 biochars carbonized from 5 common feedstocks for acetone, cyclohexane, and toluene adsorption at room temperature and $50 \mathrm{ml} \mathrm{min}^{-1}$ VOCs. The specific surface area of these biochars ranged from 0.1 to $388 \mathrm{~m}^{2} \mathrm{~g}^{-1}$, and the adsorption capacity were all less than $90 \mathrm{mg} \mathrm{g}^{-1}$. The adsorption performance of untreated biochars were supposed to have great potential to improve. Physical or chemical activation are often used for biochars to develop large specific surface area and microporous structure (Shen et al., 2019a; 2018b). Physical activation is conducted at high temperatures (around $700{ }^{\circ} \mathrm{C}$ ) in the atmosphere of oxidizing gases such as steam, $\mathrm{CO}_{2}$, air, or a mixture of them. The carbonization and chemical activation can be operated in a single step, where virgin biochar impregnated with activating agents are heated at temperature of $300-800{ }^{\circ} \mathrm{C}$. The reagents frequently used are acid, alkali and metal salt (Aguayo-Villarreal et al., 2017; Hu et al., 2017; Bedane et al., 2018). Khan et al. (2019) developed biowaste-derived biochars with $\mathrm{KOH}$ activation for $2 \mathrm{~h}$, which showed high adsorption capacity of $144 \mathrm{mg} \mathrm{g}^{-1}$ on benzene. Compared with the virgin biochar, the specific surface area and total pore volume were increased from 228 to $1397 \mathrm{~m}^{2} \cdot \mathrm{g}^{-1}$, and 0.02 to $0.51 \mathrm{~cm}^{3} \mathrm{~g}^{-1}$. Hsi et al. (2011) prepared a series of biochars from biotreated agricultural residues for toluene adsorption via adequate $50 \% \mathrm{H}_{2} \mathrm{O}(\mathrm{g}) / 50 \% \mathrm{~N}_{2}$ steam activation. The water molecule could react with the carbon surface to generate carbonyl and carboxyl groups during the activation process. The treated biochar was with large surface area of $950 \mathrm{~m}^{2} \mathrm{~g}^{-1}$ and high adsorption capacity of $227 \mathrm{mg} \mathrm{g}^{-1}$, which was comparable to commercial AC. Tham et al. (2011) studied the adsorption performance of phosphoric acid activated biochar on toluene at room temperature, $460 \mathrm{ppm}$. The results showed that high removal efficiency of $93 \%$ was obtained by impregnating acid concentration of $30 \%$. Apart from the increased surface area $\left(1404 \mathrm{~m}^{2} \cdot \mathrm{g}^{-1}\right)$, the oxygen functional groups introduced by acid also enhanced the chemical adsorption. 


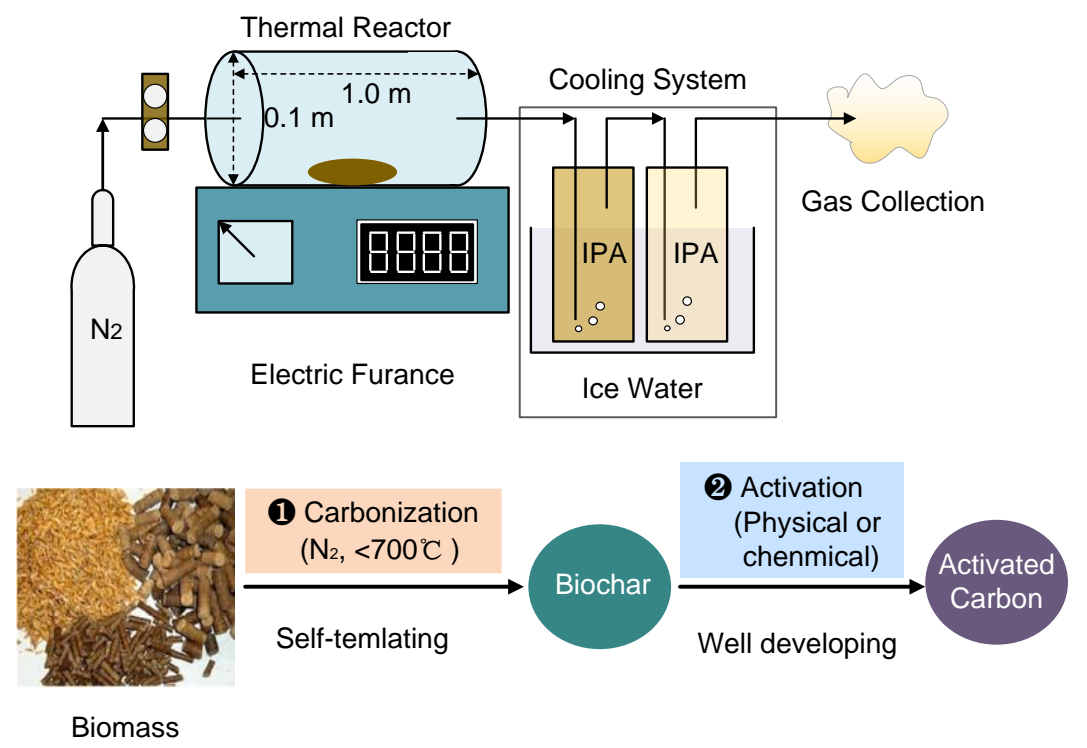

Fig. 3. The conventional carbonization and activation process of biochar (Shen et al., 2019a; 2019b).

Briefly, the pore structure of untreated biochar is undeveloped, confining its VOCs adsorption capacity.

211 The physicochemical properties of biochar can be improved a lot by physical or chemical modification.

212 Biochar is regarded as a potential alternative to commercial AC due to its abundant raw materials, effective-

213 low cost and low energy consumption. Similar to AC, there are drawbacks of biochar include the

214 flammability, pore blocking and hygroscopicity. Moreover, the production of biochar may cause the release

215 of VOCs which are harmful for the environment. The in-depth research on the complicated interaction

216 between surface groups of biochar and VOCs need to be taken far more effort.

\subsubsection{Activated carbon fiber}

Activated carbon fiber (ACF) developed in the 1960s' is in form of arranged microfilaments. It can be made into yarn, thread, fabric, felt/carpet, paper cloth and other shapes to optimize process designs for 221 engineering use (Yue et al., 2017). The raw materials used in preparation of ACF are usually poor renewable 222 such as viscose, polyacrylonitrile fibers and pitch fibers (Baur et al., 2015). Fig. 4 illustrates a schematic of 223 electrospinning system and characteristics of ACFs. The homogenous spinning solution contained 224 spinnable functional material and polymer is prepared by magnetic stirring and ultrasonication, and then 225 the nanofibers are collected on the roller under the action of the electrostatic field (Ge al., 2018; Bai et al., 226 2013). ACF is a pure carbonaceous solid with surface area and micropore volume of $810-1400 \mathrm{~m}^{2} \mathrm{~g}^{-1}$, and $2270.36-0.92 \mathrm{~m}^{3} \mathrm{~g}^{-1}$ (Liu et al., 2019). Its pore width is usually concentrated between 0.5 and $1 \mathrm{~nm}$. The 228 commercially available ACF is very expensive due to high-cost raw materials, fiber spinning and weaving, subsequent thermal processes, as well as huge weight losses during activation. Unlike AC, ACF exhibits 
faster adsorption kinetics, higher mass transfer rate due to its thin-fiber shape with short and straight micropore. Furthermore, the fibrous structure can overcome the difficulty of high pressure drop, suppressed mass transfer limitations in the adsorption bed (Meng et al., 2019). So far, ACF is widely utilized in the fields of chemical and biochemical adsorption and separation, air and water purification, catalysts or catalyst supports, masks, medical care purposes, etc. (Yue et al., 2017).
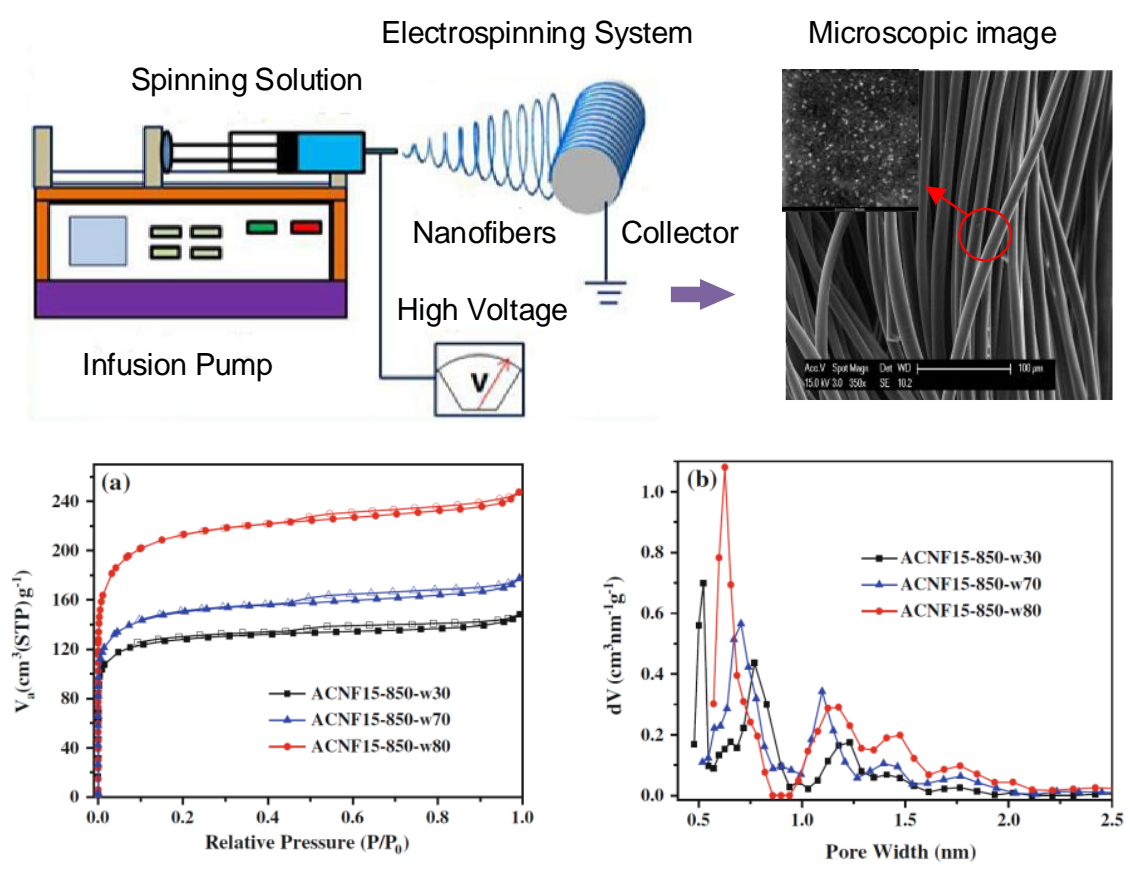

Fig. 4. Schematic of electrospun fibrous membrane and characteristics of ACFs (Ge al., 2018; Bai et al., 2013) $\mathrm{g}^{-1}$ was prepared by Yue et al. (2017). It had strong adsorption affinity for chloroform vapor, which adsorption capacity was $1004 \mathrm{mg} \mathrm{g}^{-1}$ at $22{ }^{\circ} \mathrm{C}$. Similarly, Liu et al. (2019) found the activated-carbon fibercloth (ACFC) had the unique micropore structure with pore width ranging from 0.61 to $0.69 \mathrm{~nm}$, which was superior to that of commercial AC. It exhibited high capture efficiency of isobutane (> 99\%) under relative humidity of 5-80\%. Lin et al. (2012) reported that ACFs had less surface oxygen groups $\left(<900 \mu \mathrm{mol} \mathrm{g}^{-1}\right)$ than AC (1000-4500 $\left.\mu \mathrm{mol} \mathrm{g}^{-1}\right)$. Besides, it was found that virgin ACFs tended to adsorb nonpolar VOCs (benzene, toluene) rather than polar VOCs (acetaldehyde, acetone) (Baur et al., 2015; Lillo-Ródenas et al., 2005a; 2010b). To break this limitation, Yi et al. (2008) investigated the adsorption performance of $\mathrm{CuSO}_{4}$ modified ACF on ethanol at low concentration and $20^{\circ} \mathrm{C}$. Compared with original ACF, the adsorption capacity of modified ACF was increased from 480 to $560 \mathrm{mg} \mathrm{g}^{-1}$. In addition, Baur et al. (2015) used ACFs 
modified by $\mathrm{La}_{2} \mathrm{O}_{3}, \mathrm{CaO}, \mathrm{MgO}, \mathrm{ZnO}, \mathrm{Fe}_{3} \mathrm{O}_{4}$ and $\mathrm{Al}_{2} \mathrm{O}_{3}$ to adsorb acetaldehyde at $25^{\circ} \mathrm{C}$, helium atmosphere and 1300 ppmv. The adsorption capacity of $\mathrm{La}_{2} \mathrm{O}_{3} / \mathrm{ACF}$ increased from 3.2 to $20 \mathrm{wt} . \%$ compared to original ACF. It indicated that the modification by metal oxides improved the affinity between ACF and polar VOCs due to the introduced surface oxygen groups.

As a result, the micropore structure of $\mathrm{ACF}$ is superior to that of $\mathrm{AC}$ for VOCs adsorption, while there are few amount of chemical functional groups on the ACF's surface. This results in the hydrophobic nature of ACF, which is beneficial for adsorbing nonpolar or weak polar VOCs. The modification technologies enable to introduce oxygen functional groups to enhance the affinity between the ACF's surface and polar VOCs (Yi et al., 2008; Song et al., 2017). It is worth to note that the limited application of ACF in practical industry ascribed to the high cost of fiber precursors and their associated processing costs (Xie et al., 2016; Niknaddaf et al., 2016).

\subsubsection{Graphene}

Graphene with the two-dimensional (2D) structure is consist of a sheet with hexagonally arrayed carbon atoms that share $\mathrm{sp}^{2}$ hybridized orbitals of one carbon with three neighbors (Tahriri et al., 2019). The common preparation methods include exfoliation, hydrothermal self-assembly, chemical vapor deposition and nanotube slicing (Lu et al., 2008). Graphene has excellent electrical conductivity ranging from $3000 \sim 5000 \mathrm{~W} \mathrm{mK}^{-1}$ (far beyond that of the copper), ultrahigh theoretical specific surface area along with great mechanical strength (Allahbakhsh et al., 2019; Yu et al., 2018). Therefore, graphene has been applied in electronics, sensors, photonics, energy storage, biomedicine, and environment treatment owing to its outstanding physicochemical characteristics (Plutnar et al., 2018).

Graphene oxide (GO) and reduced graphene oxide (rGO) are the typical derivatives of graphene. The

274 hydroxyl, and epoxide groups. The latter is produced by eliminating the functional groups of GO by 275 chemical treatment or thermal annealing (Shin et al., 2009). Yu et al. (2018) compared the performance of 276 benzene and toluene adsorption on $\mathrm{GO}$ and $\mathrm{rGO}$ at room temperature, $50 \mathrm{ppm}$ and $\mathrm{N}_{2}$ atmosphere. The 277 surface areas of GO and rGO were 236.4 and $292.6 \mathrm{~m}^{2} \mathrm{~g}^{-1}$, respectively. The rGO showed higher adsorption 278 capacities on benzene and toluene (276.4 and $\left.304.4 \mathrm{mg} \mathrm{g}^{-1}\right)$ than that of $\mathrm{GO}\left(216.2\right.$ and $\left.240.6 \mathrm{mg} \mathrm{g}^{-1}\right)$. It 279 might be due to more hydrophobic nature, lower oxygen content and more defect sites of rGO. In addition, 280 Sun et al. (2014) synthesized MIL-101(Cr)/ GO composite, which was with large surface area of $3502 \mathrm{~m}^{2}$ $281 \mathrm{~g}^{-1}$ and pore volume of $1.75 \mathrm{~cm}^{3} \mathrm{~g}^{-1}$. Results showed that the composite had the n-hexane uptake of 1042.1 $\mathrm{mg} \mathrm{g}^{-1}$ at $25^{\circ} \mathrm{C}$, which was much higher than that of AC. The great improvement could be attributed to not only increasing specific surface area, but also stronger surface dispersive forces of the MIL-101@GO by the introduction of the GO with dense arrays of atoms. Lakshmi et al. (2018) reported magnetic graphene 
oxide (MGO) nanoparticles had high surface areas, nano size, high sorption performance, robust structures, magnetic nature at wide-ranging $\mathrm{pH}$, and excellent chemical and thermal stabilities. MGO based materials were applied for the remediation of pollutants like metal ions, radionuclides, dyes, pesticides and opioids, which were expected to be employed for VOCs treatment.

It can be concluded that rGO exhibits strong hydrophobicity due to the removal of plentiful oxygen groups, which favor adsorbing nonpolar or weak polar VOCs. Specially, MOF/GO composite seems to be a potential candidate as an efficient adsorbent for VOCs adsorption. However, the relative complicated

292 synthesis and severe aggregation of graphene remain great challenges for its industrial applications. 293 Therefore, replacement or removal of certain chemicals is required to be further discovered and studied to 294 shorten the fabrication period and result in a better fabrication method (Diaz et al., 2007; Li et al., 2012; 295 Koduru et al., 2019).

\subsubsection{Carbon nanotube}

Carbon nanotube (CNT) is comprised of a graphene sheet, which is rolled up in form of a cylindrical structure with $\mathrm{sp}^{2}$ hybridized carbon atoms (Vashist et al., 2011). It can be divided into single-walled carbon nanotube (SWCNT) and multi-walled carbon nanotube (MWCNT) based on their arrangement of graphene cylinders (Raphey et al., 2019). It is commonly synthesized by the methods of arc discharge, laser ablation, and chemical vapor deposition (CVD). The arc discharge and laser ablation methods prefer a higher yield compared to CVD method (Smalley et al., 1998). CNT is a novel nanomaterial with unique characteristics like electrical conductivity, optical activity, and mechanical strength. In addition, the larger surface area, natural hydrophobicity as well as strong thermal stability make CNT superior to remove trace contaminants from liquid and gas phase (Iijima et al., 1991; Na et al., 2019). However, the utilization of CNTs for VOC abatement is quite rare.

Yang et al. (2008) evaluated the adsorption behavior of CNT for indoor formaldehyde at low concentration $\left(1.50 \mathrm{mg} \mathrm{m}^{-3}\right)$, which adsorption capacity was $62.49 \mathrm{mg} \mathrm{g}^{-1}$. It demonstrated that the surface of CNT exhibited good hydrophobicity and consistency, which can maintain a strong interaction with organic compounds as promising adsorbent. In order to promote the application to treat polar VOCs, Hsu et al. (2012) used the functional SWCNT oxidized by $\mathrm{NaOCl}$ to adsorb isopropyl alcohol vapor in air stream, and the adsorption capacity was $82 \mathrm{mg} \mathrm{g}^{-1}$. Furthermore, modified MWCNT through covalent

314 functionalization prepared to adsorb polar VOCs by Hussain et al. (2009). The polar functionality on the 315 MWCNT surface dramatically altered their sorption characteristics, which prolonged the breakthrough time from 12 to $35 \mathrm{~min}$ for ethanol. 
Although CNT is an optional VOCs adsorbents, it is worth to note that aggregation of CNT is still a challenge for its wide application. To overcome the CNT aggregation, surface oxidation and coating with surfactants is effective solutions for dispersion CNT in liquid phase.

\subsection{Oxygen-contained materials}

\subsubsection{Zeolite}

Zeolite is with crystalline aluminosilicate framework and consists of infinite three-dimensional (3D) arrangement of $\mathrm{TO}_{4}$ tetrahedron ( $\mathrm{T}$ is $\mathrm{Al}$ or $\mathrm{Si}$ ) (Mekki et al., 2019). The two tetrahedrons share the oxygen atoms, resulting in crosslinking in space that generates channels and regular dimensions of cavities which can accommodate organic small molecules. The structural formula of zeolite is $\mathrm{A}_{(\mathrm{x} / \mathrm{q})}\left[\left(\mathrm{AlO}_{2}\right)_{\mathrm{x}}\left(\mathrm{SiO}_{2}\right)_{\mathrm{y}}\right] \mathrm{n}\left(\mathrm{H}_{2} \mathrm{O}\right)$ (A: Ca, Na, K, Ba, Sr and other cations), which is containing 16-21 wt.\% of water. Zeolite is widely used as chemical sieve, adsorbent and catalyst due to its excellent properties such as hydrophobicity, large surface area (250-800 $\left.\mathrm{m}^{2} \mathrm{~g}^{-1}\right)$, tunable porosities, nonflammability. Specially, the textural properties of zeolite can be tailored by varying the $\mathrm{Si} / \mathrm{Al}$ ratio (Nien et al., 2017). Carbon-based materials often suffer from the drawbacks of flammability and regeneration difficulty. The superior hydrothermal and chemical stability of zeolite enable to overcome these problems (Jafari et al., 2018). Besides, the temperature of complete desorption for zeolite is as low as $150{ }^{\circ} \mathrm{C}$, while that for carbon-based materials is over $300{ }^{\circ} \mathrm{C}(\mathrm{Su}$ et al., 2010). As shown in Fig.5, zeolites including silicalite-1 (MFI-structure type), beta (*BEA-structure type), SSZ-23 (STT-structure type), and chabazite (CHA-structure type), have considerable potential as adsorbents for VOCs adsorption (Cosseron et al., 2013).
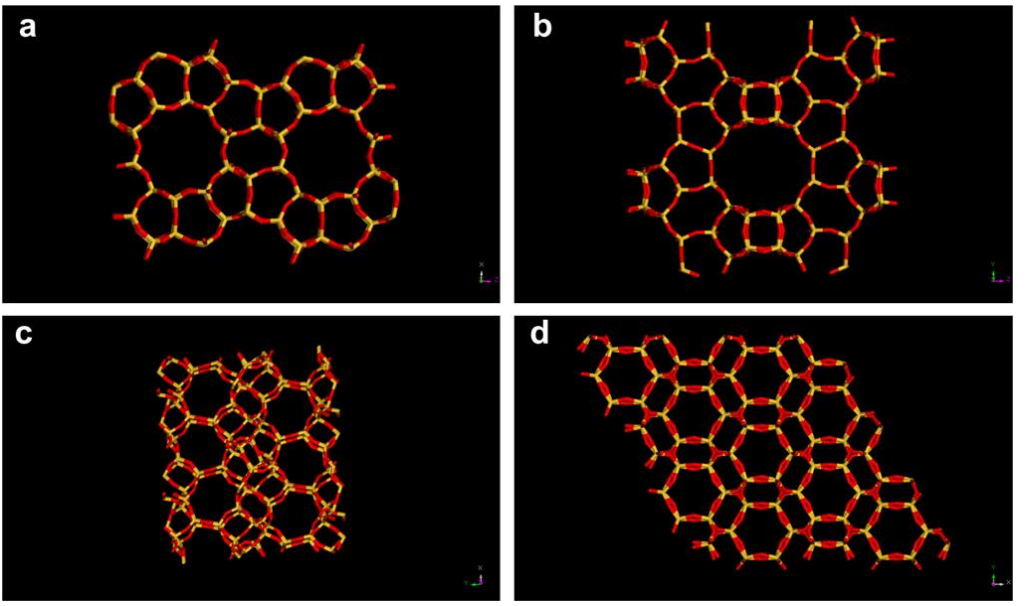

Fig.5. Structures of the MFI-type zeosil (a), ${ }^{* B E A-t y p e ~ z e o s i l ~(b), ~ S T T-t y p e ~ z e o s i l ~(c) ~ a n d ~ C H A-~}$ type zeosil (d). 
MFI zeolites (ZSM-5) and FAU zeolites ( $\mathrm{NaX}$ and $\mathrm{NaY}$ ) with different $\mathrm{Si} / \mathrm{Al}$ ratios were synthesized by Kang et al. (2018). Their adsorptive removal of dichloromethane vapor at $30^{\circ} \mathrm{C}, 5000 \mathrm{ppm}$ were assessed. It showed that ZSM-5 (200) with the highest Si/Al ratio 204.5, showed the best adsorption capacity (179.2 $\mathrm{mg} \mathrm{g}^{-1}$ ) and was barely affected under the relative humidity of $10-90 \%$. Zhu et al. (2017) also obtained innovative all-silica beta zeolite with excellent hydrophobicity, which surface area and total pore volume were $638 \mathrm{~m}^{2} \mathrm{~g}^{-1}, 0.31 \mathrm{~cm}^{3} \mathrm{~g}^{-1}$, respectively. It exhibited the adsorption capacity of $206.8 \mathrm{mg} \mathrm{g}^{-1}$ on $\mathrm{n}$-hexane at $25^{\circ} \mathrm{C}$ and hydrous condition, which was little different with that at anhydrous condition. Lee et al. (2011) investigated adsorption and thermal desorption of acetone and toluene vapors in dealuminated Y-zeolite bed at $20^{\circ} \mathrm{C}, 4500 \mathrm{ppm}$ and $\mathrm{N}_{2}$ atmosphere, which surface area and total pore volume were $704 \mathrm{~m}^{2} \mathrm{~g}^{-1}, 0.47$ $\mathrm{cm}^{3} \mathrm{~g}^{-1}$, respectively. The results suggested that Y-zeolite could be reused without a significant decrease in uptake after several regeneration cycles. Nigar et al. (2015) also studied the desorption study of n-hexane (500 ppm) on $\mathrm{NaY}$ under microwave heating power of $150 \mathrm{~W}$, which surface area and total pore volume were $750 \mathrm{~m}^{2} \mathrm{~g}^{-1}, 0.34 \mathrm{~cm}^{3} \mathrm{~g}^{-1}$, respectively. It found that the adsorption capacity of used $\mathrm{NaY}$ remained $98 \%$ of that of fresh $\mathrm{NaY}$ after two regeneration cycles. tunable specific surface and pore structure. The Si content of zeolite is associated with its water resistance, which can be tailored in the synthesis process. Zeolite is regarded one of the conventional adsorbents for VOCs adsorption thanks to its high adsorption capacity, good thermal stability and easy reproducibility. However, the synthesis process of zeolite is complex and time-consuming. In addition, the source materials, such as tetraethyl orthosilicate and cetyltrimethyl ammonium bromide are relatively expensive compared to AC. These shortcomings would be detrimental for the widespread application of synthetic zeolites (Tamon et al., 1999; Deng et al., 2017).

\subsubsection{Metal organic framework}

Metal organic framework (MOF) firstly discovered by Hoskins et al (1989), is a novel class of crystalline hybrid porous materials. Different kinds of porous MOFs are presents in Fig.6, they are constructed from metal ions or clusters coordinated with organic ligands in ordered one, two, or three dimensional frameworks (Silva et al., 2015). Evaporation solvent method, diffusion method, hydrothermal or solvent-thermal method, ultrasonic and microwave method can be used for the synthesis of MOF (Zhu et al., 2019). Notably, the structure of MOF can be flexibly controlled through selecting matching organic ligands. MOF has been attracted worldwide interest over the last two decades for its distinguished properties, such as ultra-high and surface area (up to $\left.3000 \mathrm{~m}^{2} \mathrm{~g}^{-1}\right)$, excellent thermal stability $\left(>400^{\circ} \mathrm{C}\right.$ ), tailorable pore structure, and facile functionalization (Yang et al., 2011). The great potential applications of MOFs in gas storage, separations, heterogeneous catalysis along with sensing have been widely explored (Luebbers et 
al., 2010).The open metal sites on the pore surfaces of MOFs are available for enhancing diverse VOCs adsorption. Unlike conventional adsorbents, MOF enables to remain their permanent structure and crystalline order after regeneration (Zhao et al., 2018).

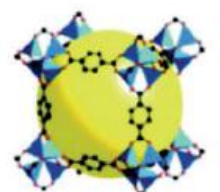

MOF-5

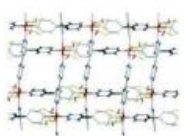

ELM-11

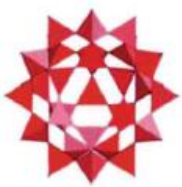

Cr-MIL-100

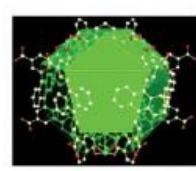

$\mathrm{PCN}-14$

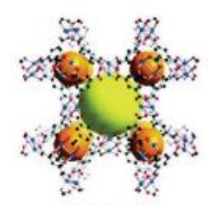

HKUST-1

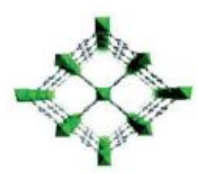

MIL-47

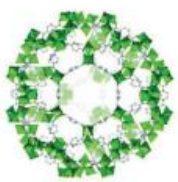

Cr-MIL-101

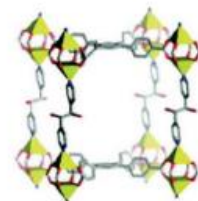

DO-MOF

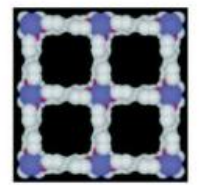

[CuSiF 6 (4,4'-bpy)]

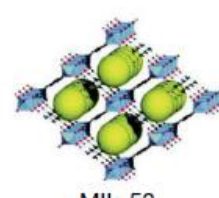

MIL-53

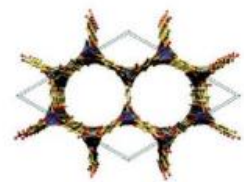

Ni-CPO-27

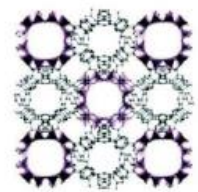

$\left[\mathrm{Be}_{12}(\mathrm{OH})_{12}(\mathrm{BTB})_{4}\right]$

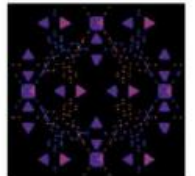

MOF-14

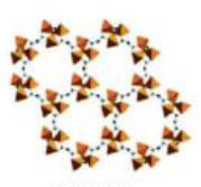

MIL-88

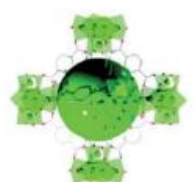

UiO-66

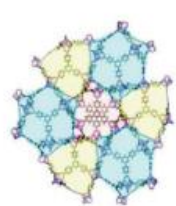

UMCM-2

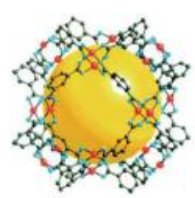

MOP-1
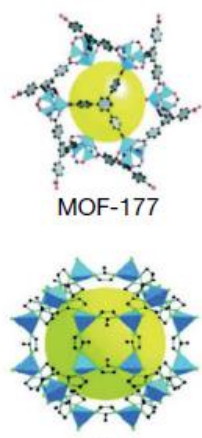

ZIF-8

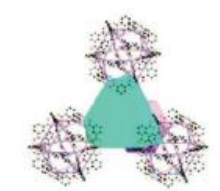

NOTT-116

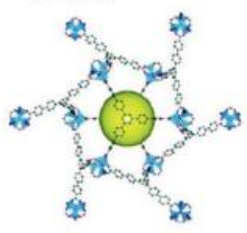

MOF-200

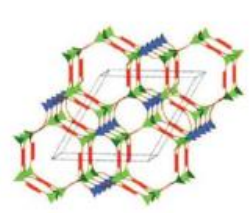

UTSA-20

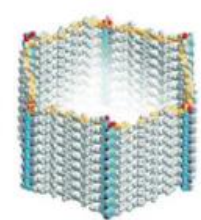

IRMOF-74-XI

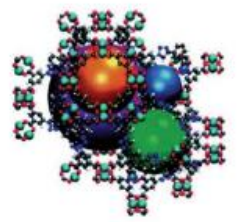

NU-125

Fig. 6. Schematic diagram of different kinds of porous MOFs (Silva et al., 2015).

Diverse types of MOFs including MIL series, UiO series along with ZIF series, have been synthesized to treat VOCs containments. Vellingiri et al. (2017) compared the different types of MOFs for toluene adsorption under ambient conditions. The equilibrated adsorption capacities of all MOFs were measured in the order of ZIF-67 $\left(224 \mathrm{mg} \mathrm{g}^{-1}\right)>\mathrm{UiO}-66\left(166 \mathrm{mg} \mathrm{g}^{-1}\right)>$ MOF-199 $\left(159 \mathrm{mg} \mathrm{g}^{-1}\right)>$ MIL-101(98.3 mg $\left.\mathrm{g}^{-1}\right)$. The maximum adsorption capacity of ZIF-67 might be attributed to the largest surface area of 1401 $\mathrm{m}^{2} \mathrm{~g}^{-1}$. Xian et al. (2015) also found that adsorption capacities of MIL-101 for 1,2-dichloroethane, ethyl acetate and benzene were $960.9,510.2$ and $293.7 \mathrm{mg} \mathrm{g}^{-1}$, which were much higher than those of conventional adsorbents. However, the adsorption capacities of MIL-101 were significantly decreased 
under the humid condition due to the competitive adsorption between water molecule and VOCs. A novel enhanced hydrophobic MIL(Cr)-Z1 using naphthalene dicarboxylic acid as ligand was synthesized by Zhu et al. (2017), the surface area and total pore volume of which were $2080 \mathrm{~m}^{2} \mathrm{~g}^{-1}, 1.23 \mathrm{~cm}^{3} \mathrm{~g}^{-1}$. The adsorption capacity of MIL(Cr)-Z1 on benzene at $20^{\circ} \mathrm{C}$ and the relative humidity of 5, 40 and $60 \%$ were 261.7, 229.6, $205.4 \mathrm{mg} \mathrm{g}^{-1}$, respectively. Shafiei et al. (2018) synthesized a new modified MIL-101(Cr) by a new linker to cluster molar ratio (2:1 instead of 1:1) and different modulators ( $\mathrm{HF}$ and $\left.\mathrm{HNO}_{3}\right)$, the surface area and pore volume of which were $4293 \mathrm{~m}^{2} \mathrm{~g}^{-1}, 2.43 \mathrm{~cm}^{3} \mathrm{~g}^{-1}$. The regeneration efficiency of modified MIL-101(Cr) (99.7\%) was higher than that of commercial AC (87.2\%). Kim et al. (2018) investigated the adsorption performance of amine-functionalized MOF (MIL-125- $\left.\mathrm{NH}_{2}\right)$ for VOCs. The results showed that the adsorption capacities tend to follow the order of polarity among the VOCs (p-xylene < toluene < benzene $<$ acetone < isopropanol) due to strong interaction between amine groups and polar VOCs.

In short, MOF is the most promising adsorbent for VOCs adsorption due to its tunable pore structure and extraordinary physicochemical properties. Generally, the adsorption capacity of MOF on VOCs is superior to conventional adsorbents (AC and zeolite). The modification technologies can be flexibly applied for MOF to enhance the hydrophobic property and adsorptive selectivity. Nonetheless, some drawbacks are also existing to hinder its industrial application such as weak dispersive forces owing to their large amount of void space as well as the insufficient open metal sites beneficial for coordination and catalysis (Zhu et al., 2019; Wang et al., 2018). Furthermore, the utilization of MOF for VOCs adsorption is still an unaffordable option on account of its high preparation cost (Sampieri et al., 2018).

\subsubsection{Clay}

Clay is a class of water-bearing aluminosilicate minerals with layered structures, and it is the composition of rock and soil (Liu et al., 2018). Kaolinite, montmorillonite, halloysite are three common representatives of clay minerals. They have been pervasively applied to be adsorbents, catalysts, carriers, and templates due to their strong heat resistance and abundant raw materials (Deng et al., 2017). As reported, estimated deposits of Ca-bentonite alone consist of 2.5 billion tons of material in the global world. The cost $\left(\$ 40 \mathrm{t}^{-1}\right)$ of nature clays is much cheaper than that of AC (Morozov et al., 2014; Qu et al., 2009). The large surface area, unique combined micro- and mesoporosity and fast mass transfer rates make clay become a potential adsorbent for VOCs abatement.

Deng et al. (2017) evaluated the adsorption performance of porous clay minerals for benzene at $30{ }^{\circ} \mathrm{C}$ and $\mathrm{N}_{2}$ atmosphere. Compared to conventional adsorbents, pristine clays had unitary micropore structure and the pore size ranged from 0.4 to $0.8 \mathrm{~nm}$, the surface area and total pore volume of which ranged from 17.9 to $107.7 \mathrm{~m}^{2} \mathrm{~g}^{-1}, 0.050$ to $0.270 \mathrm{~cm}^{3} \mathrm{~g}^{-1}$. The adsorption capacity on benzene ranged from 56.7 to 141.2 $\mathrm{mg} \mathrm{g}^{-1}$. In order to improve the textural property and adsorption capacity of clays, Wang et al. (2016) 
explored the effects of hydrochloric acid modification on clay minerals for toluene adsorption at $25{ }^{\circ} \mathrm{C}$, $2000 \mathrm{ppm}$ and $\mathrm{N}_{2}$ atmosphere. The results demonstrated that the adsorption capacity of acid-activated clay on toluene increased from 44.6 to $90.4 \mathrm{mg} \mathrm{g}^{-1}$ as the increased surface area from 228 to $329 \mathrm{~m}^{2} \mathrm{~g}^{-1}$ and introduced surface functional groups. It was reported by Kimura et al. (1998) that the surface silanol groups on the surface of clay had strong hydrophilicity, which is easy to absorb water in the air. Organosilanes with different head groups and chemical properties, were used by Mu et al. (2018) to modify the surface properties of diatomite for methane. The surface silylation altered the surface of diatomite from hydrophilicity to hydrophobicity, which promoted the adsorption selectivity of methane under the humid condition.

It can be concluded that raw clay has been proposed as an alternative adsorbent for VOCs adsorption due to low cost and desirable thermal stability. The adsorption affinity between clay and VOCs is limited due to the presence of silanol groups $(\mathrm{Si}-\mathrm{OH})$ on the clay's surface and the undeveloped pore structure. Modified methods such as acid and organic modifications are regarded as the affirmative measures to overcome the above difficulty and improve the adsorption capacity or hydrophobicity of clay.

\subsubsection{Silica gel}

Silica gel (SG) is an amorphous inorganic material with a 3D tetrahedral structure and silanol groups on the surface. Its molecular formula is $\mathrm{mSiO}_{2} \cdot \mathrm{nH}_{2} \mathrm{O}$ (Yang et al., 2003). The synthesis of SG is typically using tetramethoxysilane as the primary precursor (Kim et al., 2017). SG has excellent thermal, mechanical, and chemical stability, low density, high microporous surface area, and plenty functional groups (such as silanols and siloxanes). As a novel porous adsorbent, the research on SG for VOCs adsorption is seldom reported.

SG was employed for toluene adsorption at $25^{\circ} \mathrm{C}$ and $12000 \mathrm{ppm}$ by Sui et al. (2017), the surface area and total pore volume of which were $765.6 \mathrm{~m}^{2} \mathrm{~g}^{-1}$ and $0.444 \mathrm{~cm}^{3} \mathrm{~g}^{-1}$. The results implied that SG was a suitable adsorbent for toluene adsorption with high concentration due to its rapid adsorption, high adsorption capacity (437.4 $\mathrm{mg} \mathrm{g}^{-1}$ ) and longer lifetime. Sigot et al. (2015) compared three adsorbents of AC, zeolite and $\mathrm{SG}$ for the adsorption of $\mathrm{VOSiC}$ at $25^{\circ} \mathrm{C}$. It was found that $\mathrm{SG}$ was the most efficient adsorbent for VOSiC vapor, the adsorption capacity of which was $250 \mathrm{mg} \mathrm{g}^{-1}$. However, SG often presents poor adsorption performance under humid environment due to hydrophilic silicon hydroxyl on the silica surface. The modification method of coating trimethylchlorosilane (TMCS) assisted with microwave irradiation certified by Huang et al., 2017 enabled to improve the hydrophobicity of SG surface effectively. Furthermore, the sufficient and in-depth researches on adsorption mechanism of SG for VOCs are imperative. 


\subsection{Organic polymer}

Organic polymer is composed of light, non-metallic elements such as $\mathrm{C}, \mathrm{H}, \mathrm{O}, \mathrm{N}$, and B with extremely lower density than other known porous materials (Wu et al., 2015). It can be divided into two categories: hypercrosslinked polymer (HCP) and macroporous polymer. HCP represents a novel class of predominantly microporous organic material, which is low-cost and mostly synthesized by the FriedelCrafts alkylation reaction (Fig.7) (Wang et al., 2015). The permanent porosity $(0.5 \sim 2 \mathrm{~nm}$ ) in HCP is attributed to extensive crosslinking reactions, which hinders the polymer chains from collapsing into a dense, nonporous state. Such highly crosslinked nature of HCP confers them high inner specific surface area (up to $1000 \sim 1500 \mathrm{~m}^{2} / \mathrm{g}$ ). While macroporous polymer is main with mesopore and macropore (2 50 $\mathrm{nm}$ ) (Xu et al., 2013, Jia et al., 2013). Organic polymer especially HCP has garnered an increasing amount of interest for VOCs removal, which presents tailorable porosity, lightweight, strong thermal stability, and flexible regenerability. Moreover, HCP exhibits hydrophobic nature under the humid condition due to the absence of surface chemical functional groups.

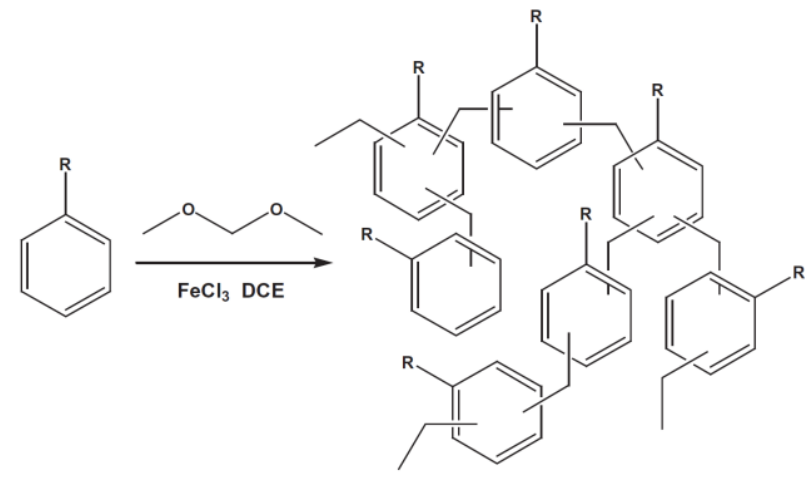

Fig. 7. Friedel-Crafts polymerization using formaldehyde dimethyl acetal (Wang et al., 2015).

Long et al. (2012) prepared a novel HCP with high surface area $\left(1244.2 \mathrm{~m}^{2} \mathrm{~g}^{-1}\right)$ and specific bimodal pore size distribution in the regions of micropore $(0.5-2.0 \mathrm{~nm})$ and meso-macropore $(30-70 \mathrm{~nm})$. It showed that the adsorption capacity $\left(0.553 \mathrm{ml} \mathrm{g}^{-1}\right)$ on benzene at $30{ }^{\circ} \mathrm{C}$ and $\mathrm{N}_{2}$ atmosphere were higher than that of AC (0.411 ml g $\left.\mathrm{m}^{-1}\right)$. Similarly, Zhang et al. (2012) and Wang et al. (2014) obtained HCPs with welldeveloped microporous and mesoporous structures for enhancing adsorption of n-hexane, dichloromethane and 2-butanone at $25^{\circ} \mathrm{C}$, the adsorption capacities of which were $0.955,1343$ and $1.130 \mathrm{ml} \mathrm{g}^{-1}$. Wang et al. (2016) developed a novel HCP with surface area of $1345 \mathrm{~m}^{2} \mathrm{~g}^{-1}$ via one-step Friedel-Crafts reaction. The synthesized polymer presented superhydrophobic nature and excellent adsorption capacity on benzene at $25^{\circ} \mathrm{C}$ and $800 \mathrm{ppm}$. The adsorption capacity of $\mathrm{HCP}$ on benzene was $124.2 \mathrm{mg} \mathrm{g}^{-1}$ at $30 \%$ relative humidity, which kept about $90 \%$ of that $\left(137.4 \mathrm{mg} \mathrm{g}^{-1}\right)$ at dry condition. 
Therefore, HCP would be a potential adsorbent for air purification and environmental protection under both dry and humid conditions due to its large surface area and superhydrophobic nature. However, complex synthesis processes may hinder its development and popularization in large-scale and real application (Wang et al., 2016; Wang et al., 2013).

\subsection{Composite materials}

The adsorbent with a single material is hard to satisfy practical needs in the complicated industrial application such as multi-component and high humidity. Composite material with hierarchically porous structure exhibits remarkably improved adsorption performance (Zhu et al., 2019). It has been applied in the fields of photoelectronics, gas storage, adsorption/separation, heterogeneous catalysis, chemical sensing, and drug delivery (Ojha et al., 2019). The preparation of hierarchical nanocomposites has drawn rise attention, and numerous studies revealed that MOF-based and zeolite-based composites are the potential adsorbents for VOCs abatement under different conditions.

As mentioned in section of 2.2.2, MOF had ultrahigh surface area, tunable porosity and stable thermal property, which exhibits outstanding adsorption capacity for VOCs. However, its large amount of void space, insufficient unsaturated metallic centers as well as open framework fail to provide strong dispersive forces to capture light weighted VOCs vapors (Liu et al., 2016). In order to overcome these difficulties, a surface coating of a dense arrangement of atoms and a porous network is imperative. Various MOF-based composites such as MOF/carbon (MOF-C), MOF/metal oxide, MOF/silica and MOF/organic polymer have been developed as the efficient adsorbents for air purification. Notably, the addition of carbon-based materials such as GO or CNT into MOF have shown increasing surface area, dispersion force and active sites on the crystal surface (Zhu et al., 2019). Zheng et al. (2018) reported that the adsorption capacity of MIL-101/GO on carbon tetrachloride was up to $2368.1 \mathrm{mg} \mathrm{g}^{-1}$ at $30{ }^{\circ} \mathrm{C}$, which increased $16 \%$ in comparison with that of pure MIL-101 (2044.4 $\mathrm{mg} \mathrm{g}^{-1}$ ). MIL-101/GrO composites were well above those of conventional adsorbents, such as AC $\left(600 \mathrm{mg} \mathrm{g}^{-1}\right)$ and zeolite $\left(430 \mathrm{mg} \mathrm{g}^{-1}\right)$. As shown in Fig. 8, Cu-BTC/GO obtained by Li et al. (2016) exhibited the maximum toluene uptake of $709.5 \mathrm{mg} \mathrm{g}^{-1}$ at $25{ }^{\circ} \mathrm{C}$, which had an

512 increase of $47 \%$ in comparison with $\mathrm{Cu}$-BTC. More interestingly, the water-stability of Cu-BTC/GO had 513 greatly been enhanced. After soaked in water for $10 \mathrm{~h}$, it still remained original structure and porosity and 514 its BET surface area remained $1205 \mathrm{~m}^{2} \mathrm{~g}^{-1}$. It may be ascribed to the coordination between the oxygen groups in the $\mathrm{GO}$ and $\mathrm{Cu}^{2+}$ mental center in $\mathrm{Cu}-\mathrm{BTC}$. Furthermore, the presence of carbonaceous materials enabled to prevent these unoccupied Lewis metal sites inside MOFs from being poisoned by blocking the channels, which enhanced adsorption interactions with small VOCs molecules Liu et al. (2016). 

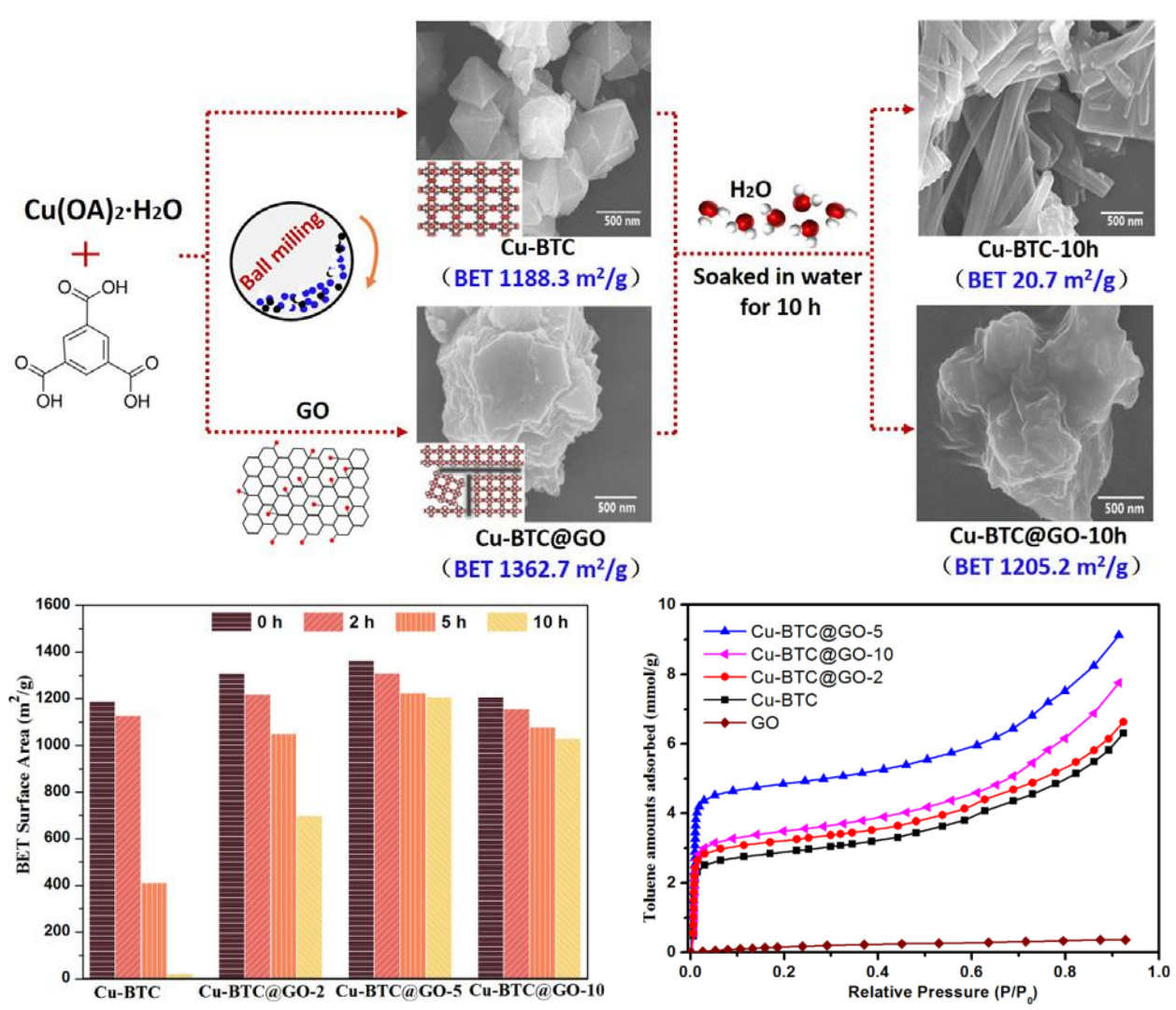

Fig. 8. Mechanochemical synthesis of $\mathrm{Cu}-\mathrm{BTC} / \mathrm{GO}$ composites and effects on toluene adsorption performance (Li et al., 2016).

Zeolite is considered as the conventional adsorbent for VOCs capture due to its hydrophobicity, large surface area, controllable porosities and nonflammability. However, the drawbacks of nanoparticle agglomeration and monomodal microporosity $(<1 \mathrm{~nm})$ are still existing, which hinder the diffusion and mass transfer of certain macromolecules such as mesitylene, m-xylene and oxylene (Liu et al., 2019). Therefore, coating zeolite crystals at the surface of macroporous supports to fabricate hybrid composites is an effective strategy to overcome these difficulties. Various materials including clay minerals, MOFs, ordered mesoporous silicates, etc. have been applied as permanent supports. Among them, diatomite (Dt) is an attractive support with low cost, well-developed porosity as well as predominately masoporous structure $(50-800 \mathrm{~nm})$. Yu et al. (2015a; 2015b) prepared hierarchically porous Dt/MFI-type zeolite composites with higher benzene adsorption capacity of $62.5 \mathrm{mg} \mathrm{g}^{-1}$ at $25{ }^{\circ} \mathrm{C}$ in comparison with Dt. The

533 Dt-coated zeolites enabled to integrate the advantages of both zeolites and supports. The resultant 534 hierarchically porous structure (meso-/micropores or macro-/micropores) was beneficial for improving the efficiency of diffusion performance and mass transport. Yuan et al. (2016) also synthesized Dt/silicalite composite for benzene uptake from industrial processes by a facile pre-modification in situ synthesis route. 
The results showed that the composite exhibited considerably high benzene adsorption capacity ( $246.0 \mathrm{mg}$ $\mathrm{g}^{-1}$ ) at $25^{\circ} \mathrm{C}$, which was much higher than that of Dt or silicalite. It might be due to the improved dispersity and reduced mass transfer resistance. Additionally, the pore structure could be regulated through varying the zeolite content, and the pole volume ranged from 0.051 to $0.720 \mathrm{~cm}^{3} \mathrm{~g}^{-1}$.

Some other composite materials such as GAC/ACF, GO/CNT, SiC, etc. also have potential to be the effective adsorbents for VOCs capture. It is worth noting that the pre-synthesis or pretreatment process of the hierarchically porous structured composites may cause the extra expense (Yuan et al., 2016). Thus, the development of simple and flexible synthesis method for composite adsorbents is still needed to be placed emphasis in future research work.

The physiochemical properties and performance of different porous materials for VOCs adsorption are summarized in Table 2.

\subsection{Other porous materials}

Fly ash (FA) as a kind of industrial waste is mainly derived from coal-fired power plants. It contains valuable oxide components, such as $\mathrm{SiO}_{2}, \mathrm{Al}_{2} \mathrm{O}_{3}, \mathrm{CaO}, \mathrm{MgO}, \mathrm{Na}_{2} \mathrm{O}$, and $\mathrm{TiO}_{2}$, and essential elements, including P, K, Mg, Zn, Fe, Mn, and others (Ge et al., 2018). Based on its unique characteristics including honeycomb structure, functional groups, unburned carbon content in the ash. Many researches have reported that FA and its derivatives (zeolite) are optional adsorbent for heavy metals removal from aqueous solutions. Ge et al. (2019) pointed that FA in the form of electrospun nanofibrous membranes had high adsorption capacity for trapping of BTX aromatic hydrocarbons and heavy metal ions. Bandura et al. (2016) obtained the similar results by synthetic zeolites from fly ash for an effective trapping of xylenes, toluene and benzene. In brief, FA is a cheap, durable, easy-to-use, promising adsorbent for adsorbing some harmful substances and the research of its application on VOCs adsorption is still lacking.

Sewage sludge as a potential precursor of adsorbent for wastewater treatment constitutes a paradigmatic application of the "zero-residue" concept in an anthropogenic activity. To solve its shortcoming of limited specific surface area, Anfruns et al. (2011) prepared adsorbents from pyrolysed sewage-sludge following two different methodologies, namely acid washing and activation with alkaline hydroxides for toluene, methyl ethyl ketone and limonene abatement. The adsorption performance of sludge-based adsorbents (with specific surface area up to $1000 \mathrm{~m}^{2} \mathrm{~g}^{-1}$ ) was comparable to commercial AC.

Many other porous materials such as titanate nanotube (Lee et al., 2010), carbon cryogels microsphere (Tamon et al., 1999), ordered mesoporous carbon (Tang et al., 2015) etc. are envisioned to make more efforts to improve the efficiency of VOCs adsorption in the practical application. 
Table 2

Summary of physiochemical properties and performance of different porous materials for VOC adsorption.

\begin{tabular}{|c|c|c|c|c|c|c|}
\hline Adsorbent & $\begin{array}{l}\text { Specific surface areas } \\
\mathrm{m}^{2} \cdot \mathrm{g}^{-1}\end{array}$ & $\begin{array}{l}\text { Total pore volume } \\
\mathrm{cm}^{3} \cdot \mathrm{g}^{-1}\end{array}$ & Adsorbate & $\begin{array}{l}\text { Adsorption capacity } \\
\text { mg.g }^{-1}\end{array}$ & Adsorption Condition & References \\
\hline \multicolumn{7}{|l|}{ ACs } \\
\hline Coal-base & 838 & 0.436 & Toluene & 137.3 & $\mathrm{~N}_{2}, 200 \mathrm{ppm}$ & (Yang et al., 2018) \\
\hline $\mathrm{AC}$ & 952 & 0.458 & Acetone & 147.5 & $\mathrm{~N}_{2}, 25^{\circ} \mathrm{C}, 2000 \mathrm{ppm}$ & (Li et al., 2012) \\
\hline Coconut shell-base & 868 & 0.500 & Benzene & 336 & $\mathrm{~N}_{2}, 30^{\circ} \mathrm{C}, 400 \mathrm{~mL} / \mathrm{min}$ & (Liu et al., 2016) \\
\hline Coal-base & 893 & 0.418 & Chlorobenzene & 51.26 & $5 \% \mathrm{O}_{2}, 200 \mathrm{ppm}, 300 \mathrm{ml} \mathrm{min}^{-1}$ & (Guo et al., 2013) \\
\hline \multicolumn{7}{|l|}{ Biochars } \\
\hline Date Palm Pits & 1100 & - & Benzene & 93.7 & 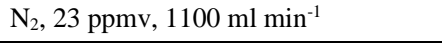 & (Vohra et al., 2015) \\
\hline \multicolumn{7}{|l|}{ ACFs } \\
\hline Polyacrylonitryl & 1662.0 & 0.108 & Toluene & 538.8 & Air, $30^{\circ} \mathrm{C}, 86.5 \mathrm{ppm}$ & (Kim et al., 2012) \\
\hline Lignin & - & - & Acetone & 106.71 & $\mathrm{~N}_{2}, 25^{\circ} \mathrm{C}, 3000 \mathrm{mg} \mathrm{m}^{-3}, 150 \mathrm{ml} \mathrm{min}^{-1}$ & (Meng et al., 2019) \\
\hline \multicolumn{7}{|l|}{ Graphenes } \\
\hline Graphite powder & 292.6 & - & Toluene & 304.4 & $\mathrm{~N}_{2}, 10^{\circ} \mathrm{C}, 50 \mathrm{ppm}, 40 \mathrm{ml} \mathrm{min}^{-1}$ & (Yu et al., 2018) \\
\hline \multicolumn{7}{|l|}{ Zeolites } \\
\hline HZSM-5 & 334 & 0.13 & Benzene & 1.72 & $\mathrm{~N}_{2}, 10^{\circ} \mathrm{C}, 50 \mathrm{ppm}$ & (Aziz et al., 2017) \\
\hline \multicolumn{7}{|l|}{ MOFs } \\
\hline ZIF-67 & 1401 & 1.22 & Toluene & 224 & $\mathrm{~N}_{2}, 25^{\circ} \mathrm{C}, 0.0379$ bar & (Vellingiri et al., 2017) \\
\hline $\operatorname{MIL}(\mathrm{Cr})-101$ & 2086 & 1.23 & Benzene & 227.3 & $5 \%$ humidity, $25^{\circ} \mathrm{C}, 2 \mathrm{ppm}$ & (Zhu et al., 2017) \\
\hline \multicolumn{7}{|l|}{ Clays } \\
\hline Palygorskite & 329 & 0.554 & Toluene & 90.4 & $\mathrm{~N}_{2}, 60{ }^{\circ} \mathrm{C}, 2000 \mathrm{ppm}, 50 \mathrm{ml} \mathrm{min}^{-1}$ & (Zhu et al., 2017) \\
\hline Montmorillonite & 69.5 & 0.119 & Benzene & 141.2 & $\mathrm{~N}_{2}, 25^{\circ} \mathrm{C}, 3 \mathrm{mg} \mathrm{min}^{-1}$ & (Deng et al., 2017) \\
\hline \multicolumn{7}{|l|}{ Silica gel } \\
\hline Commercial SG & 765.6 & 0.444 & Toluene & 437 & 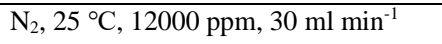 & (Sui et al., 2017) \\
\hline \multicolumn{7}{|l|}{ Organic polymers } \\
\hline Polydopamine & 3291.03 & 1.78 & Toluene & 1254.95 & $\mathrm{~N}_{2}, 25^{\circ} \mathrm{C}$ & (Wang et al., 2018) \\
\hline Benzyl chloride & 1345 & 1.75 & Benzene & 1394.3 & $\mathrm{~N}_{2}, 550 \mathrm{ppm}, 50 \mathrm{ml} \mathrm{\textrm {min } ^ { - 1 }}$ & (Wang et al., 2016) \\
\hline Styrene-divinylbenzene & 1020.7 & - & Chlorobenzene & 389.8 & $30^{\circ} \mathrm{C}$ & (Long et al., 2010) \\
\hline
\end{tabular}




\section{Mechanism of adsorbate-adsorbent interaction}

571

572

573

574

575

576

577

578

579

580

581

582

583

584

585

586

587

588

589

590

591

592

593

594

595

\subsection{Physical adsorption}

Physical adsorption can be ascribed to the intermolecular gravitation, namely Van der Waals force or dispersion force. Because of the weak interaction, no chemical bonds involved and low adsorption heat, the solid adsorbents can be regenerated easily and keep their original structure unchanged (Le-Minh et al., 2018). Yang et al. (2018) considered that the physical adsorption process could be divided into three stages. As illustrated in Fig.9, in the external surface adsorption stage, mass transfer occurs from the gas phase to the surface of adsorbent via convection, axial dispersion, and particle diffusion. The rate is determined by the specific surface area. During the internal diffusion stage, VOCs vapors enter into the internal surface through pore diffusion. Pore structure and volume are the dominated factors. In the final equilibrium stage, the ratio of micro-, meso- and macropore volume are the key factors (Zhang et al., 2017). The rate of whole physical adsorption is controlled by the VOCs concentration.
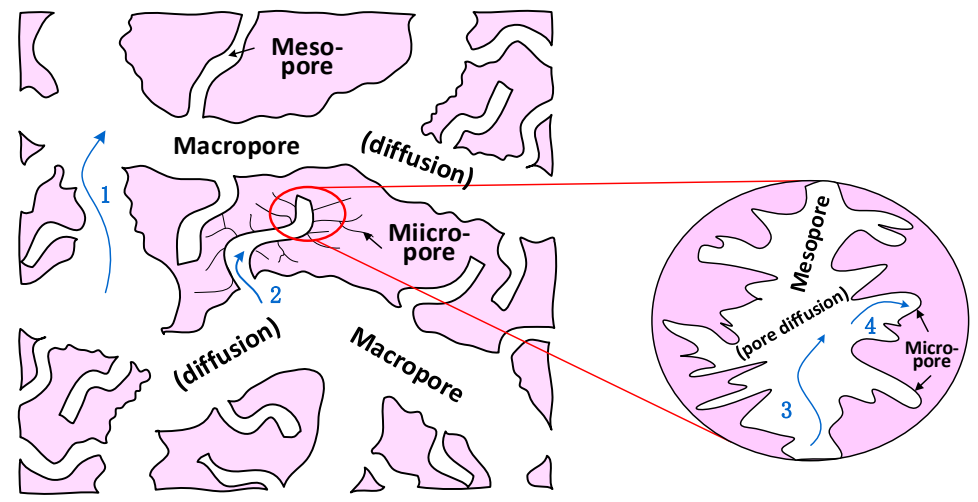

Fig. 9. Illustration of physical adsorption on the porous adsorbent (1. Convection and dispersion in gas; 2. Convective mass transfer; 3. Pore diffusion; 4. Adsorption on surfaces.).

In term of porous adsorbents, physical adsorption mainly depend on their specific surface area and pore structure. Carter et al. (2011) investigated the effect of specific surface area on formaldehyde adsorption at $26{ }^{\circ} \mathrm{C}, 36.5 \mathrm{ppm}$. It found that ACF with the largest specific surface area $\left(1084 \mathrm{~m}^{2} \mathrm{~g}^{-1}\right)$ and total pore volume $\left(0.41 \mathrm{~cm}^{3} \mathrm{~g}^{-1}\right)$ showed the best adsorption capacity (400 $\mathrm{mg} \mathrm{g}^{-1}$ ) compared to another two GACs. Similar phenomenon was observed by Wang et al. (2016), the benzene adsorption capacity $\left(133 \mathrm{mg} \mathrm{g}^{-1}\right)$ of $\mathrm{HCP}$ at $100{ }^{\circ} \mathrm{C}, 550 \mathrm{ppm}$ and $\mathrm{N}_{2}$ atmosphere was three times of that of AC. It might be due to larger surface area $\left(1345 \mathrm{~m}^{2} \mathrm{~g}^{-1}\right)$ of HCP than AC. Vellingiri et al. (2017) found that although ZIF-67 had the superior textural properties (surface area 
and total pore volume: $\left.1401 \mathrm{~m}^{2} \mathrm{~g}^{-1}, 1.22 \mathrm{~cm}^{3} \mathrm{~g}^{-1}\right)$ to UiO-66- $\mathrm{NH}_{2}\left(1250 \mathrm{~m}^{2} \mathrm{~g}^{-1}, 0.62 \mathrm{~cm}^{3} \mathrm{~g}^{-1}\right)$, UiO66- $\mathrm{NH}_{2}$ could adsorb $140 \mathrm{mg} \mathrm{g}^{-1}$ toluene, much higher than that $\left(50.8 \mathrm{mg} \mathrm{g}^{-1}\right)$ of ZIF-67 at $25^{\circ} \mathrm{C}$. It indicated that adsorbents with the largest specific surface area and pore volume had no direct relationship to the best adsorption capacity (Gil et al., 2014). Furthermore, Yu et al. (2018) compared acetone adsorption amounts of four kinds ACs with different textural properties. They

601 pointed that AC with the largest microporous surface area $\left(329 \mathrm{~m}^{2} \mathrm{~g}^{-1}\right)$ amd micropore volume $602\left(0.167 \mathrm{~cm}^{3} \mathrm{~g}^{-1}\right)$ obtained the best adsorption ability $\left(318.9 \mathrm{mg} \mathrm{g}^{-1}\right)$ despite the lower total surface 603 area. It suggested that the micropore structure was the crutial factor to affect the physical 604 adsorption behavior of adsorbents.

605 The micropores can offer main adsorptive sites and dominate the adsorption capacity of 606 adsorbents, but the role of macropores and mesopores cannot be ignored. In most cases, only 607 macropores are exposed directly to the external surface of porous adsorbents. Mesopores are 608 branches of the macropores (similar to the vascular tissue of the human body), which provide the 609 transport channels for VOCs molecules entering into the micropores. Macropores have a very small 610 contribution to the total surface area (about 5\%), while meso- and micropores contribute most 611 proportions (95\%). Overall, the adsorption capacity relies on not only well-developed micropores, 612 but also suitable mesopores and macropores. It's worth noting that too much narrower micropore 613 (size $<0.7 \mathrm{~nm}$ ) volume could increase the diffusion resistance leading to low diffusion rates (Le614 Minh et al., 2018; Zhang et al., 2017).

615 Yang et al. (2011) studied the adsorption of VOCs with different molecule shapes and sizes 616 on MIL-101 at $25{ }^{\circ} \mathrm{C}$ and $0.55 \mathrm{P} / \mathrm{P}_{0}$. It was reported that acetone, benzene, toluene, ethylbenzene, 617 and p-xylene could enter the MIL-101 pores, but o- and m-xylene cannot due to the long distance 618 between the two methyl groups in them $(1.07$ and $1.16 \mathrm{~nm})$, which are longer than the pore 619 diameters of MIL-101 (0.85-1.9 nm). Based on the pore filling mechanism, the physical adsorption 620 shows the size- and shape- selectivity towards VOCs molecules. It contains three probable cases in 621 the adsorption process as follows: i) VOCs molecule size is larger than pore diameter, so no 622 adsorption process occurs due to the steric hindrance. ii) VOCs molecule size is equal to pore 623 diameter, VOCs molecules are strongly captured by adsorbents and not easy to desorption attribute 624 to the superposition of potential energy fields in adjacent wall pores. iii) VOCs molecule size is 625 smaller than pore diameter, capillary condensation can easily occur in the pore and increase the 626 adsorption capacity. When VOCs molecule size far smaller than pore diameter, VOCs are easy to 627 desorption. In general, most VOCs molecule size are in the same order of magnitude as that of 628 narrow micropores except for the BTEX molecules (benzene, toluene, ethylbenzene, and xylenes). 
In particular, it is reported that the optimal ratio of pore diameter to VOCs molecule size is ranging from 1.7 3.0 for excellent adsorption performance.

From the point of the macroscopic view, physical adsorption process of porous materials is determined by specific surface area, pore structure, surface properties, and adsorbate properties. From the microscopic view, it is mainly determined by van Edward force, micropore filling and capillary condensation. The large surface specific area and well-developed pore structure especially micropore structure have positive effect on physical adsorption. However, physical adsorption is a complicated process, which is controlled by multi-factors instead of just one single factor. Hence, it is significant to consider both absorbent and adsorbate characteristics while attempting to improve physical adsorption capacity.

\subsection{Chemical adsorption}

Chemical adsorption refers to the chemical reaction between surface functional groups of adsorbent and adsorbate molecules. The difference between physical adsorption and chemical adsorption are summarized as follows: i) Chemical adsorption usually involves one single surface layer, while physical adsorption involves multilayers especially in the high pressure (Le-Minh et al., 2018; Schnelle et al., 2001); ii) Chemical adsorption presents more selectivity than physical adsorption because the chemical reaction only occurs between special groups and certain VOCs; iii) The adsorption heat used for old and new bonds alternating during the chemical reaction is much higher, which need enough high activation energy. So the adsorption rate of chemisorption can be accelerated by high temperature, while physical adsorption is completely opposite; iv) Chemical adsorption is usually irreversible owing to the strong combination of chemical bonds, and the original forms of adsorbate may be changed during the desorption process (Bansal et al., 2005). Physical adsorption is a reversible process, and adsorbents can be regenerated easily. Physical adsorption and chemical adsorption exist simultaneously in the practical adsorption process.

The surface functional groups of porous materials are responsible for chemical adsorption for VOCs.

The reactive sites on the adsorbent surface derive from the defect positions, which are in form of unsaturated atoms at the edges of the basal planes (Chiang et al., 2002). The unsaturated atoms enable to combine with plentiful heteroatoms like oxygen, hydrogen, sulfur, nitrogen, halogens and metal ions. The surface chemistry of porous adsorbents are regulated by the nature of raw material and modification technologies such as chemical impregnation, calcination treatment and steam activation (Qiao et al., 2002). Among the common surface functional groups, the oxygen and 
nitrogen containing groups are acknowledged as the most important species for the chemical adsorption.

The oxygen-containing groups are the most abundant species in the porous materials, which can be divided into three types as acidic, neutral and basic functional groups. Carboxylic acids are formed through the liquid-phase oxidation, while neutral and basic functional groups such as hydroxyl and carbonyl derive from the gas-phase oxidation (Lillo-Ródenas et al., 2005). Most adsorbents are nonpolar in nature, however the oxygen-containing surface functional groups facilitate their surface polarity. These oxygen-containing groups prefer to adsorb the polar VOCs such as methanol, ethanol and acetone through the formation of hydrogen bonds. The adsorption capacity of polar compounds are affected by the amount of oxygen containing groups. It is demonstrated that carboxyl and hydroxyl provide reactive sites for substitution reaction or acidbase neutralization. Quinones are expected to join in the redox behavior to oxidize or reduce organic compounds, and then generate reactive oxygen species for further oxidation (Pignatello et al., 2017).

The nitrogen-containing groups are caused by the treatments of ammonium, nitric acid and nitrogenous compounds, which tend to increase the $\mathrm{pH}$ of adsorbents (Shen et al., 2008). The adsorption performance of adsorbents containing various nitrogen groups outperform that of caustic impregnated adsorbents owing to high dispersion of nitrogen compounds in small pores. The extra p-electrons of pyrollic and quaternary nitrogen at high energy states facilitate the oxidation reaction by forming superoxide ions, which are with high hydrophilicity. Nitrogen functional groups can improve active sites on adsorbent surface for chemical adsorption (Figueiredo 2013).

The chemical surface functional groups make small contributions to total surface area. It still remains divergence as to which is the dominant factor, textural property or surface chemistry. It is necessary to keep the balance between them in order to explore the VOCs adsorption behavior of porous adsorbents in a comprehensive way. The research on chemical adsorption mechanism is far from sufficient. The interaction mechanism between surface functional groups of adsorbent and VOCs molecules need in-depth exploration and discussion.

\subsection{Competitive adsorption}

If the VOCs such as benzene, n-hexane and methanol have the similar monolayer volumes, porous adsorbents have no selectivity in the separate adsorption of each component and show almost adsorption capacity (Morozov et al., 2014). The adsorption process of binary or multicomponent VOCs vapors on porous adsorbents is more complicated. As VOCs from industrial organic waste gas are composed of at least two mixed gases, the competitive adsorption in the 
mixed gas system may occur due to the different affinity of each component. Physical and chemical

698 properties both control the adsorption ability of porous materials. The adsorption process is actually

699 a dynamic equilibrium process of continuous adsorption and desorption. When the concentration

700 of VOCs vapors with strong adsorption affinity reaches a certain degree, competitive binding would

701 be inevitably formed on the adsorption site to replace those with weak adsorption affinity (Pak et

702 al., 2016). It is confirmed that polarity degree, molecular weight, boiling point of VOCs have

703 significant effects on the competitive adsorption process.

704 Meng et al. (2019) proposed the competitive adsorption process and related adsorption 705 mechanisms in Fig.10 among toluene, methanol and acetone on ACF. In the multicomponent 706 adsorption, the results revealed that methanol and acetone are physically adsorbed mainly via 707 dipole-dipole interactions. While the adsorption of toluene was controlled by physical and 708 chemical processes through a strong affinity between the adsorbate and adsorbent. There was a 709 stable electron donor-acceptor complex formed owing to the aromatic ring of toluene as electron 710 acceptor to combine with carbonyl or lactone as electron donor. It was worth noting that the 711 stronger adsorption of toluene or acetone could displace the weaker adsorption of methanol. In 712 addition, Khazraei Vizhemehr et al. (2015) indicated that the adsorption rate of lighter compound 713 (MEK) was faster than that of heavier ones (n-hexane and toluene), then the heavier one would 714 displace the adsorbed lighter ones, resulting in their forced-desorption. Wang et al. (2012) 715 evaluated eight VOCs adsorption capacities of beaded AC, and found the breakthrough curve of 716 the low boiling point VOCs (n-Butanol, n-Butyl Acetate) rolled up. Their concentrations firstly 717 increased beyond their influent concentrations and then decreased, finally ultimately approached 718 their influent values. It represented that the low boiling point compounds were desorbed as they 719 were displaced by the high boiling point compounds (Indan, 2,2-Dimethyl-propylbenzene), which 720 have stronger adsorbate-adsorbent interaction. 


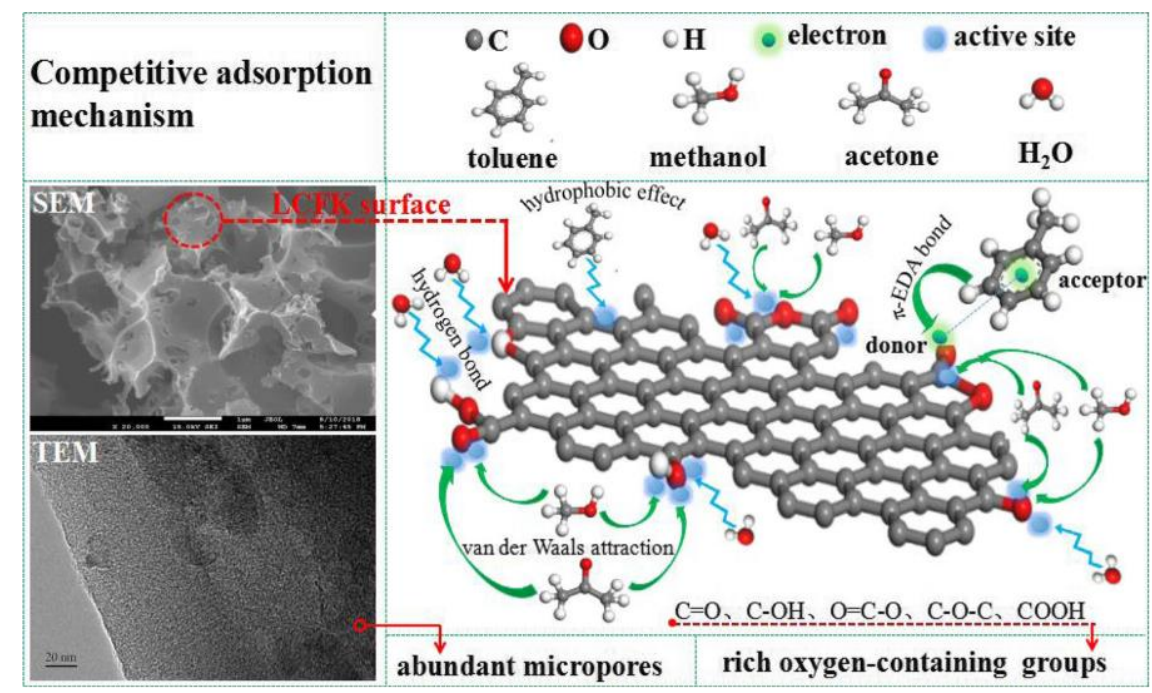

Fig. 10. The competitive adsorption process and the relevant mechanism (Meng et al., 2019). and VOCs is also fierce in some practical industrial process. According to the Dubinin-Serpinsky theory, water molecules may occupy the adsorption sites in the pores competitively via three ways, namely, surface oxygen functional groups reaction, hydrogen bonding and capillary condensation. Liu et al. (2016) observed that the benzene adsorption capacity of bare-AC under the relative humidity of $50 \%$ and $90 \%$ were dropped to $256,166 \mathrm{mg} \mathrm{g}^{-1}$, which were decreased $24 \%, 51 \%$ of that under dry condition. Similar observation has been reported by Liu et al. (2019) on ACFC for isobutane adsorption, indicating that high relative humidity caused the blockage of micropores available for hydrophobic VOCs. However, except for competitive adsorption, the cooperative adsorption between water and hydrophilic or water miscible VOCs existed under some certain conditions. Morozov et al. (2014) compared the adsorption performance of montmorillonites for benzene, $n$-hexane and methanol in the presence of water. The adsorption capacity of hydrophobic VOCs (benzene and n-hexane) showed a significant decrease as the increasing relative humidity from $26 \%$ to $100 \%$. On the contrary, the adsorption of hydrophilic methanol was promoted due to its dissolution in the water films.

The competitive adsorption on porous materials in the mixture VOCs gas system is affected 742 adsorption affinity with adsorbent with polar surface than weak polar VOCs. VOCs with high 743 boiling point and heavier molecular weight have priority to occupy adsorption sites in the 744 competitive adsorption process. Furthermore, the adsorption capacity of hydrophobic VOCs can be 745 significantly reduced under the humidity condition. In order to alleviate the negative influence of 

technologies are feasible and imperative.

\section{Modification technology for enhancing VOCs adsorption}

The industrial applications of some porous materials may be limited due to their sensibility to high temperature, lack of adsorption selectivity and hydrophilic nature. To overcome these drawbacks, modification technologies termed as physical and chemical modification have been developed such as activated with acid or alkali regents, doped with heteroatoms, impregnation with active species etc. (Xu et al., 2018).Physical modification is commonly carried out under the oxidizing gases such as $\mathrm{CO}_{2}$, steam, air, etc. with high temperature (700-1000 $\left.{ }^{\circ} \mathrm{C}\right)$. Chemical modification involves carbonization and activation in a single step, where the raw materials impregnated with chemical agents are heated under an inert atmosphere at lower temperature $\left(\leq 700{ }^{\circ} \mathrm{C}\right)$. Physical activation without using corrosive or harmful chemical agent is more environmentally-protected than that of chemical modification (Hsi et al., 2011; Xu et al., 2018). Chemical modification possesses the superiorities of shorter production cycle, lower energy consumption as well as flexible operation.

\subsection{Physical modification}

\subsection{1. $\mathrm{CO}_{2}$ activation}

$\mathrm{CO}_{2}$ as a typical activation gas is used in the physical activation to manufacture porous adsorbent at high temperatures. It performs the function of pore-forming and pore-expanding by reacting with carbon atoms in the active position and surface active groups of adsorbents. The related reactions are shown as follows (take AC for example):

When the activating agent is $\mathrm{CO}_{2}$,

When air or oxygen is mixed with the activating agent,

The reaction between $\mathrm{CO}_{2}$ and $\mathrm{C}(4-1)$ is endothermic, while the reactions between $\mathrm{O}_{2}$ and $\mathrm{C}$, $\mathrm{H}_{2}$ and $\mathrm{CO}$ (4-2-4-4) are exothermic. It is difficult to control the temperature in the furnace during 
the activation process, and the local temperature is prone to be too high making the activation uneven. A small amount of oxygen in the gas mixture could accelerate the activation rate due to faster carbon and oxygen reaction rate. The activation degree depend on the mass loss of porous materials, and it is linear positive correlated to activation time, heat temperature along with gas velocity. After $\mathrm{CO}_{2}$ activation, the structure of adsorbents maintain essentially unchanged, and no obvious defects are observed on the surface (Lillo-Ródenas et al., 2010; Águeda et al., 2011; Hu et al., 2016). $\mathrm{CO}_{2}$ activation mainly develops new narrow micropores and enlarges the original micropores, which result in widening the pore size distribution. Yamamoto et al. (2010) prepared carbon cryogel microspheres modified by $\mathrm{CO}_{2}$ activation $\left(5\right.$ vol. $\% \mathrm{CO}_{2}, 800^{\circ} \mathrm{C}$ for $\left.2 \mathrm{~h}\right)$. It showed that the micro- and meso-pore surface area increased from 311, 293 to $472,341 \mathrm{~m}^{2} \mathrm{~g}^{-1}$, respectively. Similarly, Qiu et al. (2018) found the mesopore volume of AC modified by $\mathrm{CO}_{2} /$ microwave (300ml $\min ^{-1} \mathrm{CO}_{2}$ for $20 \mathrm{~min}$ and $2.45 \mathrm{GHz}, 0.8 \mathrm{~kW}$ microwave irradiation for $40 \mathrm{~min}$ ) increased from $0.122 \mathrm{~cm}^{3} \mathrm{~g}^{-1}$ to $0.270 \mathrm{~cm}^{3} \mathrm{~g}^{-1}$. The adsorption capacity of $\mathrm{CO}_{2}$ activated $\mathrm{AC}$ on toluene $(109.5 \mathrm{mg}$ $\left.\mathrm{g}^{-1}\right)$ was higher than that of original AC $\left(95.3 \mathrm{mg} \mathrm{g}^{-1}\right)$. Mazlan et al. (2016) investigated the effect of activation temperature $\left(700,720,740\right.$, and $\left.760{ }^{\circ} \mathrm{C}\right)$ and time $(60,90$, and $120 \mathrm{~min})$ on the characteristics of ACs. It resulted that the produced $\mathrm{AC}$ in the activation condition of $740{ }^{\circ} \mathrm{C}, 60$ min possessed the largest surface area $\left(465 \mathrm{~m}^{2} \mathrm{~g}^{-1}\right)$, highest total and micro- pore volume $(0.239$ $\left.\mathrm{cm}^{3} \mathrm{~g}^{-1}, 0.186 \mathrm{~cm}^{3} \mathrm{~g}^{-1}\right)$.

Regarding the surface chemistry, no new chemical bonds and functional groups can be formed after $\mathrm{CO}_{2}$ activation. Lillo-Ródenas et al. (2010) observed that total oxygen-containing groups were decreased from 815 to $735 \mu \mathrm{mol} \mathrm{g}{ }^{-1}$ as the increased activation degree. It is suggested that the oxygen functional groups such as phenolic hydroxyl and carboxyl acid groups decomposed at high temperature. The removal of surface oxygen groups weaken the surface acidity of porous adsorbents, enhancing the hydrophobicity toward nonpolar VOCs molecules adsorption in the presence of water (Hu et al., 2016; Qiu et al., 2018).

$\mathrm{CO}_{2}$ activation is commonly operated at over $700{ }^{\circ} \mathrm{C}$ for $1-2 \mathrm{~h}$, which has positive effects on the textural property and surface chemistry of adsorbents. The well-developed pore structure and low content of surface oxygen groups caused by $\mathrm{CO}_{2}$ activation are beneficial for nonpolar VOCs adsorption. The porosity of adsorbents could be controlled by optimizing the $\mathrm{CO}_{2}$ activation temperature and time. Excessive activation would lead to the overexpansion of micropores and reduce the amount of available pores, which is detrimental to the VOCs adsorption (Guo et al., 2016). 


\subsubsection{Stream activation}

Steam activation is widely used in the preparation of porous adsorbents due to its costeffective advantage. The activation mechanism of steam activation method is shown as equations (4-5), (4-6):

When the activating agent is $\mathrm{H}_{2} \mathrm{O}$,

$$
\mathrm{C}+\mathrm{H}_{2} \mathrm{O} \rightarrow \mathrm{CO}+\mathrm{H}_{2} \quad\left(\Delta \mathrm{H}=+117 \mathrm{~kJ} \mathrm{~mol}^{-1}\right)
$$

The inverse reaction of (4-5) occurs when the reaction temperature is above $800{ }^{\circ} \mathrm{C}$ in the practical reaction,

$$
\mathrm{C}+\mathrm{H}_{2} \mathrm{O} \leftrightarrow \mathrm{CO}+\mathrm{H}_{2} \quad(\mathrm{~T}>1073 \mathrm{~K})
$$

Lillo-Ródenas et al. (2010) obtained ACFs modified by stream activation. It was found that the surface area increased from 1026 to $1752 \mathrm{~m}^{2} \mathrm{~g}^{-1}$ as the increasing activation temperature and time (from 820 to $910{ }^{\circ} \mathrm{C}, 0.92$ to $1.5 \mathrm{~h}$ ), and the toluene adsorption capacity increased from 270 to $360 \mathrm{mg} \mathrm{g}^{-1}$. Similar phenomenon was observed by Romero-Anaya et al. (2010), indicating that both $\mathrm{CO}_{2}$ activation $\left(880{ }^{\circ} \mathrm{C}\right.$ for $\left.5-24 \mathrm{~h}\right)$ and steam activation $\left(840{ }^{\circ} \mathrm{C}\right.$ for $\left.0.75-6 \mathrm{~h}\right)$ improved the porosity of ACs with a constant structure. AC with the surface area of $1880 \mathrm{~m}^{2} \mathrm{~g}^{-1}$ and total pore volume of $0.77 \mathrm{~cm}^{3} \mathrm{~g}^{-1}$ were obtained by stream activation at $840{ }^{\circ} \mathrm{C}$ for $6 \mathrm{~h}$, which showed toluene adsorption capacity of $430 \mathrm{mg} \mathrm{g}^{-1}$. It indicates that the micropores were generated inside the adsorbent by $\mathrm{CO}_{2}$ activation, while those by stream activation were generated outside.

$\mathrm{CO}_{2}$ evolves at low temperatures as a result of the decomposition of the acidic groups such as carboxylic groups, anhydrides or lactones, whereas the evolution of $\mathrm{CO}$ is originated at higher temperatures by decomposition of basic, neutral or weakly acidic groups such as phenols, ethers and carbonyls (Lillo-Ródenas et al., 2010). Alcañiz-Monge et al. (2012) evaluated the evolution levels of $\mathrm{CO}$ and $\mathrm{CO}_{2}$ during temperature programmed desorption experiments on the ACFs modified by steam. Results indicated that more amount of surface oxygen groups developed after steam activation, and was positively affected by activation time. Similar phenomenon was observed by Guo et al. (2016), indicating that stream activation (flowing 30 vol.\% steam for $0.5 \mathrm{~h}$ ) can improve the amount of oxygen containing in surface groups, which attributes to the interaction between water molecules and the carbon matrix under thermal treatment.

Stream activation commonly at $700-950{ }^{\circ} \mathrm{C}, 0.5-6 \mathrm{~h}$ is an effective physical modification method for improving the porosity of adsorbents. The increasing oxygen contents introduced by steam activation make modified adsorbents favor the adsorption of polar VOCs vapors.

\subsection{Chemical modification}




\subsubsection{Acid treatment}

Acid treatment is a common and low-cost chemical modification method, involving the regents like phosphoric acid $\left(\mathrm{H}_{3} \mathrm{PO}_{4}\right)$, nitric acid $\left(\mathrm{HNO}_{3}\right)$, sulfuric acid $\left(\mathrm{H}_{2} \mathrm{SO}_{4}\right)$, hydrochloric acid $(\mathrm{HCl})$, etc. These acid reagents act as both dehydrating agents and oxidants during the carbonization and activation process (Hu et al., 2016). The frameworks of most raw materials can preserve after acid modification, while physical and chemical properties of adsorbents are obviously changed. The acid modification is mainly affected by impregnation ratio, activation temperature and time.

Sirimuangjinda et al. (2012) found that the surface area of $\mathrm{H}_{3} \mathrm{PO}_{4}$ treated $\mathrm{AC}$ with impregnation ratio of $1: 1,1: 2,1: 3$ at $600^{\circ} \mathrm{C}$ for 30 minutes in $\mathrm{N}_{2}$ atmosphere was $557.3,833.5,455.1 \mathrm{~m}^{2} / \mathrm{g}$, respectively. However the irregular pore structure obtained at the impregnation ratio of 1:3 due to the pore collapsing with the excessive modification. Similar phenomenon was observed by Kang et al. (2010), they found the optimum impregnation content was $0.25 \mathrm{M}$ impregnated $\mathrm{H}_{3} \mathrm{PO}_{4}$ for 1 h. The VOCs (toluene and isopropanol) removal efficiencies of $\mathrm{H}_{3} \mathrm{PO}_{4}$ treated AC were increased $2-3 \%$ of that of virgin AC. In particular, in the case of 5 or $10 \mathrm{wt} . \% \mathrm{H}_{2} \mathrm{SO}_{4}$ treated AC under stirring for $12 \mathrm{~h}$, its surface area and pore volume were decreased from 1067 to $840 \mathrm{~m}^{2} \mathrm{~g}^{-1}$ and 0.58 to 0.45 $\mathrm{cm}^{3} \mathrm{~g}^{-1}$, respectively. It may be resulted from the erosion of carbon skeletal structure by strong acid. The micropore surface area and micropore volume were slightly increased after $\mathrm{H}_{2} \mathrm{SO}_{4}$ treatment. It might be in the reason of evolved gas from the oxidation reaction between the acid and materials on carbon surface, which reopened the closed holes and generating new micropores (Pak et al., 2016). For the activation temperature, Ramos et al. (2010) reported that the increasing acid activation temperature from 864 to $963{ }^{\circ} \mathrm{C}$ ( $10 \mathrm{wt} \%$ concentration, overnight) reduced the AC yield owing to the significant release of volatile compounds. The surface area and micropore volume were increased from 1229 to $1705 \mathrm{~m}^{2} \mathrm{~g}^{-1}, 0.48$ to $0.64 \mathrm{~cm}^{3} \mathrm{~g}^{-1}$, respectively, and the adsorption capacity was increased from 322.5 to $506.8 \mathrm{mg} \mathrm{g}^{-1}$. Tu et al. (2015) demonstrated that prolonged activation time from 1 to $6 \mathrm{~h}$ in the $3 \mathrm{M}$ citric acid-modified process had minimal effect on the textural properties of adsorbent.

The surface chemistry of modified adsorbent is also affected during the acid treatment process. Aguayo-Villarreal et al. (2017) demonstrated that the phosphate groups (3.25\%) were introduced by $\mathrm{H}_{3} \mathrm{PO}_{4}$ treated $\mathrm{AC}\left(800{ }^{\circ} \mathrm{C}, 1 \mathrm{M}\right.$ for $\left.4 \mathrm{~h}\right)$, which could interact with the hydroxyl group of 1butanol leading to improving adsorption capacity (237.3 $\mathrm{mg} \mathrm{g}^{-1}$ ) of 1-butanol. Yu et al. (2018) observed $\mathrm{HNO}_{3}$ modified $\mathrm{AC}\left(30 \mathrm{wt} . \%, 60^{\circ} \mathrm{C}\right.$ for $\left.2 \mathrm{~h}\right)$ containing large amount of carboxylic groups $\left(0.855 \mathrm{mmol} \mathrm{g}^{-1}\right)$ exhibited an excellent acetone adsorption capacity of $318.9 \mathrm{mg} \mathrm{g}^{-1}$. As shown in Fig.11, it might be attributed to the combination of the main active site with acetone. On the contrary, Li et al. (2011) found that uptake amount of hydrophobic o-xylene was reduced $21.6 \%$ 
after $\mathrm{H}_{2} \mathrm{SO}_{4}$ modification ( $9 \mathrm{M}, 70{ }^{\circ} \mathrm{C}$ for $2 \mathrm{~h}$ ). It might be due to introduced oxygen-containing groups (5.02\%) including carboxylic acids, lactones, and phenols. Most of them had acid characteristics, leading to an acidic surface, which favored adsorbing hydrophilic VOCs. In addition, Romero-Anaya et al. (2015) noted that the adsorption capacity of acid treated AC for low concentration of ethanol was depended on the amount of oxygen containing groups, while textural properties such as the porosity were the dominated factor at high concentration.

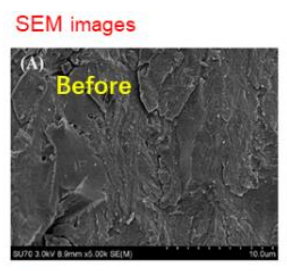

XPS spectra
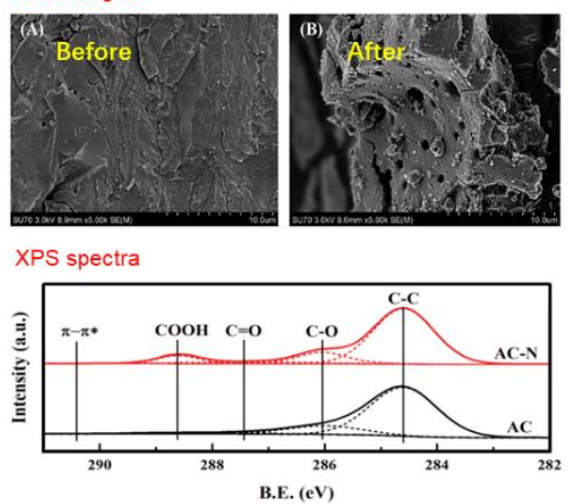

Adsorption mechanism $\mathrm{H}_{3} \mathrm{C}-\mathrm{C}-\mathrm{CH}_{3}$

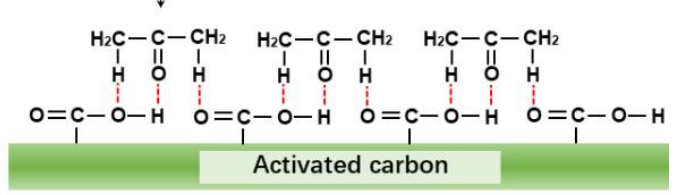

884

885

Fig. 11. Adsorption mechanism of interaction between acetone and carboxylic groups on AC (Yu et al., 2018).

Acid treatment enables to improve the development of pore structure and introduce plentiful oxygen-containing groups of adsorbents, which strengthen the particular interaction between acid adsorbent surface and hydrophilic VOCs. The adsorption selectivity and adsorption capacity of adsorbents for VOCs are enhanced by acid treatment. Impregnation ratio, activation temperature and time are the crucial factors that affect the efficiency of acid treatment, and it is significant to explore and choice the optimal activation conditions.

\subsubsection{Alkali treatment}

Alkali treatment is a well-known method to improve the development of microporosity for porous materials. The alkali activating agents commonly include potassium hydroxide, sodium hydroxide, potassium carbonate, etc. Gil et al. (2014) obtained ACs with narrow pore-size distribution by means of alkali treatment $\left(\mathrm{KOH}, \mathrm{NaOH}\right.$ and $\mathrm{K}_{2} \mathrm{CO}_{3}$ at $750{ }^{\circ} \mathrm{C}$ for $\left.1 \mathrm{~h}\right)$. The $\mathrm{KOH}$ activated AC with the surface area, total pore volume and micropore volume of $1599 \mathrm{~m}^{2} \mathrm{~g}^{-1}, 0.695$ $\mathrm{cm}^{3} \mathrm{~g}^{-1}$ and $0.521 \mathrm{~cm}^{3} \mathrm{~g}^{-1}$ exhibited the highest toluene adsorption capacity of $700 \mathrm{mg} \mathrm{g}^{-1}$. Similar phenomenon was observed by Silvestre-Albero et al. (2010), indicating that ACs with different 
$\mathrm{KOH} /$ carbon ratio from $1: 1$ to $4: 1\left(800{ }^{\circ} \mathrm{C}\right.$ for $\left.2 \mathrm{~h}\right)$ presented high textural development. The appropriate alkali treatment can achieve high specific surface area, and well-developed pore structure, while excessive activation degree may result in the destruction of pore structure due to the corrosive effect. Yu et al. (2015) proven that optimal $\mathrm{NaOH}$ etching time was $72 \mathrm{~h}$ at room temperature for the parent Dt/MFI-type zeolite composite with an increased mesoporosity and preserved macroporosity and microporosity (benzene adsorption capacity of $50.7 \mathrm{mg} \mathrm{g}^{-1}$ ). Further treatment (calcined at $550{ }^{\circ} \mathrm{C}$ in air for $6 \mathrm{~h}$ ) broadened the mesopore size distribution, whereas the macropores sourced from the diatomite support were significantly damaged and a fraction of the micropores was narrowed to approximately $0.49 \mathrm{~nm}$.

A facile synthesis of porous carbons from silica-rich biochar via a ball-milling assisted KOH activation (at $750^{\circ} \mathrm{C}$ for $1 \mathrm{~h}$ ) for toluene adsorption was reported by Shen et al. (2019). The resultant porous carbon with large surface area $\left(1818 \mathrm{~m}^{2} \mathrm{~g}^{-1}\right)$ exhibited an ultra-long breakthrough time (2784 $\mathrm{min}$ ) and ultra-high adsorption capacity $\left(263.6 \mathrm{mg} \mathrm{g}^{-1}\right)$. They suggested that the alkali activation with a higher mass ratio of $\mathrm{KOH}$ contributed to the ash removal, which promoted the development of pores. The $\mathrm{KOH}$ activation of silica-rich biochar proceeded via the following reactions (4-7-411). $\mathrm{SiO}_{2}$ in the biochar could react with $\mathrm{KOH} / \mathrm{K}_{2} \mathrm{CO}_{3}$ to form $\mathrm{K}_{2} \mathrm{SiO}_{3}$ (4-12 and 4-13), which was subsequently stripped by the washing process (Shen et al., 2019a; 2019b; Kim et al., 2018; Zhang et al., 2019). The redox process between alkali agents and porous materials at high temperature might decrease the $\mathrm{O} / \mathrm{C}$ ratio, which could affect the surface chemistry of adsorbents. Alkali-treated adsorbents have superior potential for nonpolar VOCs adsorption, rather than polar VOCs (Zhang et al.; 2019; Kim et al., 2018). It has been confirmed by a mass of investigations that alkali-treated adsorbents showed higher adsorption capacity of benzene, toluene, o-xylene and methane, while an opposite behavior in the adsorption of ethanol, acetone.

$$
\begin{array}{lc}
6 \mathrm{KOH}+2 \mathrm{C} \rightarrow 2 \mathrm{~K}+3 \mathrm{H}_{2}+2 \mathrm{~K}_{2} \mathrm{CO}_{3} & 4-7 \\
\mathrm{~K}_{2} \mathrm{CO}_{3} \rightarrow \mathrm{K}_{2} \mathrm{O}+\mathrm{CO}_{2} & 4-8 \\
\mathrm{~K}_{2} \mathrm{CO}_{3}+2 \mathrm{C} \rightarrow 2 \mathrm{~K}\left(\text { or } \mathrm{K}_{2} \mathrm{O}\right)+3 \mathrm{CO} & 4-9 \\
2 \mathrm{~K}+\mathrm{CO}_{2} \rightarrow \mathrm{K}_{2} \mathrm{O}+\mathrm{CO} & 4-10 \\
\mathrm{~K} & \mathrm{O}+\mathrm{C} \rightarrow 2 \mathrm{~K}+\mathrm{CO}
\end{array}
$$

Alkali treatment can react with $\mathrm{C}$ and $\mathrm{SiO}_{2}$ and broaden the pore structure of adsorbents, which improve the development of textural properties. Besides, the removal of the oxygen-containing 
groups during the redox process enhances the adsorption capacity of alkali-treated adsorbents for nonpolar VOCs. The adsorption performance of alkali treated adsorbents are influenced by the impregnation ratio, temperature and time, while excessive activation often backfires. The coactivation of $\mathrm{HCl}$ and $\mathrm{NaOH}$ was proved by Zhang et al. (2012) to be a potential method to fabricate zeolites from coal fly ash. The comprehensively modified adsorbent exhibited superior benzene adsorption capacity of $151 \mathrm{mg} \mathrm{g}^{-1}$. Zhou et al. (2014) also synthesized zeolite materials by acid solution $(\mathrm{HCl})$ and mixed alkali solution $\left(\mathrm{NaOH}\right.$ and $\mathrm{KOH}$ ) pretreatment (at $80^{\circ} \mathrm{C}$ for $2 \mathrm{~h}$ ) from

\subsubsection{Nitrogen doping}

Nitrogen doping by ammonia treatment is a simple and efficient method for tailoring the textural properties and surface chemistry of porous materials. Some defects and increasing surface roughness can be observed in the magnification images, and numerous holes on the wall of fingerlike pores are generated. Mohammed et al. (2015) obtained ammonia treated AC $\left(6.6 \mathrm{M} \mathrm{NH}_{3} \cdot \mathrm{H}_{2} \mathrm{O}\right.$, $70{ }^{\circ} \mathrm{C}$ for $2 \mathrm{~h}$ ) with the lower BET surface area and pore volume $\left(361.8 \mathrm{~m}^{2} \mathrm{~g}^{-1}\right.$ and $\left.0.16 \mathrm{~cm}^{3} \mathrm{~g}^{-1}\right)$ compare to bare-AC $\left(478 \mathrm{~m}^{2} \mathrm{~g}^{-1}\right.$ and $\left.0.61 \mathrm{~cm}^{3} \mathrm{~g}^{-1}\right)$, but it showed higher adsorption capacity on benzene (63 $\mathrm{mg} \mathrm{g}^{-1}$ ). Similarly, Kim et al. (2018) found that MIL-101- $\mathrm{NH}_{2}$ exhibited high adsorption capacity on benzene, toluene, p-Xylene, acetone and isopropanol (317, 293, 301, 355 and $\left.321 \mathrm{mg} \mathrm{g}^{-1}\right)$. The BET surface areas and pore volumes of MIL-101- $\mathrm{NH}_{2}$ were significantly decreased from 3028 to $2070 \mathrm{~m}^{2} \mathrm{~g}^{-1}, 1.84$ to $1.28 \mathrm{~cm}^{3} \mathrm{~g}^{-1}$, respectively, due to the inclusion of the $\mathrm{NH}_{2}$ group in the structure.

Guo et al. (2014) observed that Boehm titration results showed that ammonia treated AC (30 $\mathrm{wt} \% \mathrm{NH}_{3} \cdot \mathrm{H}_{2} \mathrm{O}$ for $12 \mathrm{~h}$ at $\left.20{ }^{\circ} \mathrm{C}\right)$ had much more basic groups $\left(2.2 \mathrm{mmol} \mathrm{g}^{-1}\right)$ than acidic groups, phenolic and carboxylic $\left(0.2,0.1,0.2 \mathrm{mmol} \mathrm{g}^{-1}\right.$, respectively). It was consistent with the results of Mohammed et al. (2015), where ammonia treated AC was rich in basic surface functional group which showed high removal efficiency (91 and 92.3\%) of benzene and toluene. Li et al. (2011) pointed that ammonia treatment enhanced the basic properties of the AC, which was translated into the increase in the removal efficiency of nonpolar o-xylene by $26.5 \%$.

\section{The improved adsorption performance of nitrogen doped adsorbents for nonpolar VOCs can} be obtained because of the removal of polar functional groups. However, significant decrease on available surface area and pore volume are inevitable after nitrogen doping, which is due to the blockage or enlargement of pores. 


\subsubsection{Metal/metal oxide doping}

Metal/metal oxide doping is used to enhance the selective adsorption of porous adsorbents by the interaction between the metal and some specific VOCs molecular. The principle is that porous adsorbents firstly physically adsorb high valence of metal compounds, and then high valence of metal compounds are reduced by the surface active groups of porous adsorbents. The strong affinity between low valence of reduction products and some VOCs molecules can enhance the adsorption selectivity of porous adsorbents. In general, metal/metal oxide doping changes the surface chemistry along with the surface polarity of porous adsorbent, so that the predominant adsorption mechanism is transformed from physical adsorption to chemical adsorption (Aguayo-Villarreal et al., 2017). Doping with metal species like metal salts $\left(\mathrm{CaCl}_{2}, \mathrm{ZnCl}_{2}, \mathrm{FeCl}_{3}, \mathrm{Cu}\left(\mathrm{NO}_{3}\right)_{2}\right)$, metal oxides $\left(\mathrm{Fe}_{2} \mathrm{O}_{3}, \mathrm{MgO}, \mathrm{CuO}\right)$ is commonly used for metal-loading method. Up to now, metal/metal oxide modified technology has been widely applied for VOCs adsorption, and some progress are obtained.

Peng et al. (2018) synthesized $\mathrm{Cu}$-doped mesoporous silica $\left(\mathrm{Cu}\left(\mathrm{NO}_{3}\right)_{2}\right.$, at room temperature for $20 \mathrm{~s}$ ) for removal of low-concentrated $\mathrm{CH}_{3} \mathrm{SH}$. In contrast to the ineffectivity of baremesoporous silica, Modified mesoporous silica with $3 \mathrm{wt} . \% \mathrm{Cu}$ showed much longer breakthrough time (118 $\mathrm{min}$ ) of $\mathrm{CH}_{3} \mathrm{SH}$ adsorption despite the surface area decreased from 678.77 to $567.13 \mathrm{~m}^{2}$ $\mathrm{g}^{-1}$. As shown in Fig.12, It was deduced that surface groups on $\mathrm{CuO}$ nanoparticles and the $\mathrm{Si}-\mathrm{O}-\mathrm{Cu}$ group were highly possibly transformed into a hydrated complex, which was much more effective in capturing $\mathrm{CH}_{3} \mathrm{SH}$ with its empty $\mathrm{Cu}-3 \mathrm{~d}$ orbit. Similar phenomenon was observed by Wang et al. (2018), indicating that $\mathrm{Cu}$-doped MOF (30 wt.\% $\mathrm{Cu}\left(\mathrm{NO}_{3}\right)_{2}$ ) showed the increasing adsorption capacity (from 103.4 to $114 \mathrm{mg} \mathrm{g}^{-1}$ ) on benzene due to providing more adsorption sites. Rengga et al. (2017) found that the surface area of $\mathrm{Ag}-\mathrm{AC}\left(0.1 \mathrm{M} \mathrm{AgNO}_{3}\right.$ stirred for $1 \mathrm{~h}$ under inert atmosphere) and AC were 685 and $783 \mathrm{~m}^{2} \mathrm{~g}^{-1}$, respectively. Formaldehyde tended to be adsorbed on $\mathrm{Ag}-\mathrm{AC}\left(119.3 \mathrm{mg} \mathrm{g}^{-1}\right)$ rather than $\mathrm{AC}\left(59.3 \mathrm{mg} \mathrm{g}^{-1}\right)$, but the potential adsorption mechanism was still confused. Aguayo-Villarreal et al. (2017) indicated that the adsorption of toluene was favored by the $\mathrm{Fe}_{2} \mathrm{O}_{3}\left(0.1 \mathrm{M} \mathrm{FeCl}{ }_{3}\right.$ calcined at $1000 \mathrm{~K}$ for $\left.4 \mathrm{~h}\right)$, which was associated with the possible interaction of hydrogens of methyl group in toluene molecule with the oxygen of $\mathrm{Fe}_{2} \mathrm{O}_{3}$. In addition, acetaldehyde chemisorption on $\mathrm{MgO}$ nanoparticles was investigated by Baur et al. (2015). It suggested that the interaction between carbonyl group of acetaldehyde and $\mathrm{Mg}^{2+}$ or $\mathrm{O}^{2-}$ ion improved chemical adsorption ability of $\mathrm{MgO}$-doped $\mathrm{AC}\left(5\right.$ wt. \% $\left.\mathrm{Mg}\left(\mathrm{NO}_{3}\right)_{2}\right)$. 


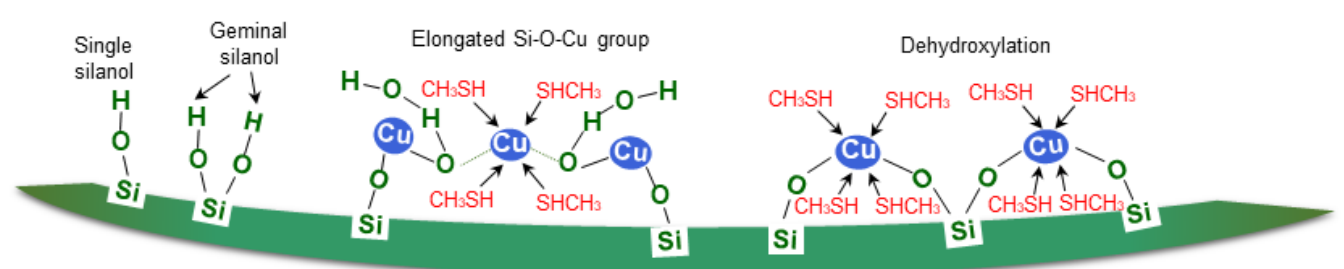

1003

1004

1005

1006

1007

1008

1009

1010

1011

1012

1013

1014

1015

1016

1017

1018

1019

1020

1021

1022

1023

1024

1025

1026

1027

1028

1029

1030

1031

1032

Fig. 12. Adsorption mechanism of $\mathrm{CH}_{3} \mathrm{SH}$ on $\mathrm{Cu}$-doped mesoporous silica (Peng et al., 2018).

Metal/metal oxide doping is mainly in the form of metal salt solution impregnation, which greatly enhances the selective chemical adsorption of specific VOCs. The deposition of metal nanoparticles leads to the blockage of the outer surface and openings of pore structures, while the available surface area and pore volume of modified adsorbents can be reduced. It seems that the metal/metal oxide doping is suitable for the uptake of VOCs with low concentration due to the limited reaction sites. The potential adsorption mechanism between the metal/metal oxide and specific VOCs molecule need to be further explored.

\subsubsection{Organic polymer coating}

The porous materials are expected to possess nature of water resistance under the humidity condition, whereas most raw materials fail to meet this demand (Liu et al., 2018). The hydrophilicity of ACs caused by oxygen-containing surface groups has detrimental influences on the VOCs separation in the humid environment. MOFs have the disadvantages of vulnerable structures and sensitivity to water, which limit their wide industrial application. The adsorption affinity between siliceous material (zeolites and clays) and VOCs in the humid conditions can be weakened due to the presence of hydrophilic silanol groups (Mu et al., 2018, Liu et al., 2018, Wang et al., 2016). The application of hydrophobic coating technologies for hydrophilic materials is in urgent demand. Hydrophobic coating using organic polymer materials with low surface energy, such as polydimethylsiloxane (PDMS), trimethylchlorosilane (TMCS), polyacrylonitrile (PAN), and polyfurfurylalcohol (PFA), have been widely explored to graft thin films onto adsorbent surface (Mu et al., 2018; Liu et al., 2016; Wang et al., 2014; Kim et al., 2012; Machowski et al., 2016).

It is reported that organic polymer coating changed both pore structure and surface chemistry of adsorbents. As shown in Fig. 13, Kim et al. (2012) observed the roll-up phenomenon in the breakthrough curve of toluene on bare-ACF under humid condition, where the breakthrough time was decreased from 412.5 (dry) to $339.7 \mathrm{~min}$ (humid). After coating PDMS (2 g, $100{ }^{\circ} \mathrm{C}$ ), 
PDMS/ACF with more hydrophobic surface retained $90 \%$ breakthrough time, and the roll-up 1034 phenomenon disappeared. Wang et al. (2016) developed hydrophobic functionalized SBA-15-

1035

1036

1037

1038

1039

1040

1041

1042

1043

1044

1045

1046

1047

1048

1049

1050

1051

1052

1053

1054
TMCS $\left(0.5 \mathrm{~g}, 70{ }^{\circ} \mathrm{C}\right.$ for $\left.24 \mathrm{~h}\right)$, which exhibited selective adsorption of $\mathrm{n}$-hexane $\left(690 \mathrm{mg} \mathrm{g}^{-1}\right)$ in the humid condition, and lower water vapor adsorption capacity $\left(65.5 \mathrm{mg} \mathrm{g}^{-1}\right)$ comparing to commercial SG and AC. Liu et al. (2016) observed dramatically improved humidity resistance after coating PDMS (The mass ratio of PDMS and $\mathrm{AC}=100: 1$, at $150,250^{\circ} \mathrm{C}$ for $1 \mathrm{~h}$ ). When the relative humidity increased from 0 to $90 \%$, the decrease on benzene adsorption capacities of bare-AC, PDMS/AC-150 and PDMS/AC-250 were 35.5\%, 14.3\%, 3.96\%, respectively. However, the surface area of AC decreased from 868 to $811 \mathrm{~m}^{2} \mathrm{~g}^{-1}$ after PDMS coating at $250^{\circ} \mathrm{C}$. Liu et al. (2018) also found the reduced surface area (from 886 to $744 \mathrm{~m}^{2} \mathrm{~g}^{-1}$ ) and pore volume (from 1.11 to 1.05 $\left.\mathrm{cm}^{3} \mathrm{~g}^{-1}\right)$ in term of silicon phenyl grafted mesoporous silica.

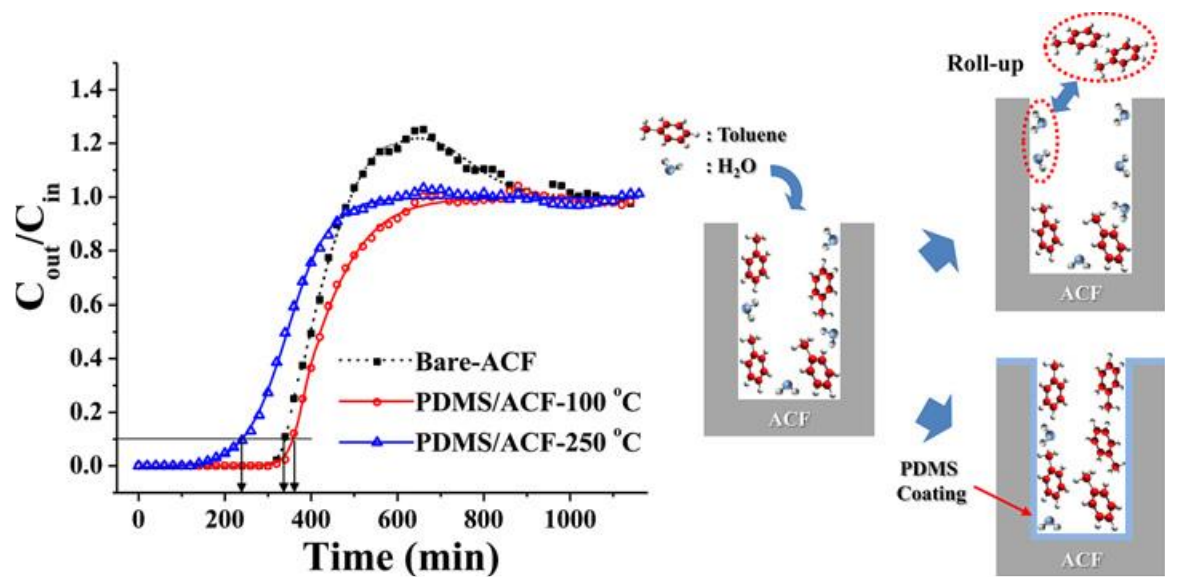

The leading role of hydrophobicity and total micropore volume in water adsorption depended on the relative humidity condition in the air stream $\left(\mathrm{P}_{\text {water }} / \mathrm{P}_{\text {air }}\right)$ (Fig. 14). Liu et al. (2016) illustrated that hydrophobicity was dominant in $\mathrm{P}_{\text {water }} / \mathrm{P}_{\text {air }}=0.1-0.6$, because the surface adsorption of selfaccumulating water clusters was determined by the amount of hydrophilic sites on the adsorbent surface. While under the condition of $\mathrm{P}_{\text {water }} / \mathrm{P}_{\text {air }}=0.7-1.0$, hydrophobicity and total micropore volume both played key role in the water vapor adsorption due to the adsorption mechanism of pore filling along with surface adsorption. 

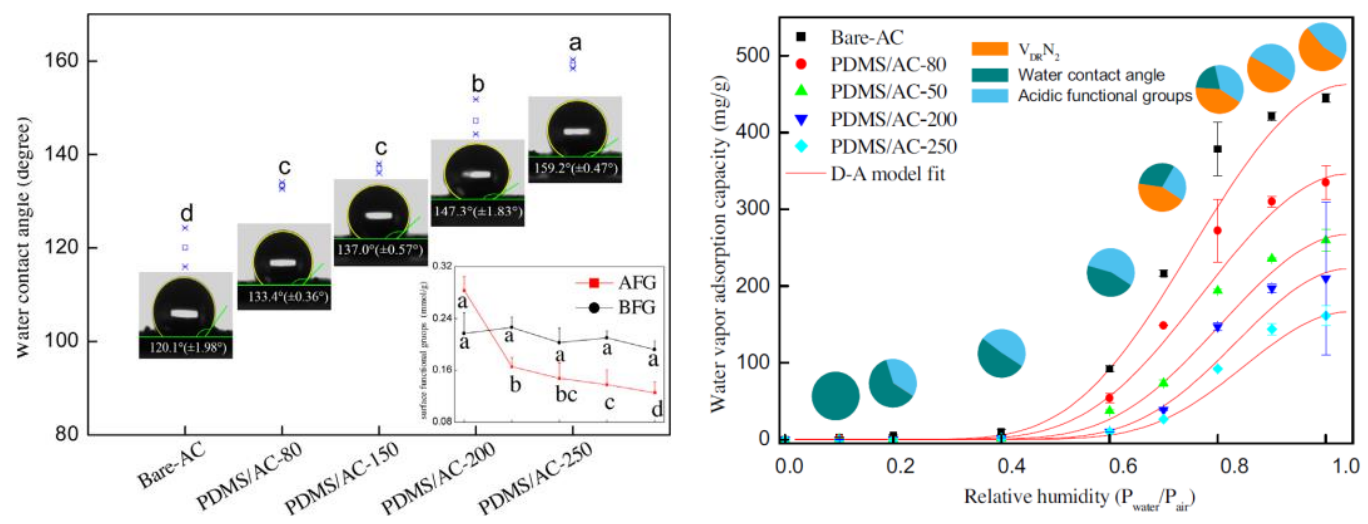

Fig. 14. Contributions of total micropore volume, water contact angle, and acidic functional groups to water vapor adsorption under different relative humidity (Liu et al., 2016).

The surface hydrophobicity and water resistance of porous materials can be improved by organic polymer coating. The organic polymer coated adsorbents are suitable for VOCs adsorption modification process are required to be overcome as well as the understanding of the interaction between organic polymer coated surface of adsorbents and VOCs.

\subsection{Other modification technologies}

The modification technology of ultraviolet irradiation is also applied for tailoring the physiochemical properties of porous materials. The wavelength of ultraviolet radiation is ranging from 100 to $400 \mathrm{~nm}$, the energy of which is stronger than that of visible light. The radiation effect is mild and facile to control. As a simple and economical advanced oxidation technology, ultraviolet radiation is able to introduce oxygen-containing functional groups into the surface of adsorbents, which have strong adsorption affinity with polar VOCs molecular. Li et al. (2016) obtained coconut shell based biochar modified by ultraviolet irradiation (UV light at a wavelength of $365 \mathrm{~nm}$ ), the surface area and micropore volume of which were increased from 448.6 to 639.6 $\mathrm{m}^{2} \mathrm{~g}^{-1}, 0.19$ to $0.28 \mathrm{~cm}^{3} \mathrm{~g}^{-1}$ compared to original biochar. The introduced acid functional groups

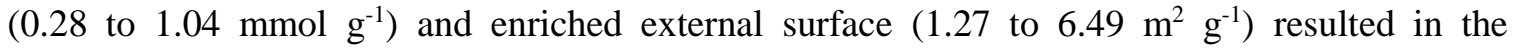
enhancement of toluene adsorption capacity $\left(231.33 \mathrm{mg} \mathrm{g}^{-1}\right)$ on modified biochar.

Combination of chemical and physical modification is used as an alternative to improve the adsorption performance of porous materials. Qiu et al. (2018) developed a pore-expanding technique through innovative modification by $\mathrm{CO}_{2} /$ microwave. Hierarchical pore structure was 
1082 formed and the phenolic hydroxyl and carboxyl groups on the surface of activated carbon were 1083 reduced after the combined modification. Kim et al. (2018) reported that KOH/microwave resulted 1084 in enlargement of graphene's specific surface area. The removal efficiency for toluene and 1085 acetaldehyde gas was up to $98 \%$ and $30 \%$, respectively. Other combined modification of chemical 1086 and physical methods like $\mathrm{CO}_{2} / \mathrm{HNO}_{3}, \mathrm{H}_{2} \mathrm{PO}_{4} /$ microwave gives surprising performance on VOCs 1087 adsorption. This can be a potential modification method for improving the adsorption ability of the 1088 porous materials.

1089 To sum up, physical modification need to be implemented under high temperature, which is 1090 with high energy consumption and not cost-effective. The used corrosive or harmful chemical agent 1091 during chemical modification may cause the secondary environmental pollution. The development 1092 of green and high efficient chemical agent and simple modification method are the challenges of 1093 modification technology for further large-scale utilization. The combination of physical and 1094 chemical modification can integrate the advantages of both, which tend to generate porous 1095 adsorbents with hierarchical pore structure. Furthermore, the in-depth and thorough understanding 1096 of the mechanism is crucial for enhancing the adsorption selectivity of chemical modification 1097 technology. 
Table 3

Summary of physiochemical properties of adsorbents after chemical modification.

\begin{tabular}{|c|c|c|c|c|c|c|c|c|c|c|c|c|c|}
\hline \multirow[t]{2}{*}{ Raw materials } & \multirow[t]{2}{*}{ Chemical regents } & \multirow[t]{2}{*}{ Modification methods } & \multirow[t]{2}{*}{ Adsorbates } & \multirow[t]{2}{*}{ Polarity } & \multicolumn{2}{|c|}{ Specific surface area $\left(\mathrm{m}^{2} \cdot \mathrm{g}^{-1}\right)$} & \multicolumn{2}{|c|}{ Pore volume $\left(\mathrm{cm}^{3} / \mathrm{g}\right)$} & \multirow{2}{*}{ Surface chemistry } & \multicolumn{2}{|c|}{ Adsorption capacity $\left(\mathrm{mg}^{-1} \mathrm{~g}^{-1}\right)$} & \multirow{2}{*}{$\begin{array}{l}\text { Adsorption } \\
\text { conditions }\end{array}$} & \multirow[t]{2}{*}{ References } \\
\hline & & & & & Before & After & Before & After & & Before & After & & \\
\hline \multicolumn{14}{|l|}{ Acid treatment } \\
\hline Almond shell & $\mathrm{H}_{3} \mathrm{PO}_{4}$ & $\begin{array}{l}\text { T: } 467^{\circ} \mathrm{C} \\
\mathrm{IR}^{\mathrm{a}}: 1.17: 1 \\
\mathrm{t}: 45 \mathrm{~min}\end{array}$ & Toluene & Nonpolar & - & $\mathrm{S}_{\mathrm{BET}}: 1117$ & - & $\begin{array}{l}\mathrm{V}_{\mathrm{T}}: 0.724 \\
\mathrm{~V}_{\text {mes }}: 0.494 \\
\mathrm{~V}_{\text {mic }}: 0.181\end{array}$ & $\begin{array}{l}\text { Introduced } \\
\text { carboxylic, } \\
\text { phenolic ,carbonyl, } \\
\text { lactone }\end{array}$ & - & 230.2 & $\begin{array}{l}25^{\circ} \mathrm{C} \\
500 \mathrm{ppm}\end{array}$ & $\begin{array}{l}\text { (Marti'nez de Yuso et al., } \\
\text { 2013) }\end{array}$ \\
\hline Stellerite & $\mathrm{H}_{2} \mathrm{SO}_{4}$ & $\begin{array}{l}95^{\circ} \mathrm{C} \\
5: 1 \\
2 \mathrm{~h}\end{array}$ & 2-butoxyethanol & Polar & $\mathrm{S}_{\text {BET }}: 6.4$ & $S_{\mathrm{BET}}: 167.5$ & $\mathrm{~V}_{\mathrm{T}}: 0.021$ & $\mathrm{~V}_{\mathrm{T}}: 0.060$ & $\begin{array}{l}\text { Destroyed the } \\
\text { crystalline } \\
\text { framework }\end{array}$ & 5.9 & 81.1 & $\begin{array}{l}25^{\circ} \mathrm{C} \\
500 \mathrm{ppm}\end{array}$ & (Zhang et al., 2018) \\
\hline Palygorskite & $\mathrm{HCl}$ & $\begin{array}{l}40^{\circ} \mathrm{C} \\
100 \mathrm{ml} 5 \mathrm{M}: 5 \mathrm{~g} \\
4 \mathrm{~h}\end{array}$ & Toluene & Nonpolar & $\begin{array}{l}\mathrm{S}_{\mathrm{BET}}: 228 \\
\mathrm{~S}_{\text {mic }}: 48 \\
\mathrm{~S}_{\mathrm{ext}}: 180\end{array}$ & $\begin{array}{l}\mathrm{S}_{\text {ВET }}: 329 \\
\mathrm{~S}_{\text {mic }}: 101 \\
\mathrm{~S}_{\text {ext }}: 228\end{array}$ & $\begin{array}{l}\mathrm{V}_{\mathrm{T}}: 0.442 \\
\mathrm{~V}_{\text {mic }}: 0.012\end{array}$ & $\begin{array}{l}\mathrm{V}_{\mathrm{T}}: 0.554 \\
\mathrm{~V}_{\text {mic }}: 0.055\end{array}$ & $\begin{array}{l}\text { The leaching of } \\
\text { octahedral cations at } \\
\text { the edge of channels } \\
\text { is in an order of } \\
\mathrm{Mg}^{2+}>\mathrm{Fe}^{3+}>\mathrm{Al}^{3+}\end{array}$ & 44.6 & 90.4 & $\begin{array}{l}60^{\circ} \mathrm{C} \\
2000 \mathrm{ppm} \\
50 \mathrm{ml} \cdot \mathrm{min}^{-1}\end{array}$ & (Zhu et al., 2017) \\
\hline Sawdust & $\mathrm{H}_{3} \mathrm{PO}_{4}$ & $\begin{array}{l}800^{\circ} \mathrm{C} \\
0.1 \mathrm{M}: 30 \mathrm{~g} \\
4 \mathrm{~h}\end{array}$ & 1-Butanol & Polar & - & $\mathrm{S}_{\mathrm{BET}}: 654$ & - & $\begin{array}{l}\mathrm{V}_{\mathrm{T}}: 0.261 \\
\mathrm{~V}_{\text {mes }}: 0.012 \\
\mathrm{~V}_{\text {mic: }}: 0.249\end{array}$ & $\begin{array}{l}\text { Increased phosphate } \\
\text { groups }\end{array}$ & 14.61 & 237.3 & $\begin{array}{l}25^{\circ} \mathrm{C} \\
150 \mathrm{ppm} \\
150 \mathrm{ml} \cdot \mathrm{min}^{-1}\end{array}$ & (Aguayo-Villarreal et al., 2017) \\
\hline Coconut shell & $\mathrm{HNO}_{3}$ & $\begin{array}{l}60^{\circ} \mathrm{C} \\
40 \mathrm{ml} 30 \mathrm{wt} \%: 5 \mathrm{~g} \\
2 \mathrm{~h}\end{array}$ & Acetone & Polar & $\mathrm{S}_{\mathrm{BET}}: 283$ & $\mathrm{~S}_{\mathrm{BET}}: 382$ & $\begin{array}{l}\mathrm{V}_{\mathrm{T}}: 0.157 \\
\mathrm{~V}_{\text {mic: }}: 0.113\end{array}$ & $\begin{array}{l}\mathrm{V}_{\text {T: }}: 0.228 \\
\mathrm{~V}_{\text {mic }}: 0.167\end{array}$ & $\begin{array}{l}\text { Increased carboxylic } \\
\text { groups }\end{array}$ & 196.9 & 318.9 & $\begin{array}{l}27^{\circ} \mathrm{C} \\
500 \mathrm{ppm} \\
250 \mathrm{ml} \cdot \mathrm{min}^{-1}\end{array}$ & (Yu et al., 2018) \\
\hline UiO-66 & $\mathrm{CH}_{3} \mathrm{COOH}$ & $\begin{array}{l}120^{\circ} \mathrm{C} \\
5 \mathrm{ml} \\
2 \mathrm{~h}\end{array}$ & $\begin{array}{l}\text { Dichloromethan } \\
\mathrm{e}\end{array}$ & Polar & $\begin{array}{l}\mathrm{S}_{\text {BET: }}: 980 \\
\mathrm{~S}_{\text {mic }}: 861\end{array}$ & $\begin{array}{l}\mathrm{S}_{\mathrm{BEt}}: 1447 \\
\mathrm{~S}_{\text {mic }}: 1400\end{array}$ & $\begin{array}{l}\mathrm{V}_{\mathrm{T}}: 0.59 \\
\mathrm{~V}_{\text {mic: }}: 0.33\end{array}$ & $\begin{array}{l}\mathrm{V}_{\mathrm{T}}: 0.61 \\
\mathrm{~V}_{\text {mic: }}: 0.54\end{array}$ & $\begin{array}{l}\text { Introduced } \\
\text { "missing-linker" } \\
\text { defects }\end{array}$ & 424.5 & 549.4 & $\begin{array}{l}25^{\circ} \mathrm{C} \\
44 \mathrm{kPa}\end{array}$ & (Zhou et al., 2017) \\
\hline $\mathrm{AC}$ & $\mathrm{H}_{2} \mathrm{SO}_{4}$ & $\begin{array}{l}105^{\circ} \mathrm{C} \\
10 \mathrm{wt} \% \\
12 \mathrm{~h}\end{array}$ & Benzene & Polar & $\begin{array}{l}\mathrm{S}_{\mathrm{BET}}: 1067 \\
\mathrm{~S}_{\text {mic }}: 280 \\
\mathrm{~S}_{\text {ext }}: 786\end{array}$ & $\begin{array}{l}\mathrm{S}_{\mathrm{BET}}: 840 \\
\mathrm{~S}_{\mathrm{mic}}: 336 \\
\mathrm{~S}_{\mathrm{ext}}: 503\end{array}$ & $\begin{array}{l}\mathrm{V}_{\mathrm{T}}: 0.58 \\
\mathrm{~V}_{\text {mic }}: 0.14\end{array}$ & $\begin{array}{l}\mathrm{V}_{\mathrm{T}}: 0.45 \\
\mathrm{~V}_{\text {mic: }}: 0.16\end{array}$ & $\begin{array}{l}\text { Increased oxygen- } \\
\text { containing groups }\end{array}$ & 45 & 66 & $\begin{array}{l}25^{\circ} \mathrm{C} \\
150 \mathrm{ppm} \\
0.3 \mathrm{~m} \cdot \mathrm{s}^{-1}\end{array}$ & (Pak et al., 2016) \\
\hline Coconut shell & $\mathrm{HNO}_{3}$ & $\begin{array}{l}70^{\circ} \mathrm{C} \\
10 \mathrm{M} \\
2 \mathrm{~h}\end{array}$ & O-xylene & Nonpolar & $\mathrm{S}_{\mathrm{BET}}: 731$ & $\mathrm{~S}_{\mathrm{BET}}: 528$ & $\mathrm{~V}_{\mathrm{T}}: 0.168$ & $\mathrm{~V}_{\mathrm{T}}: 0.170$ & $\begin{array}{l}\text { Increased oxygen- } \\
\text { containing groups }\end{array}$ & 214 & 187 & $\begin{array}{l}22-27^{\circ} \mathrm{C} \\
2176-2239 \mathrm{mg} \\
\mathrm{m}^{-3} \\
45 \mathrm{ml} \cdot \mathrm{min}^{-1} .\end{array}$ & (Li et al., 2011) \\
\hline Coconut shells & $\mathrm{H}_{3} \mathrm{PO}_{4}$ & $\begin{array}{l}300{ }^{\circ} \mathrm{C} \\
1 \mathrm{wt} \% . \\
2 \mathrm{~h}\end{array}$ & $\begin{array}{l}\text { Methyl ethyl } \\
\text { ketone }\end{array}$ & & $\mathrm{S}_{\mathrm{BET}}: 892$ & $\mathrm{~S}_{\mathrm{BET}}: 1109$ & $\begin{array}{l}\mathrm{V}_{\mathrm{T}}: 0.42 \\
\mathrm{~V}_{\text {mes: }}: 0.08 \\
\mathrm{~V}_{\text {mic: }}: 0.35\end{array}$ & $\begin{array}{l}\mathrm{V}_{\mathrm{T}}: 0.52 \\
\mathrm{~V}_{\text {mes: }}: 0.09 \\
\mathrm{~V}_{\text {mic: }}: 0.43\end{array}$ & - & - & 302.9 & $\begin{array}{l}25^{\circ} \mathrm{C} \\
1 \mathrm{~mol} \% \\
40 \mathrm{ml}^{-m_{n}-1}\end{array}$ & (Kim et al., 2010) \\
\hline \multicolumn{14}{|l|}{ Alkali treatment } \\
\hline Rice husk & $\mathrm{KOH}$ & $\begin{array}{l}750^{\circ} \mathrm{C} \\
3: 1 \\
1 \mathrm{~h}\end{array}$ & Toluene & Nonpolar & $\mathrm{S}_{\mathrm{BET}}: 132.86$ & $\mathrm{~S}_{\mathrm{BET}}: 1818.45$ & $\begin{array}{l}\mathrm{V}_{\mathrm{T}}: 0.07 \\
\mathrm{~V}_{\text {mes }}: 0.06 \\
\mathrm{~V}_{\text {mic }}: 0.01\end{array}$ & $\begin{array}{l}\mathrm{V}_{\mathrm{T}}: 0.9 \\
\mathrm{~V}_{\text {mes: }}: 0.84 \\
\mathrm{~V}_{\text {mic: }}: 0.11\end{array}$ & $\begin{array}{l}\mathrm{SiO}_{2} \text { removal } \\
\text { decreased organic } \\
\text { functional groups }\end{array}$ & 0.72 & 250.6 & $\begin{array}{l}20^{\circ} \mathrm{C} \\
60 \mathrm{ppm} \\
1.0 \mathrm{ml} \cdot \mathrm{min}^{-1}\end{array}$ & (Shen et al., 2019) \\
\hline Rice husk pellet & КОН & $\begin{array}{l}750^{\circ} \mathrm{C} \\
3: 1 \\
1 \mathrm{~h}\end{array}$ & Phenol & Polar & $\mathrm{S}_{\mathrm{BET}}: 172.92$ & $\mathrm{~S}_{\mathrm{BET}}: 1320.45$ & $\begin{array}{l}\mathrm{V}_{\mathrm{T}}: 0.08 \\
\mathrm{~V}_{\text {mes: }}: 0.01 \\
\mathrm{~V}_{\text {mic }}: 0.07\end{array}$ & $\begin{array}{l}\mathrm{V}_{\mathrm{T}}: 0.65 \\
\mathrm{~V}_{\text {mes: }}: 0.2 \\
\mathrm{~V}_{\text {mic: }}: 0.45\end{array}$ & $\begin{array}{l}\text { decrease ash content } \\
\text { and } \mathrm{SiO}_{2}\end{array}$ & 117.8 & 1918.9 & $\begin{array}{l}31 \mathrm{mg} \cdot \mathrm{m}^{-3} \\
300 \mathrm{ml} \cdot \mathrm{min}^{-1}\end{array}$ & (Shen et al., 2019) \\
\hline Resin & $\mathrm{KOH}$ & 4:1 & Benzene & Nonpolar & $\mathrm{S}_{\text {BET }}: 218$ & $\mathrm{~S}_{\mathrm{BET}}: 3870$ & $\begin{array}{l}\mathrm{V}_{\mathrm{T}}: 0.12 \\
\mathrm{~V}_{\text {mese }}: 0.04 \\
\mathrm{~V}_{\text {mic }}: 0.08\end{array}$ & $\begin{array}{l}\mathrm{V}_{\text {T: }}: 2.074 \\
\mathrm{~V}_{\text {mes: }}: 0.48 \\
\mathrm{~V}_{\text {mic }}: 1.59\end{array}$ & - & 7.81 & 1531 & $20{ }^{\circ} \mathrm{C}$ & (Choma et al., 2015) \\
\hline $\begin{array}{l}\text { Petroleum } \\
\text { residue }\end{array}$ & КОН & $\begin{array}{l}800^{\circ} \mathrm{C} \\
4: 1 \\
2 \mathrm{~h}\end{array}$ & Ethanol & Polar & $\mathrm{S}_{\mathrm{BET}}: 1580$ & $\mathrm{~S}_{\mathrm{BET}}: 2987$ & $\begin{array}{l}\mathrm{V}_{\mathrm{T}}: 0.66 \\
\mathrm{~V}_{\text {mes: }}: 0.04 \\
\mathrm{~V}_{\text {mic }}: 0.62\end{array}$ & $\begin{array}{l}\mathrm{V}_{\mathrm{T}}: 1.4 \\
\mathrm{~V}_{\text {mes: }}: 0.43 \\
\mathrm{~V}_{\text {mic }}: 0.97\end{array}$ & $\begin{array}{l}\text { Increased oxygen } \\
\text { groups( carbonyl, } \\
\text { quinone, etc.) }\end{array}$ & 127 & 176 & $\begin{array}{l}25^{\circ} \mathrm{C} \\
250 \mathrm{ppmv} \\
1000 \mathrm{ml} / \mathrm{min}\end{array}$ & (Silvestre-Albero et al., 2010) \\
\hline
\end{tabular}




\begin{tabular}{|c|c|c|c|c|c|c|c|c|c|c|c|c|c|}
\hline $\begin{array}{l}\text { Diatomite/MFI- } \\
\text { type zeolite }\end{array}$ & $\mathrm{NaOH}$ & $\begin{array}{l}60^{\circ} \mathrm{C} \\
10 \mathrm{ml}, 0.2 \mathrm{M} \\
1 \mathrm{~h}\end{array}$ & Benzene & Nonpolar & $\begin{array}{l}\mathrm{S}_{\mathrm{BET}}: 16.8 \\
\mathrm{~S}_{\text {mes: }}: 6.7 \\
\mathrm{~S}_{\text {mic }}: 8.7\end{array}$ & $\begin{array}{l}\mathrm{S}_{\mathrm{BET}}: 286.9 \\
\mathrm{~S}_{\text {mes }}: 37.1 \\
\mathrm{~S}_{\text {mic }}: 190.2\end{array}$ & $\begin{array}{l}\mathrm{V}_{\mathrm{T}}: 0.042 \\
\mathrm{~V}_{\text {mes: }}: 0.019 \\
\mathrm{~V}_{\text {mic }}: 0.004\end{array}$ & $\begin{array}{l}\mathrm{V}_{\mathrm{T}}: 0.255 \\
\mathrm{~V}_{\text {mes }}: 0.061 \\
\mathrm{~V}_{\text {mic }}: 0.077\end{array}$ & removal of $\mathrm{Si}$ & 11.1 & 62.5 & $25^{\circ} \mathrm{C}$ & (Yu et al., 2015) \\
\hline Peanut hull & $\mathrm{KOH}$ & $\begin{array}{l}600{ }^{\circ} \mathrm{C} \\
50 \% \\
1 \mathrm{~h}\end{array}$ & Cyclohexane & Nonpolar & $\mathrm{S}_{\mathrm{BET}}: 7$ & $\mathrm{~S}_{\mathrm{BET}}: 571$ & $\mathrm{~V}_{\mathrm{T}}: 0.01$ & $\mathrm{~V}_{\mathrm{T}}: 0.075$ & $\begin{array}{l}\text { Increased ash } \\
\text { content }\end{array}$ & 60 & 110 & $50 \mathrm{ml} \cdot \mathrm{min}^{-1}$ & (Zhang et al., 2019) \\
\hline \multicolumn{14}{|l|}{ N-doping } \\
\hline MIL-125 & $\mathrm{NH}_{3} \cdot \mathrm{H}_{2} 0$ & $\begin{array}{l}130^{\circ} \mathrm{C} \\
12 \mathrm{~h}\end{array}$ & Formaldehyde & Polar & $\mathrm{S}_{\mathrm{BET}}: 1530$ & $\mathrm{~S}_{\mathrm{BET}}: 1280$ & $\mathrm{~V}_{\mathrm{T}}: 0.67$ & $\mathrm{~V}_{\mathrm{T}}: 0.56$ & $\begin{array}{l}\text { Introduced amine } \\
\text { groups }\end{array}$ & 2.1 & 40.2 & $\begin{array}{l}20^{\circ} \mathrm{C} \\
60 \mathrm{ppm} \\
15 \mathrm{ml} \cdot \mathrm{min}^{-1}\end{array}$ & (Kim et al., 2018) \\
\hline $\begin{array}{l}\text { Mesoporous } \\
\text { silica } \\
\text { nanoparticles }\end{array}$ & $\mathrm{NH}_{3} \cdot \mathrm{H}_{2} \mathrm{O}$ & $5.0 \mathrm{~mL}, 26-28 \%$ & Aldehyde & Polar & $\mathrm{S}_{\mathrm{BET}}: 1078.4$ & $\mathrm{~S}_{\mathrm{BET}}: 910.7$ & $\mathrm{~V}_{\mathrm{T}}: 1.45$ & $\mathrm{~V}_{\mathrm{T}}: 0.89$ & $\begin{array}{l}\text { well functionalized } \\
\text { amino groups }\end{array}$ & 9.72 & 62.92 & $\begin{array}{l}\text { room temperature } \\
30 \mathrm{ppm} \\
50 \mathrm{ml} \cdot \mathrm{min}^{-1}\end{array}$ & (Peng et al., 2018) \\
\hline Commercial AC & $\mathrm{NH}_{3} \cdot \mathrm{H}_{2} \mathrm{O}$ & $\begin{array}{l}20^{\circ} \mathrm{C} \\
30 \mathrm{wt} . \% \\
12 \mathrm{~h}\end{array}$ & Chlorobenzene & Polar & $\mathrm{S}_{\text {BET }}: 783$ & $\mathrm{~S}_{\mathrm{BET}}: 657.3$ & - & $\mathrm{V}_{\text {mic }}: 0.2858$ & $\begin{array}{l}\text { nitrogen } \\
\text { doping(pyridinic-N, } \\
\text { pyrrolic-N) }\end{array}$ & - & 105.6 & $\begin{array}{l}20^{\circ} \mathrm{C} \\
250 \pm 10 \mathrm{ppm} \\
300 \mathrm{ml} \cdot \mathrm{min}^{-1}\end{array}$ & (Qi et al., 2017) \\
\hline Carbon spheres & $\mathrm{NH}_{4} \mathrm{OH}$ & $\begin{array}{l}70^{\circ} \mathrm{C} \\
0.5 \mathrm{ml}, 25-28 \% \\
10 \mathrm{~min}\end{array}$ & Benzene & Nonpolar & $\begin{array}{l}\mathrm{S}_{\text {BET }}: 1210 \\
\mathrm{~S}_{\text {mes: }}: 557 \\
\mathrm{~S}_{\text {mic }}: 653\end{array}$ & $\begin{array}{l}\mathrm{S}_{\text {BEt }}: 1082 \\
\mathrm{~S}_{\text {mes: }}: 479 \\
\mathrm{~S}_{\text {mic: }}: 603\end{array}$ & $\mathrm{~V}_{\mathrm{T}}: 1.29$ & $\mathrm{~V}_{\mathrm{T}}: 1.11$ & $\begin{array}{l}\text { introduction of } \\
\text { oxygen and nitrogen }\end{array}$ & 474 & 766 & $\begin{array}{l}25^{\circ} \mathrm{C} \\
500 \mathrm{ppm} \\
50 \mathrm{ml} \cdot \mathrm{min}^{-1}\end{array}$ & (Ma et al., 2018) \\
\hline Carbon spheres & carbon nitride & $\begin{array}{l}60^{\circ} \mathrm{C} \\
0.15 \mathrm{~g}, 1.5 \mathrm{wt} . \% \\
8 \mathrm{~h}\end{array}$ & Benzene & Nonpolar & $\begin{array}{l}\mathrm{S}_{\mathrm{BET}}: 1017 \\
\mathrm{~S}_{\text {mes: }}: 356 \\
\mathrm{~S}_{\text {mic }}: 661\end{array}$ & $\begin{array}{l}\mathrm{S}_{\text {BEт }}: 1083 \\
S_{\text {mes: }} 452 \\
S_{\text {mic: }}: 631\end{array}$ & $\begin{array}{l}\mathrm{V}_{\mathrm{T}}: 0.518 \\
\mathrm{~V}_{\text {mes }}: 0.212 \\
\mathrm{~V}_{\text {mic }}: 0.306\end{array}$ & $\begin{array}{l}\mathrm{V}_{\mathrm{T}}: 0.749 \\
\mathrm{~V}_{\text {mes }}: 0.446 \\
\mathrm{~V}_{\text {mic: }}: 0.303\end{array}$ & $\begin{array}{l}\text { Increased basic } \\
\text { groups } \\
\text { Decreased acid } \\
\text { groups }\end{array}$ & 701.0 & 750.5 & $\begin{array}{l}25^{\circ} \mathrm{C} \\
500 \mathrm{ppm} \\
50 \mathrm{ml} \cdot \mathrm{min}^{-1}\end{array}$ & (Qi et al., 2018) \\
\hline \multicolumn{14}{|c|}{ Metal/metal oxide doping } \\
\hline $\mathrm{AC}$ & $\mathrm{MgO}$ & $\begin{array}{l}550^{\circ} \mathrm{C} \\
\mathrm{N}_{2} 100 \mathrm{~mL} \cdot \mathrm{min}^{-1} \\
\mathrm{AC}-\mathrm{MgO}-10 \% \\
4 \mathrm{~h}\end{array}$ & Acetone & Polar & $\begin{array}{l}\mathrm{S}_{\mathrm{BET}}: 1464 \\
\mathrm{~S}_{\text {mess }}+\mathrm{S}_{\text {mar }}: 388 \\
\mathrm{~S}_{\text {mic }}: 1076\end{array}$ & $\begin{array}{l}\mathrm{S}_{\mathrm{BET}}: 1067 \\
\mathrm{~S}_{\text {mes }}+\mathrm{S}_{\text {mar }}: 309 \\
\mathrm{~S}_{\text {mic }}: 758\end{array}$ & $\begin{array}{l}\mathrm{V}_{\mathrm{T}}: 0.81 \\
\mathrm{~V}_{\text {mes }}+\mathrm{V}_{\text {mar }}: \\
0.23 \\
\mathrm{~V}_{\text {mic }}: 0.58\end{array}$ & $\begin{array}{l}\mathrm{V}_{\mathrm{T}}: 0.43 \\
\mathrm{~V}_{\text {mes }}+\mathrm{V}_{\text {mar: }}: \\
0.28 \\
\mathrm{~V}_{\text {mic: }}: 0.21\end{array}$ & $\begin{array}{l}\text { Introduced the } \mathrm{MgO} \\
\text { nanoparticles }\end{array}$ & 316.0 & 432.7 & $\begin{array}{l}25^{\circ} \mathrm{C} \\
85.21 \text { g.m.-3 }\end{array}$ & (Baur et al., 2015) \\
\hline $\begin{array}{l}\text { Mesoporous } \\
\text { silica }\end{array}$ & $\mathrm{Cu}$ & $\begin{array}{l}85^{\circ} \mathrm{C} \\
3 \mathrm{wt} . \% \mathrm{Cu} \\
3 \mathrm{~h}\end{array}$ & Mercaptans & Polar & $\mathrm{S}_{\mathrm{BET}}: 678.77$ & $\mathrm{~S}_{\mathrm{BET}}: 567.13$ & $\mathrm{~V}_{\mathrm{T}}: 0.636$ & $\mathrm{~V}_{\mathrm{T}}: 0.714$ & $\begin{array}{l}\text { Introduced } \mathrm{Si}-\mathrm{O}-\mathrm{Cu} \\
\text { groups }\end{array}$ & - & - & $\begin{array}{l}30^{\circ} \mathrm{C} \\
5 \mathrm{ppm} \\
50 \mathrm{ml} \cdot \mathrm{min}^{-1}\end{array}$ & (Peng et al., 2018) \\
\hline $\mathrm{ACF}$ & $\mathrm{Fe}_{3} \mathrm{O}_{4}$ & $\begin{array}{l}600^{\circ} \mathrm{C} \\
90 \mathrm{~min}\end{array}$ & Toluene & Nonpolar & $\mathrm{S}_{\mathrm{BET}}: 117$ & $\mathrm{~S}_{\mathrm{BET}}: 1466$ & $\begin{array}{l}\mathrm{V}_{\mathrm{T}}: 0.2 \\
\mathrm{~V}_{\text {mic: }}: 0.02\end{array}$ & $\begin{array}{l}\mathrm{V}_{\mathrm{T}}: 0.89 \\
\mathrm{~V}_{\text {mic: }}: 0.52\end{array}$ & $\begin{array}{l}\text { Introduced the } \\
\mathrm{Fe}_{3} \mathrm{O}_{4} \text { nanoparticles }\end{array}$ & - & 439 & - & (Song et al., 2017) \\
\hline MIL-101(Cr) & $\mathrm{Cu}$ & $0.732 \mathrm{~g}, 30 \mathrm{wt} . \%$ & Benzene & Nonpolar & $\mathrm{S}_{\mathrm{BET}}: 3367$ & $\mathrm{~S}_{\mathrm{BET}}: 2518$ & $\mathrm{~V}_{\mathrm{T}}: 2.35$ & $\mathrm{~V}_{\mathrm{T}}: 1.55$ & $\begin{array}{l}\text { Introduced the } \mathrm{Cu} \\
\text { nanoparticles }\end{array}$ & 103.4 & 114.4 & $\begin{array}{l}25^{\circ} \mathrm{C} \\
600 \mathrm{mg} \cdot \mathrm{m}^{-3}\end{array}$ & (Wang et al., 2018) \\
\hline \multicolumn{14}{|c|}{ Organic polymer coating } \\
\hline ACF & PDMS & $\begin{array}{l}100^{\circ} \mathrm{C} \\
2 \mathrm{~g} \text { PDMS, } 15 \mathrm{mg} \text { ACF }\end{array}$ & Toluene & Nonpolar & $\mathrm{S}_{\text {BET }}: 1662.0$ & $\mathrm{~S}_{\mathrm{BET}}: 1544.3$ & $\mathrm{~V}_{\text {т: }} 0.108$ & $\mathrm{~V}_{\text {T: }}: 0.102$ & $\begin{array}{l}\text { Introduced the } \\
\text { superhydrophobic } \\
\text { surface }\end{array}$ & 538.8 & 694.8 & $\begin{array}{l}30^{\circ} \mathrm{C} \\
86.5 \mathrm{ppm}\end{array}$ & (Kim et al., 2012) \\
\hline $\mathrm{AC}$ & PDMS & $250^{\circ} \mathrm{C}$ & Benzene & Nonpolar & $\mathrm{S}_{\mathrm{BET}}: 868$ & $\mathrm{~S}_{\mathrm{BET}}: 811$ & - & - & $\begin{array}{l}\text { Introduced the } \\
\text { superhydrophobic } \\
\text { surface }\end{array}$ & 166 & 320 & $\begin{array}{l}30{ }^{\circ} \mathrm{C} \\
50 \% \text { relative } \\
\text { humidity } \\
400 \mathrm{ml} \cdot \mathrm{min}^{-1}\end{array}$ & (Liu et al., 2016) \\
\hline
\end{tabular}




\begin{tabular}{|c|c|c|c|c|c|c|c|c|c|c|c|c|}
\hline SBA-15 & TMCS & $\begin{array}{l}70^{\circ} \mathrm{C} \\
1 \mathrm{~g} \cdot 100 \mathrm{ml}^{-1} \\
24 \mathrm{~h}\end{array}$ & N-hexane & Nonpolar & $\begin{array}{l}\mathrm{S}_{\mathrm{BET}}: 713 \\
\mathrm{~S}_{\mathrm{mic}}: 162\end{array}$ & $\begin{array}{l}\mathrm{S}_{\mathrm{BET}}: 602 \\
\mathrm{~S}_{\mathrm{mic}}: 85\end{array}$ & $\begin{array}{l}\mathrm{V}_{\mathrm{T}}: 0.98 \\
\mathrm{~V}_{\text {mic: }}: 0.07\end{array}$ & $\begin{array}{l}\mathrm{V}_{\mathrm{T}}: 0.88 \\
\mathrm{~V}_{\text {mic: }}: 0.03\end{array}$ & $\begin{array}{l}\text { Introduced methyl } \\
\text { groups on the } \\
\text { surface }\end{array}$ & 690 & $\begin{array}{l}0.1 \quad 1 . \mathrm{min}^{-1} \\
0.45 \mathrm{~g}^{-1} \mathrm{l}^{-1}\end{array}$ & (Wang et al., 2016) \\
\hline
\end{tabular}




\section{Challenges and the wayforward}

The VOCs adsorption performance of various porous materials was overviewed in this work, involving the interaction mechanism and the modification methods. MOF-based composites in particularly coating the inexpensive microporous materials (biochars, clays or zeolites) would be the potential alternative to conventional single absents (ACs or zeolites). The VOCs adsorption is dominated by textural properties and surface chemistry of porous adsorbents. Large specific surface area and high pore volume (in particular micropore volume) play a positive effect on physical adsorption. The chemical adsorption is associated with the surface functional groups of adsorbents as well as the polarity, boiling point, molecular size and weight of adsorbates. The relationship between the textural characteristics, chemical functional groups and VOC adsorption capacity is rarely to be quantitatively estimated. Besides, a balance between these factors needs to be taken into account to improve high adsorption capacity in some cases. The physical modification using $\mathrm{CO}_{2}$ or stream enable to develop new micropores and regulate the pore structure of adsorbents. The chemical modification including acid treatment, alkali treatment, nitrogen doping, metal doping and organic polymer coating are supposed to alter the surface chemistry of adsorbents by introducing functional groups. The organic polymer coated adsorbents exhibit outstanding hydrophobic property under the humid conditions.

With regard to the above progress, the limitations and challenges in this area are carefully addressed as follows: 1) Low-cost and good-stability adsorbents as MOF-C composites can be developed ,2) New modification method to enhance VOCs adsorption capacity and selectivity, 3) The hydrophobic property of porous materials can be substantially improved under high humility condition, 4) How to establish the acceptable evaluation system of VOCs adsorption on porous materials, 5) The correct disposal of the used adsorbents and avoidance of their secondary pollution to the environment and human health; 6) Environmental evaluation of the VOCs adsorption process by means of life cycle assessment (LCA).

Nomenclature

\begin{tabular}{llll}
\hline US EPA & US Environmental Protection Agency & CVD & Hemical vapor deposition \\
VOCs & Volatile organic compounds & MOF & Metal organic framework \\
VVOCs & Very volatile organic compounds & SG & Silica gel \\
SVOCs & Semivolatile organic compounds & TMCS & Trimethylchlorosilane \\
POMs & Particulate organic matters & HCP & Hypercrosslinked polymer \\
SOAs & Secondary organic aerosols & Dt & Diatomite \\
OVOCs & Oxygenated volatile organic compounds & FA & Fly ash
\end{tabular}




\begin{tabular}{|llll|}
\hline SNAs & Secondary nitric aerosols & PDMS & Polydimethylsiloxane \\
AC & Activated carbon & IR & Impregnation ratio \\
ACF & Activated carbon fiber & $\mathrm{S}_{\mathrm{BET}}$ & Brunauer-Emmett-Teller surface area \\
GO & Graphene oxide & $\mathrm{S}_{\text {mic }}$ & Micropore surface area \\
rGO & Reduced graphene oxide & $\mathrm{S}_{\mathrm{ext}}$ & Non-micropore (meso- and macropore) \\
& & & surface area \\
MGO & Magnetic graphene oxide & $\mathrm{V}_{\mathrm{T}}$ & Total pore volume \\
CNT & Carbon nanotube & $\mathrm{V}_{\text {mic }}$ & Micropore volume \\
SWCNT & Single-walled carbon nanotube & $\mathrm{V}_{\text {mes }}$ & Mesopore volume \\
MWCNT & Multi-walled carbon nanotube & LCA & Life cycle assessment \\
\hline
\end{tabular}

1124

\section{Conflicts of interest}

The authors declare no competing financial interest.

\section{Acknowledgement}

The authors gratefully acknowledge the support of National Natural Science Foundation grant (51676047 and 51861145102).

\section{References}

Wang, S., Ang, H.M., Tade, M.O., 2007. Volatile organic compounds in indoor environment and photocatalytic oxidation: State of the art. Environ.Int. 33, 694-705.

Hunter, P. H., 2000. Control of Volatile Organic Compound (VOC) Air Pollutants.

Zavyalova, U., Nigrovski, B., Pollok, K., Langenhorst, F., Müller, B., Scholz P., Ondruschka B., 2008. Gel-combustion synthesis of nanocrystalline spinel catalysts for vocs elimination, Applied. Catalysis. B: Environmental. 83, 221-228.

Li, L., Sun, Z., Li, H., Keener, T.C., 2012. Effects of activated carbon surface properties on the adsorption of volatile organic compounds. Journal of the Air \& Waste Management Association. 62, 1196-1202.

Wang, Y., Tao, H., Yu, D., Chang, C., 2018. Performance assessment of ordered porous electrospun honeycomb fibers for the removal of atmospheric polar volatile organic compounds. Nanomaterials (Basel), 8.

Meng, F.Y., Song, M., Wei, Y., Wang, Y., 2019. The contribution of oxygen-containing functional groups to the gas-phase adsorption of volatile organic compounds with different polarities onto lignin-derived activated carbon fibers. Environ Sci Pollut Res Int. 26, 7195-7204. 
Guenther, A., Hewitt, C.N., Erickson, D., 1995. A global model of natural volatile organic compound emissions. Journal of Geophysical Research Atmospheres. 100 (D5), 8873-8892.

Wei, W., Wang, S., Hao, J., Cheng, S., 2011. Projection of anthropogenic volatile organic compounds (VOCs) emissions in china for the period 2010-2020. Atmos Environ. 45, 6863-6871.

He, C., Cheng, J., Zhang, X., Douthwaite, M., Pattisson, S., Hao, Z., 2019, Recent advances in the catalytic oxidation of volatile organic compounds: A review based on pollutant sorts and sources. Chem Rev. 119, 4471-4568.

Yang, C., Miao, G., Pi, Y., Xia, Q., Wu, J., Li, Z., Xiao, J., 2019. Abatement of various types of VOCs by adsorption/catalytic oxidation: A review. Chem Eng J. 370, 1128-1153.

Baltrenas, P., Baltrenaite, E., Sereviciene, V., Pereira, P., 2011. Atmospheric BTEX concentrations in the vicinity of the crude oil refinery of the baltic region. Environ Monit Assess. 182, 115-127.

Yan, Y., Peng, L., Li, R., Li, Y., Li, L., Bai, H., 2017. Concentration, ozone formation potential and source analysis of volatile organic compounds (VOCs) in a thermal power station centralized area: A study in Shuozhou, China. Environ Pollut. 223, 295-304.

Papaefthimiou, P., Ioannides, T., Verykios, X.E., 1997. Combustion of Non-Halogenated Volatile Organic Compounds Over Group VIII Metal Catalysts. Applied Catalysis B Environmental. 13(34), 175-184.

Weber, R.J., Sullivan, A.P., Peltier, R.E., Russell, A., Yan, B., Zheng, M., de Gouw, J., Warneke, C., Brock, C., Holloway, J.S., Atlas, E.L., Edgerton, E., 2007. A study of secondary organic aerosol formation in the anthropogenic-influenced southeastern united states. Journal of Geophysical Research: Atmospheres, 112, n/a-n/a.

Castro-Hurtado, I., Mandayo, G.G., Castaño, E., 2013. Conductometric formaldehyde gas sensors. A review: From conventional films to nanostructured materials. Thin Solid Films. 548, 665-676.

Main, D.M., Hogan, T.J., 1983. Health Effects of Low-Level Exposure to Formaldehyde. Journal of Occupational and Environmental Medicine. 25(12), 896-900.

Kolade, M.A., Kogelbauer, A., Alpay, E., 2009. Adsorptive reactor technology for VOC abatement. Chem. Eng. Sci. 64, 1167-1177.

Alejandro-Martín, S., Valdés, H., Manero, M.H., Zaror, C., 2018. Catalytic ozonation of toluene using chilean natural zeolite: The key role of brønsted and lewis acid sites. Catalysts. 8, 5.

Kim, J., Lee, B.K., 2018. Enhanced photocatalytic decomposition of VOCs by visible-driven photocatalyst combined $\mathrm{Cu}-\mathrm{TiO}_{2}$ and activated carbon fiber. Process Safety and Environmental Protection. 119, 164-171.

Jo, W.K., Yang, C.H., 2009. Granular-activated carbon adsorption followed by annular-type photocatalytic system for control of indoor aromatic compounds. Separation and Purification Technology. 66, 438-442. 
Mohamed, E.F., Awad, G., Andriantsiferana, C., El-Diwany, A.I., 2016. Biofiltration technology for the removal of toluene from polluted air using streptomyces griseus. Environ Technol. 37, 1197 1207.

Lu, Y., Liu, J., Lu, B., Jiang, A., Wan, C., 2010. Study on the removal of indoor VOCs using biotechnology. J Hazard Mater. 182, 204-209.

Sultana, S., Vandenbroucke, A., Leys, C., De, Geyter N., Morent, R., 2015. Abatement of VOCs with alternate adsorption and plasma-assisted regeneration: A review, Catalysts. 5, 718-746.

Luengas, A., Barona, A., Hort, C., Gallastegui, G., Platel, V., Elias, A., 2015. A review of indoor air treatment technologies. Reviews in Environmental Science and Bio/Technology. 14, 499-522.

Heymes, F., Manno-Demoustier, P., Charbit, F., Fanlo, J.L., Moulin, P., 2006. A new efficient absorption liquid to treat exhaust air loaded with toluene. Chem, Eng, J. 115, 225-231.

Shih, Y.H., Li, M.S., 2008. Adsorption of selected volatile organic vapors on multiwall carbon nanotubes. J Hazard Mater. 154, 21-28.

Belaissaoui, B., Le Moullec, Y., Favre, E., 2016. Energy efficiency of a hybrid membrane/condensation process for VOC (volatile organic compounds) recovery from air: A generic approach. Energy. 95, 291-302.

Zhen, H., Jang, S.M.J., Teo, W.K., Li, K., 2006. Modified silicone-pvdf composite hollow-fiber membrane preparation and its application in VOC separation. Journal of Applied Polymer Science, 99, 2497-2503.

Serna-Guerrero, R., Sayari, A., 2007. Applications of Pore-Expanded Mesoporous Silica. 7. Adsorption of Volatile Organic Compounds. Environmental Science and Technology. 41(13), 4761-4766.

Zhu, M., Hu, P., Tong, Z., Zhao, Z., Zhao, Z., 2017, Enhanced hydrophobic MIL(Cr) metal-organic framework with high capacity and selectivity for benzene VOCs capture from high humid air. Chemical Engineering Journal. 313, 1122-1131.

Long, C., Liu, P., Li, Y., Li, A., Zhang, Q., 2011. Characterization of hydrophobic hypercrosslinked polymer as an adsorbent for removal of chlorinated volatile organic compounds. Environ. Sci. Technol. 45, 4506-4512.

Zaitan, H., Bianchi, D., Achak, O., Chafik, T., 2008. A comparative study of the adsorption and desorption of o-xylene onto bentonite clay and alumina. J Hazard Mater. 153, 852-859.

González-García, P., 2018. Activated carbon from lignocellulosics precursors: A review of the synthesis methods, characterization techniques and applications. Renewable and Sustainable Energy Reviews. 82, 1393-1414.

Le-Minh, N., Sivret, E.C., Shammay, A., Stuetz, R.M., 2018. Factors affecting the adsorption of gaseous environmental odors by activated carbon: A critical review. Critical Reviews in Environmental Science and Technology. 48, 341-375. 
Le Cloirec, P., 2012. Adsorption onto activated carbon fiber cloth and electrothermal desorption of volatile organic compound (VOCs): A specific review. Chinese Journal of Chemical Engineering. 20, 461-468.

Zhang, X., Gao, B., Creamer, A.E., Cao, C., Li, Y., 2017. Adsorption of VOCs onto engineered carbon materials: A review. J. Hazard. Mater. 338, 102-123.

Zhao, X., Li, X., Zhu, T., Tang, X., 2018. Adsorption behavior of chloroform, carbon disulfide, and acetone on coconut shell-derived carbon: Experimental investigation, simulation, and model study. Environ. Sci. Pollut. Res. Int. 25, 31219-31229.

Romero-Anaya, A.J., Lillo-Ródenas, M.A., Linares-Solano, A., 2015. Factors governing the adsorption of ethanol on spherical activated carbons. Carbon. 83, 240-249.

Yang, X., Yi, H., Tang, X., Zhao, S., Yang, Z., Ma, Y., Feng, T., Cui, X., 2018. Behaviors and kinetics of toluene adsorption-desorption on activated carbons with varying pore structure. J. Environ. Sci (China). 67, 104-114.

Yu, X., Liu, S., Lin, G., Zhu, X., Zhang, S., Qu, R., Zheng, C., Gao, X., 2018. Insight into the significant roles of microstructures and functional groups on carbonaceous surfaces for acetone adsorption. RSC. Advances. 8, 21541-21550.

Zhou, K., Li, L., Ma, X., Mo, Y., Chen, R., Li, H., Li, H., 2018. Activated carbons modified by magnesium oxide as highly efficient sorbents for acetone. RSC Advances. 8, 2922-2932.

Amitay-Rosen, T., Leibman, A., Nir, I., et al., 2015. The Effects of Aging on the Dynamic Adsorption of Hazardous Organic Vapors on Impregnated Activated Carbon. Journal of Occupational and Environmental Hygiene. 12(2), 130-137.

Jahandar Lashaki, M., Atkinson, J.D., Hashisho, Z., Phillips, J.H., Anderson, J.E., Nichols, M., 2016. The role of beaded activated carbon's pore size distribution on heel formation during cyclic adsorption/desorption of organic vapors. J. Hazard. Mater. 315, 42-51.

Jafari, S., Ghorbani-Shahna, F., Bahrami, A., Kazemian, H., 2018. Adsorptive removal of toluene and carbon tetrachloride from gas phase using zeolitic imidazolate framework-8: Effects of synthesis method, particle size, and pretreatment of the adsorbent. Microporous and Mesoporous Materials. $268,58-68$

Wang, Y., Su, X., Xu, Z., Wen, K., Zhang, P., Zhu, J., He, H., 2016. Preparation of surfacefunctionalized porous clay heterostructures via carbonization of soft-template and their adsorption performance for toluene. Applied Surface Science. 363, 113-121.

Wang, H., Tang, M., Zhang, K., Cai, D., Huang, W., Chen, R., Yu, C., 2014. Functionalized hollow siliceous spheres for VOCs removal with high efficiency and stability. J. Hazard. Mater. 268, 115123.

Wang, S., Zhang, L., Long, C., Li, A., 2014. Enhanced adsorption and desorption of VOCs vapor on novel micro-mesoporous polymeric adsorbents. J Colloid Interface Sci. 428, 185-190. 
Aguayo-Villarreal, I.A., Montes-Morán, M.A., Hernández-Montoya, V., Bonilla-Petriciolet, A., Concheso, A., Rojas-Mayorga, C.K., González, J., 2017. Importance of iron oxides on the carbons surface vs the specific surface for VOC's adsorption. Ecological Engineering. 106, 400-408.

Abdul Manap, N.R., Shamsudin, R., Maghpor, M.N., Abdul Hamid, M.A., Jalar, A., 2018. Adsorption isotherm and kinetic study of gas-solid system of formaldehyde on oil palm mesocarp bio-char: Pyrolysis effect. Journal of Environmental Chemical Engineering. 6, 970-983.

Shen, Y., Zhang, N., 2019. Facile synthesis of porous carbons from silica-rich rice husk char for volatile organic compounds (VOCs) sorption. Bioresour. Technol. 282, 294-300.

Shen, Y., Zhang, N., Fu, Y., 2019. Synthesis of high-performance hierarchically porous carbons from rice husk for sorption of phenol in the gas phase. Journal of Environmental Management. 241, 5358.

Suzuki, R.M., Andrade, A.D., Sousa, J.C., Rollemberg, M.C., 2007. Preparation and characterization of activated carbon from rice bran. Bioresour. Technol. 98, 1985-1991.

Suliman, W., Harsh, J.B., Abu-Lail, N.I., Fortuna, A.M., Dallmeyer, I., Garcia-Perez, M., 2016. Influence of feedstock source and pyrolysis temperature on biochar bulk and surface properties. Biomass and Bioenergy. 84, 37-48.

Hsi, H.C., Horng, R.S., Pan, T.A., Lee, S.K., 2011. Preparation of activated carbons from raw and biotreated agricultural residues for removal of volatile organic compounds. Journal of the Air \& Waste Management Association. 61, 543-551.

Hu, L., Peng, Y., Wu, F., Peng, S., Li, J., Liu, Z., 2017. Tubular activated carbons made from cotton stalk for dynamic adsorption of airborne toluene. J. Taiwan. Inst. Chem. E. 80, 399-405.

Bedane, A.H., Guo, T.X., Eić, M., Xiao, H., 2018. Adsorption of volatile organic compounds on peanut shell activated carbon. The Canadian Journal of Chemical Engineering. 97, 238-246.

Khan, A., Szulejko, J.E., Samaddar, P., Kim, K.-H., Liu, B., Maitlo, H.A., Yang, X., Ok, Y.S., 2019. The potential of biochar as sorptive media for removal of hazardous benzene in air. Chemical Engineering Journal. 361, 1576-1585.

Tham, Y.J., Latif, P.A., Abdullah, A.M., Shamala-Devi, A., Taufiq-Yap, Y.H., 2011. Performances of toluene removal by activated carbon derived from durian shell. Bioresour. Technol. 102, 724-728.

Yue, Z., Vakili, A., Wang, J., 2017. Activated carbon fibers from meltblown isotropic pitch fiber webs for vapor phase adsorption of volatile organic compounds. Chemical Engineering Journal. 330, 183-190.

Baur, G.B., Yuranov, I., Kiwi-Minsker, L., 2015. Activated carbon fibers modified by metal oxide as effective structured adsorbents for acetaldehyde. Catal. Today. 249, 252-258.

Ge, J., Yoon S., Choi, N., 2018, Application of fly ash as an adsorbent for removal of air and water pollutants. Applied Sciences. 8.

Bai, Y., Huang, Z., Wang, M., et al. 2013. Adsorption of benzene and ethanol on activated carbon nanofibers prepared by electrospinning. Adsorption. 19(5), 1035-1043. 
Liu, Y., Mallouk, K., Emamipour, H., Rood, M.J., Liu, X., Yan, Z., 2019. Isobutane adsorption with carrier gas recirculation at different relative humidities using activated carbon fiber cloth and electrothermal regeneration. Chemical Engineering Journal. 360, 1011-1019.

Lin, C.-L., Cheng, Y.-H., Liu, Z.-S., Chen, J.-Y., 2012. Adsorption and oxidation of high concentration toluene with activated carbon fibers. Journal of Porous Materials. 20, 883-889.

Lillo-Ródenas, M.A., Cazorla-Amorós, D., Linares-Solano, A., 2005. Behaviour of activated carbons with different pore size distributions and surface oxygen groups for benzene and toluene adsorption at low concentrations. Carbon. 43, 1758-1767.

Lillo-Ródenas, M.A., Cazorla-Amorós, D., Linares-Solano, A., 2010. Benzene and toluene adsorption at low concentration on activated carbon fibres. Adsorption. 17, 473-481.

Yi, F.Y., Lin, X.D., Chen, S.X., Wei, X.Q., 2008. Adsorption of VOC on modified activated carbon fiber. J Porous Mat. 16, 521-526.

Song, M., Zhang, W., Chen, Y., Luo, J., Crittenden, J.C., 2017. The preparation and performance of lignin-based activated carbon fiber adsorbents for treating gaseous streams. Frontiers of Chemical Science and Engineering. 11, 328-337.

Xie, Z.Z., Wang, L., Cheng, G., Shi, L., Zhang, Y.B., 2016. Adsorption properties of regenerative materials for removal of low concentration of toluene. J. Air. Waste. Manag. Assoc. 66, 12241236.

Niknaddaf, S., Atkinson, J.D., Shariaty, P., Jahandar Lashaki, M., Hashisho, Z., Phillips, J.H., Anderson, J.E., Nichols, M., 2016. Heel formation during volatile organic compound desorption from activated carbon fiber cloth. Carbon. 96, 131-138.

Tahriri, M., Del Monico, M., Moghanian, A., Tavakkoli, Yaraki M., Torres, R., Yadegari, A., Tayebi, L., 2019. Graphene and its derivatives: Opportunities and challenges in dentistry. Mater. Sci. Eng. C. Mater. Biol. Appl. 102, 171-185.

Lu, J., Do, I., Drzal, L.T., 2008. Nanometal-Decorated Exfoliated Graphite Nanoplatelet Based Glucose Biosensors with High Sensitivity and Fast Response. Acs. Nano. 2(9), 1825-1832.

Allahbakhsh, A., Arjmand, M., 2019. Graphene-based phase change composites for energy harvesting and storage: State of the art and future prospects. Carbon. 148, 441-480.

Yu, L., Wang, L., Xu, W., Chen, L., Fu, M., Wu, J., Ye, D., 2018. Adsorption of VOCs on reduced graphene oxide. J. Environ. Sci (China). 67, 171-178.

Plutnar, J., Pumera, M., Sofer, Z., 2018. The chemistry of cvd graphene, Journal of Materials Chemistry C. 6, 6082-6101.

Shin, H.J., Kim, K.K., Benayad, A., Yoon, S.M., Park, H.K., Jung, I.S., Jin, M.H., Jeong, H.K., Kim, J.M., Choi, J.Y., Lee, Y.H., 2009. Efficient reduction of graphite oxide by sodium borohydride and its effect on electrical conductance. Adv. Funct. Mater. 19, 1987-1992.

Sun, X., Xia, Q., Zhao, Z., et al., 2014. Synthesis and adsorption performance of MIL-101(Cr)/graphite oxide composites with high capacities of n-hexane. Chemical Engineering Journal. 239, 226-232. 
Lakshmi, P., Lingamdinne, et al. 2018. A comprehensive review of applications of magnetic graphene oxide based nanocomposites for sustainable water purification. J. Environ. Manage. 231, 622-634.

Diaz, E., Ordonez, S., Vega, A., 2007. Adsorption of volatile organic compounds onto carbon nanotubes, carbon nanofibers, and high-surface-area graphites. J. Colloid. Interface. Sci. 305, 7-16.

Li, J., Lu, R., Dou, B., Ma, C., Hu, Q., Liang, Y., Wu, F., Qiao, S., Hao, Z., 2012. Porous graphitized carbon for adsorptive removal of benzene and the electrothermal regeneration. Environ. Sci. Technol. 46, 12648-12654.

Koduru, J.R., Karri, R.R., Mubarak, N.M., 2019. Smart Materials, Magnetic Graphene Oxide-Based Nanocomposites for Sustainable Water Purification. Sustainable Polymer Composites and Nanocomposites.

Vashist, S.K., Zheng, D., Al-Rubeaan, K., Luong, J.H., Sheu, F.S., 2011. Advances in carbon nanotube based electrochemical sensors for bioanalytical applications. Biotechnol. Adv. 29, 169-188.

Raphey, V.R., Henna, T.K., Nivitha, K.P., Mufeedha, P., Sabu, C., Pramod, K., 2019. Advanced biomedical applications of carbon nanotube. Mater. Sci. Eng. C. Mater. Biol. Appl. 100, 616-630.

Smalley, R.E., 1998. Crystalline ropes of metallic carbon nanotubes. Supercarbon. 33, 31-40.

Iijima, S., 1991. Helical microtubules of graphitic carbon. Nature. 354. 56-58.

Na, C.J., Yoo, M.J., Tsang, D.C.W., Kim, H.W., Kim, K.H., 2019.High-performance materials for effective sorptive removal of formaldehyde in air. J Hazard Mater. 366, 452-465.

Yang, S., Zhu, Wei, Z., Yang, F. X., 2017. Enhancement of formaldehyde removal by activated carbon fiber via in situ growth of carbon nanotubes, Build. Environ. 126(2017), 27-33.

Hsu, S. C., Lu, C., 2012. Adsorption kinetic, thermodynamic, and desorption studies of isopropyl alcohol vapor by oxidized single-walled carbon nanotubes. Journal of the Air \& Waste Management Association. 59, 990-997.

Hussain, C.M., Saridara, C., Mitra, S., 2009. Modifying the sorption properties of multi-walled carbon nanotubes via covalent functionalization. Analyst. 134, 1928-1933.

Mekki, A., Boukoussa, B., 2019. Structural, textural and toluene adsorption properties of microporousmesoporous zeolite omega synthesized by different methods. Journal of Materials Science. 54, 8096-8107.

Nien, K.C., Chang, F.T., Chang, M.B., 2017. Adsorption of mesitylene via mesoporous adsorbents. J. Air. Waste. Manag. Assoc. 67, 1319-1327.

Su, Y.C., Kao, H.M., Wang, J.L., 2010. Mesoporous silicate mcm-48 as an enrichment medium for ambient volatile organic compound analysis. J. Chromatogr. A. 1217, 5643-5651.

Cosseron, A.F., Daou, T.J., Tzanis, L., Nouali, H., Deroche, I., Coasne, B., Tchamber, V., 2013. Adsorption of volatile organic compounds in pure silica cha, *bea, mfi and stt-type zeolites. Microporous and Mesoporous Materials. 173, 147-154. 
Kang, S., Ma, J., Wu, Q., Deng, H., 2018. Adsorptive removal of dichloromethane vapor on FAU and MFI zeolites: Si/al ratio effect and mechanism. Journal of Chemical \& Engineering Data. 63, 22112218.

Zhu, Z., Xu H., Jiang, J., Wu, H., Wu, P., 2017. Hydrophobic nanosized all-silica beta zeolite: Efficient synthesis and adsorption application. ACS. Appl. Mater. Interfaces. 9, 27273-27283.

Lee, D.G., Kim, J.H., Lee, C.H., 2011. Adsorption and thermal regeneration of acetone and toluene vapors in dealuminated y-zeolite bed. Sep. Purif. Technol. 77, 312-324.

Nigar, H., Navascués, N., de la Iglesia, O., Mallada, R., Santamaría, J., 2015. Removal of VOCs at trace concentration levels from humid air by microwave swing adsorption, kinetics and proper sorbent selection. Separation and Purification Technology. 151, 193-200.

Tamon, H., Ishizaka, H. Yamamoto, T. Suzuki, T. 1999. Preparation of mesoporouscarbon by freeze drying. Carbon. 37, 2049-2055.

Deng, L., Yuan, P., Liu, D., Annabi-Bergaya, F., Zhou, J., Chen, F., Liu, Z., 2017. Effects of microstructure of clay minerals, montmorillonite, kaolinite and halloysite, on their benzene adsorption behaviors. Applied Clay Science. 143, 184-191.

Hoskins, B.F., Robson, R., 1989. Infinite polymeric frameworks consisting of three dimensionally linked rod-like segments. J. Am. Chem. Soc. 111, 5962-5964.

Silva, P., Vilela, S.M.F., Tome, J.P.C., Almeida Paz, F.A. 2015. Multifunctional metal-organic frameworks: from academia to industrial applications. Chemical Society Reviews. 44, 6774-6803.

Zhu, L., Meng, L., Shi, J., Li, J., Zhang, X., Feng, M., 2019. Metal-organic frameworks/carbon-based materials for environmental remediation: A state-of-the-art mini-review. Journal of Environmental Management, 232, 964-977.

Yang, K., Sun, Q., Xue, F., Lin, D., 2011. Adsorption of volatile organic compounds by metal-organic frameworks mil-101: Influence of molecular size and shape. J. Hazard. Mater. 195, 124-131.

Luebbers, M.T., Wu, T., Shen, L., Masel, R.I., 2010. Trends in the adsorption of volatile organic compounds in a large-pore metal-organic framework, irmof-1. Langmuir. 26, 11319-11329.

Zhao, Y.T., Yu, L.Q., Xia, X., Yang, X.Y., Hu, W., Lv, Y.K., 2018. Evaluation of the adsorption and desorption properties of zeolitic imidazolate framework-7 for volatile organic compounds through thermal desorption-gas chromatography. Analytical Methods. 10, 4894-4901.

Vellingiri, K., Kumar, P., Deep, A., Kim, K.H., 2017. Metal-organic frameworks for the adsorption of gaseous toluene under ambient temperature and pressure. Chemical Engineering Journal. 307, 1116-1126.

Xian, S., Yu, Y., Xiao, J., Zhang, Z., Xia, Q., Wang, H., Li, Z., 2015. Competitive adsorption of water vapor with VOCs dichloroethane, ethyl acetate and benzene on mil-101(Cr) in humid atmosphere. RSC Advances. 5, 1827-1834. 
Shafiei, M., Alivand, M.S., Rashidi, A., Samimi, A., Mohebbi-Kalhori, D., 2018. Synthesis and adsorption performance of a modified micro-mesoporous MIL-101(Cr) for VOCs removal at ambient conditions. Chemical Engineering Journal. 341, 164-174.

Kim, B., Lee, Y.R., Kim, H.Y., Ahn, W.S., 2018. Adsorption of volatile organic compounds over MIL125- $\mathrm{NH}_{2}$. Polyhedron. 154, 343-349.

Wang, D., Wu, G., Zhao, Y., Cui, L., Shin, C.H., Ryu, M.H., Cai, J., 2018. Study on the Copper(ii)doped MIL-101(Cr) and its performance in VOCs adsorption. Environ. Sci. Pollut. Res. Int. 25, 28109-28119.

Sampieri, A., Perez-Osorio, G., Hernandez-Espinosa, M.A., Ruiz, L., II, Ruiz-Reyes, M., ArriolaMorales, J., Narvaez-Fernandez, R.I., 2018. Sorption of BTEX on a nanoporous composite of SBA-15 and a calcined hydrotalcite. Nano. Converg. 5, 21.

Liu, C., Cai, W., Liu, L., 2018. Hydrothermal carbonization synthesis of al-pillared montmorillonite@carbon composites as high performing toluene adsorbents. Applied Clay Science. 162, 113-120.

Morozov, G., Breus, V., Nekludov, S., Breus, I., 2014. Sorption of volatile organic compounds and their mixtures on montmorillonite at different humidity. Colloids and Surfaces A: Physicochemical and Engineering Aspects. 454, 159-171.

Qu, F., Zhu, L.Z., Yang, K., 2009. Adsorption behaviors of volatile organic compounds (VOCs) on porous clay heterostructures (PCH). J. Hazard. Mater.170(1), 7-12.

Kimura, T., Kuroda, K.Y., Sugahara, K., Kuroda, J., 1998. Porous Mater. 5, 127-132.

Mu, Y., Cui, M., Zhang, S., Zhao, J., Meng, C., Sun, Q., 2018. Comparison study between a series of new type functional diatomite on methane adsorption performance. Microporous and Mesoporous Materials. 267, 203-211.

Yang, R.T., 2003. Adsorbents Fundamentals and Applications, John Wiley \& Sons, Hoboken, New Jersey, Etats-Unis.

Kim, M.I., Kim, S., Lim, C.S., Seo, B., 2017. Adsorption of acetaldehyde at room temperature in a continuous system using silica synthesized by the sol-gel method. Korean Journal of Chemical Engineering. 34, 2773-2779.

Sui, H., Liu, H., An, P., He, L., Li, X., Cong, S., 2017. Application of silica gel in removing high concentrations toluene vapor by adsorption and desorption process. Journal of the Taiwan Institute of Chemical Engineers. 74, 218-224.

Sigot, L., Ducom, G., Germain, P., 2015. Adsorption of octamethylcyclotetrasiloxane (d4) on silica gel (sg): retention mechanism, Microporous and Mesoporous Materials. 213, 118-124.

Huang, W., Xu, J., Tang, B., Wang, H., Tan, X., Lv, A., 2017. Adsorption performance of hydrophobically modified silica gel for the vapors of $n$-hexane and water. Adsorption Science \& Technology. 36, 888-903. 
Wu, Q., Huang, W., Wang, H.J., Pan, L.L., Zhang, C.L., Liu, X.K., 2015. Reversely swellable porphyrin-linked microporous polyimide networks with super-adsorption for volatile organic compounds. Chinese Journal of Polymer Science. 33, 1125-1132.

Xu, S., Luo, Y., Tan, B., 2013. Recent development of hypercrosslinked microporous organic polymers. Macromol Rapid Commun. 34, 471-484.

Jia, L., Yu, W., Long, C., Li, A., 2013. Adsorption equilibrium and dynamics of gasoline vapors onto polymeric adsorbents. Environmental Science and Pollution Research. 21, 3756-3763.

Wang, W.Q., Wang, J., Chen, J.G., Fan, X.S., Liu, Z.T., Liu, Z.W., Jiang, J., Hao, Z., 2015. Synthesis of novel hyper-cross-linked polymers as adsorbent for removing organic pollutants from humid streams. Chemical Engineering Journal. 281, 34-41.

Long, C., Li, Y., Yu, W., Li, A., 2012. Removal of benzene and methyl ethyl ketone vapor: Comparison of hypercrosslinked polymeric adsorbent with activated carbon. J. Hazard. Mater. 203-204, 251256.

Zhang, L., Song, X., Wu, J., Long, C., Li, A., Zhang, Q., 2012. Preparation and characterization of micro-mesoporous hypercrosslinked polymeric adsorbent and its application for the removal of VOCs. Chemical Engineering Journal. 192, 8-12.

Wang, J., Wang, W.Q., Hao, Z., Wang, G., Li, Y., Chen, J.G., Li, M., Cheng, J., Liu, Z.T., 2016. A superhydrophobic hyper-cross-linked polymer synthesized at room temperature used as an efficient adsorbent for volatile organic compounds. RSC Advances. 6, 97048-97054.

Wang, G., Dou, B., Wang, J., Wang, W., Hao, Z., 2013. Adsorption properties of benzene and water vapor on hyper-cross-linked polymers. RSC Advances. 3,

Ojha, D.P., Song, J.H., Kim, H.J., 2019. Facile synthesis of graphitic carbon-nitride supported antimony-doped tin oxide nanocomposite and its application for the adsorption of volatile organic compounds. J. Environ. Sci (China). 79, 35-42.

Liu, G.Q., Wan, M.X., Huang, Z.H., Kang, F.Y., 2016. Preparation of graphene/metal-organic composites and their adsorption performance for benzene and ethanol, Carbon. 104,

Zheng, Y., Chu, F., Zhang, B., Yan, J., Chen, Y., 2018. Ultrahigh adsorption capacities of carbon tetrachloride on MIL-101 and MIL-101/graphene oxide composites. Microporous and Mesoporous Materials. 263, 71-76.

Li, Y., Miao, J., Sun, X., Xiao, J., Li, Y., Wang, H., Xia, Q., Li, Z., 2016. Mechanochemical synthesis of Cu-BTC@go with enhanced water stability and toluene adsorption capacity. Chemical Engineering Journal. 298, 191-197.

Liu, X.W., Sun, T.J., Hu J.-L., Wang S.D., 2016. Composites of metal-organic frameworks and carbonbased materials: Preparations, functionalities and applications. J. Mater. Chem. A. 4, 3584-3616.

Liu, Y., Tian, T., 2019. Fabrication of diatomite/silicalite-1 composites and their property for VOCs adsorption. Materials (Basel). 12. 
Yu, W., Yuan, P., Liu, D., Deng, L., Yuan, W., Tao, B., Cheng, H., Chen, F., 2015. Facile preparation of hierarchically porous diatomite/MFI-type zeolite composites and their performance of benzene adsorption: The effects of $\mathrm{NaOH}$ etching pretreatment. J. Hazard. Mater. 285, 173-181.

Yu, W., Deng, L., Yuan, P., Liu, D., Yuan, W., Chen, F., 2015. Preparation of hierarchically porous diatomite/MFI-type zeolite composites and their performance for benzene adsorption: The effects of desilication. Chemical Engineering Journal. 270, 450-458.

Yuan, W., Yuan, P., Liu, D., Deng, L., Zhou, J., Yu, W., Chen, F., 2016. A hierarchically porous diatomite/silicalite-1 composite for benzene adsorption/desorption fabricated via a facile premodification in situ synthesis route. Chemical Engineering Journal. 294, 333-342.

Liu, H.B., Yang, B., Xue, N.D., 2016. Enhanced adsorption of benzene vapor on granular activated carbon under humid conditions due to shifts in hydrophobicity and total micropore volume. J. Hazard. Mater. 318, 425-432.

Guo, Y., Li, Y., Zhu, T., et al. 2013. Adsorption of $\mathrm{SO}_{2}$ and chlorobenzene on activated carbon. Adsorption. 19(6), 1109-1116.

Vohra, S.M., 2015. Adsorption-Based Removal of Gas-Phase Benzene Using Granular Activated Carbon (GAC) Produced from Date Palm Pits. Arabian Journal for Science and Engineering. 40(11), 3007-3017.

Kim, K.D., Park, E.J., Seo, H.O., Jeong, M.G., Kim, Y.D., Lim, D.C., 2012. Effect of thin hydrophobic films for toluene adsorption and desorption behavior on activated carbon fiber under dry and humid conditions. Chemical Engineering Journal. 200-202, 133-139.

Aziz, A., Kim, K.S., 2017. Adsorptive Volatile Organic Removal from Air onto NaZSM-5 and HZSM5: Kinetic and Equilibrium Studies. Water Air and Soil Pollution, 228(9):319.

Wang, X., Ma, C., Xiao, J., 2018. Benzene/toluene/water vapor adsorption and selectivity of novel CPDA adsorbents with high uptakes of benzene and toluene. Chemical Engineering Journal. 335, 970-978.

Wang, Y., Su, X., Xu, Z., Wen, K., Zhang, P., Zhu, J., He, H., 2016. Preparation of surfacefunctionalized porous clay heterostructures via carbonization of soft-template and their adsorption performance for toluene. Applied Surface Science. 363:113-121.

Zhu, J.X., Zhang, P., Wang, Y.B., Wen, K., 2017. Effect of acid activation of palygorskite on their toluene adsorption behaviors. Applied clay science.159, 60-67.

Long, C., Li, Q., Li, Y., et al. 2010. Adsorption characteristics of benzene-chlorobenzene vapor on hypercrosslinked polystyrene adsorbent and a pilot-scale application study. Chemical Engineering Journal. 160(2), 723-728.

Chu, F., Zheng, Y., Wen, B., et al. 2018. Adsorption of toluene with water on zeolitic imidazolate framework-8/graphene oxide hybrid nanocomposites in a humid atmosphere. RSC Advances. 8, 2426-2432. 
Ge, J.C., Choi, N.J., 2019. Performance of electrospun nanofibrous membranes for trapping of BTX aromatic hydrocarbons and heavy metal ions: Mechanisms, isotherms and kinetics. Journal of Cleaner Production. 217, 388-397.

Bandura, L., Panek, R., Rotko, M., Franus, W., 2016. Synthetic zeolites from fly ash for an effective trapping of BTX in gas stream, Microporous and Mesoporous Materials. 223, 1-9.

Anfruns, A., Martin, M.J., Montes-Morán, M.A., 2011. Removal of odourous VOCs using sludge-based adsorbents. Chemical Engineering Journal. 166, 1022-1031.

Lee, C.K., Chen, H.C., Liu, S.S., Huang, F.C., 2010. Effects of acid washing treatment on the adsorption equilibrium of volatile organic compounds on titanate nanotubes. Journal of the Taiwan Institute of Chemical Engineers. 41, 373-380.

Tang, L., Zhang, S., Zeng, G.M., Zhang, Y., Yang, G.D., Chen, J., Wang, J.J., Wang, J.J., Zhou, Y.Y., Deng, Y.C., 2015. Rapid adsorption of 2,4-dichlorophenoxyacetic acid by iron oxide nanoparticles-doped carboxylic ordered mesoporous carbon. J. Colloid. Interface. Sci. 445, 1-8.

Carter, E.M., Katz, L.E., Speitel, G.E., Jr., Ramirez, D., 2011. Gas-phase formaldehyde adsorption isotherm studies on activated carbon: Correlations of adsorption capacity to surface functional group density. Environ. Sci. Technol. 45, 6498-6503.

Gil, R.R., Ruiz, B., Lozano, M.S., Martín, M.J., Fuente, E., 2014. VOCs removal by adsorption onto activated carbons from biocollagenic wastes of vegetable tanning. Chemical Engineering Journal. $245,80-88$.

Schnelle, K.B., Brown, C.A., 2001. Adsorption for HAP and VOC control air pollution control technology handbook (Handbook Series for Mechanical Engineering, pp.). CRC Press. 1-29

Bansal, R. C., and Goyal, M. 2005. Activated carbon adsorption. Boca Raton: Taylor and Francis Group. Chiang, H.L., Chiang, P.C., Huang, C.P., 2002, Ozonation of activated carbon and its effects on the adsorption of VOCs exemplified by methylethyl ketone and benzene. Chemosphere. 47, 267-275.

Qiao, W., Korai, Y., Mochida, I., Hori, Y., Maeda, T., 2002. Preparation of an activated carbon artifact: oxidative modification of coconut shell-based carbon to improve the strength. Carbon. 40, 351358.

Pignatello, J.J., Mitch, W.A., Xu, W., 2017. Activity and reactivity of pyrogenic carbonaceous matter toward organic compounds. Environ. Sci. Technol. 51, 8893-8908.

Shen, W., Li, Z., and Liu, Y. 2008. Surface chemical functional groups modification of porous carbon. Recent. Patents. Chem. Eng. 1, 27-40.

Figueiredo, J.L., 2013. Functionalization of porous carbons for catalytic applications. J. Mater. Chem. A. 1 ,

Pak, S.H., Jeon, M.J., Jeon, Y.W., 2016. Study of sulfuric acid treatment of activated carbon used to enhance mixed VOC removal. International Biodeterioration \& Biodegradation. 113, 195-200.

Khazraei Vizhemehr, A., Haghighat, F., Lee, C.S, et al. 2015. Evaluation of Gas-Phase Filter Performance for a Gas Mixture. Clean-Soil. Air. Water. 43(4), 469-478. 
Wang, H., Jahandar Lashaki, M., Fayaz, M., et al., 2012. Adsorption and Desorption of Mixtures of Organic Vapors on Beaded Activated Carbon. Environmental Science \& Technology. 46(15), 8341-8350.

Xu, C., Ruan, C.Q., Li, Y., Lindh, J., Strømme, M., 2018. High-performance activated carbons synthesized from nanocellulose for CO $\backslash$ r2\rCapture and Extremely Selective Removal of Volatile Organic Compounds. Advanced Sustainable Systems. 1700147.

Águeda, V.I., Crittenden, B.D., Delgado, J.A., Tennison, S.R., 2011. Effect of channel geometry, degree of activation, relative humidity and temperature on the performance of binderless activated carbon monoliths in the removal of dichloromethane from air. Separation and Purification Technology. $78,154-163$.

Hu, L., Cheng, W., Zhang, W., Wu, F., Peng, S., Li, J., 2016. Monolithic bamboo-based activated carbons for dynamic adsorption of toluene. Journal of Porous Materials. 24, 541-549.

Yamamoto, T., Kataoka, S., Ohmori, T., 2010. Characterization of carbon cryogel microspheres as adsorbents for VOC, J. Hazard. Mater. 177, 331-335.

Qiu, W.J., Dou, K., Zhou, Y., Huang, H.F., Chen, Y.F., Lu, H.F., 2018. Hierarchical pore structure of activated carbon fabricated by $\mathrm{CO} 2 /$ microwave for volatile organic compounds adsorption. Chinese Journal of Chemical Engineering. 26, 81-88.

Mazlan, M.A.F., Uemura, Y., Yusup, S., Elhassan, F., Uddin, A., Hiwada, A., Demiya, M., 2016. Activated carbon from rubber wood sawdust by carbon dioxide activation. Procedia Engineering. $148,530-537$.

Guo, Z., Huang, J., Xue, Z., Wang, X., 2016. Electrospun graphene oxide/carbon composite nanofibers with well-developed mesoporous structure and their adsorption performance for benzene and butanone. Chem. Eng. J. 306, 99-106.

Romero-Anaya, A.J., Lillo-Ródenas, M.A., Linares-Solano, A., 2010. Spherical activated carbons for low concentration toluene adsorption. Carbon. 48, 2625-2633.

Alcañiz-Monge, J., Pérez-Cadenas, M., Marco-Lozar J.P., 2012. Removal of Harmful Volatile Organic Compounds on Activated Carbon Fibres Prepared by Steam or Carbon Dioxide Activation. Adsorption Science and Technology. 30(6):473-482.

Sirimuangjinda, A., Hemra, K., Atong, D., Pechyen, C., 2012. Production and characterization of activated carbon from waste tire by $\mathrm{H}_{3} \mathrm{PO}_{4}$ Treatment for Ethylene Adsorbent Used in Active Packaging. Advanced Materials Research. 506, 214-217.

Kang, Y.H., Shiue, A., Hu, S.C., Huang, C.Y., Chen, H.T., 2010. Using phosphoric acid-impregnated activated carbon to improve the efficiency of chemical filters for the removal of airborne molecular contaminants (AMCs) in the make-up air unit (MAU) of a cleanroom. Building and Environment. 45, 929-935. 
Pak, S.H., Jeon, M.J., Jeon, Y.W., 2016. Study of sulfuric acid treatment of activated carbon used to enhance mixed VOC removal. International Biodeterioration \& Biodegradation. S0964830516301172.

Ramos, M.E., Bonelli, P.R., Cukierman, A.L., Ribeiro Carrott, M.M., Carrott, P.J., 2010. Adsorption of volatile organic compounds onto activated carbon cloths derived from a novel regenerated cellulosic precursor. J. Hazard. Mater. 177, 175-182.

Tu, T.T., Lee, M., Kuo, S.T., Den, W., 2015. Citric acid-modified carbon chemical filtration for cleanroom air quality control: Study on n-methyl-2-pyrrolidone and the interference of co-existing toluene, Indoor and Built Environment. 25, 772-785.

Li, L., Liu, S., Liu, J., 2011. Surface modification of coconut shell based activated carbon for the improvement of hydrophobic VOC removal. J. Hazard. Mater. 192(2), 683-690.

Zhang, X., Gao, B., Fang, J., Zou, W., Dong, L., Cao, C., Zhang, J., Li, Y., Wang, H., 2019. Chemically activated hydrochar as an effective adsorbent for volatile organic compounds (VOCs). Chemosphere. 218, 680-686.

Kim, J.M., Kim, J.H., Lee, C.Y., Jerng, D.W., Ahn, H.S., 2018. Toluene and acetaldehyde removal from air on to graphene-based adsorbents with microsized pores. J. Hazard. Mater. 344, 458-465.

Zhang, B., Chen, Y., Wei, L., Zu, Z., 2012. Preparation of molecular sieve $\mathrm{x}$ from coal fly ash for the adsorption of volatile organic compounds. Microporous and Mesoporous Materials. 156, 36-39.

Zhou, L., Chen, Y.-L., Zhang, X.H., Tian, F.M., Zu, Z.N., 2014. Zeolites developed from mixed alkali modified coal fly ash for adsorption of volatile organic compounds, Materials Letters. 119, 140142.

Mohammed, J., Nasri, N.S., Ahmad Zaini, M.A., Hamza, U.D., Ani, F.N., 2015. Adsorption of benzene and toluene onto $\mathrm{KOH}$ activated coconut shell based carbon treated with $\mathrm{NH}_{3}$. International Biodeterioration \& Biodegradation. 102, 245-255.

Guo, Y., Li, Y., Wang, J., Zhu, T., Ye, M., 2014. Effects of activated carbon properties on chlorobenzene adsorption and adsorption product analysis. Chemical Engineering Journal. 236, 506-512.

Peng, S., Li, W., Deng, Y., Li, W., Ma, X., Chen, Y., 2018. Removal of low concentration $\mathrm{CH}_{3} \mathrm{SH}$ with regenerable Cu-doped mesoporous silica. J. Colloid. Interface. Sci. 513, 903-910.

Rengga, W.D.P., Chafidz, A., Sudibandriyo, M., Nasikin, M., Abasaeed, A.E., 2017. Silver nanoparticles deposited on bamboo-based activated carbon for removal of formaldehyde. Journal of Environmental Chemical Engineering. 5, 1657-1665.

Liu, S., Peng, Y., Chen, J., Shi, W., Yan, T., Li, B., Zhang, Y., Li, J., 2018. Engineering surface functional groups on mesoporous silica: Towards a humidity-resistant hydrophobic adsorbent. Journal of Materials Chemistry A. 6, 13769-13777. 
Wang, H., Wang, T., Han, L., Tang, M., Zhong, J., Huang, W., Chen, R., 2016. VOC adsorption and desorption behavior of hydrophobic, functionalized SBA-15. Journal of Materials Research. 31, 516-525.

Machowski, K., Natkański, P., Białas, A., Kuśtrowski, P., 2016. Influence of thermal treatment conditions on efficiency of pfa/mcm-48 composite and cmk-1 carbon replica in adsorption of volatile organic compounds. Journal of Thermal Analysis and Calorimetry. 126, 1313-1322.

Martínez de Yuso, A., Izquierdo, M.T., Rubio, B., et al., 2013. Adsorption of toluene and toluene-water vapor mixture on almond shell based activated carbons. Adsorption.19(6):1137-1148.

Zhang, G., Liu, Y., Zheng, S., et al., 2018. Adsorption of volatile organic compounds onto natural porous minerals. J. Hazard. Mater. 364, 317-324.

Zhou, L., Zhang, X., Chen, Y., 2017. Modulated synthesis of zirconium metal-organic framework UiO66 with enhanced dichloromethane adsorption capacity. Materials Letters. 197, 167-170.

Kim, K.J., Ahn, H.G., 2010. The adsorption and desorption characteristics of a binary component system of toluene and methylethylketone on activated carbon modified with phosphoric acid. Carbon. 48(8), 2198-2202.

Choma, J., Osuchowski, L., Dziura, A., 2015. Benzene and Methane Adsorption on Ultrahigh Surface Area Carbons Prepared from Sulphonated Styrene Divinylbenzene Resin by KOH Activation. Adsorption Science \& Technology. 33(6-8):587-594.

Silvestre-Albero, A., Ramos-Fernández, J.M., Martínez-Escandell, M., Sepúlveda-Escribano, A., Silvestre-Albero, J., Rodríguez-Reinoso, F., 2010. High saturation capacity of activated carbons prepared from mesophase pitch in the removal of volatile organic compounds. Carbon. 48, 548556.

Qi, J.W., Li, Y., Wei, J.P., Li, J.S., Sun, S.Y., 2017. Nitrogen doped porous hollow carbon spheres for enhanced benzene removal. Separation and purification technology. 188, 112-118.

Ma, X.C., Li, L.Q., Chen, G.F., et al., 2018. Porous carbon materials based on biomass for acetone adsorption: Effect of surface chemistry and porous structure. Applied Surface Science. 459:657664.

Qi, J., Wei, G., Li, Y., et al. 2018. Porous carbon spheres for simultaneous removal of benzene and $\mathrm{H}_{2} \mathrm{~S}$. Chemical Engineering Journal. S1385894718301797.

Li, Q., Yong, Y., Ding, W.C., et al., 2016. Studies of Dynamic Adsorption Behavior of VOCs on Biochar Modified by Ultraviolet Irradiation. Environmental Science. 37(6), 2065-2072. 